Illinois State University

ISU ReD: Research and eData

Theses and Dissertations

$12-6-2016$

\title{
Pathways To A Brighter Future: Narratives Of Latino Students' Perceptions At Community College
}

Columba Myra Gaytan-Morales

Illinois State University, mgaytan@ucenter.org

Follow this and additional works at: https://ir.library.illinoisstate.edu/etd

Part of the Community College Education Administration Commons, Community College Leadership Commons, Higher Education Administration Commons, and the Higher Education and Teaching Commons

\section{Recommended Citation}

Gaytan-Morales, Columba Myra, "Pathways To A Brighter Future: Narratives Of Latino Students' Perceptions At Community College" (2016). Theses and Dissertations. 672.

https://ir.library.illinoisstate.edu/etd/672

This Dissertation is brought to you for free and open access by ISU ReD: Research and eData. It has been accepted for inclusion in Theses and Dissertations by an authorized administrator of ISU ReD: Research and eData. For more information, please contact ISUReD@ilstu.edu. 


\title{
PATHWAYS TO A BRIGHTER FUTURE: NARRATIVES OF LATINO STUDENTS' PERCEPTIONS AT COMMUNITY COLLEGE
}

\author{
Columba Myra Gaytan-Morales
}

\section{Pages}

Helping Latino students into leadership roles begins with a college experience. Latino students are the largest and fastest growing student population within community colleges, yet they are less likely to graduate. Blame is often placed on minority students and their families for the students' poor academic performance. Deficit thinking models have impacted this way of thinking and this adds to the variety of factors that prevent students' from successfully completing a college degree. An analysis of nine Latino students' college experiences was examined to determine the types of barriers that were evident. Critical Race Theory and Latino Critical Race narrative theory were used to highlight the voices and experiences of Latino students. Student perception of the barriers were described along with how they overcame these barriers. Narrative data, literature and researcher professional and personal experiences were used to find common themes that impacted Latino students' completion of college, they are as follows: 1) family-support, 2) peer-support, 3) cultural-mentoring, and 4) the resilienceresistance skills, which students bring to the higher education system. The findings of this study provide evidence of the investment in education that Latino families have when they feel accepted within a higher education setting.

KEYWORDS: Community College, Latino, Narratives, Perceptions, Students 


\title{
PATHWAYS TO A BRIGHTER FUTURE: NARRATIVES OF LATINO STUDENTS' PERCEPTIONS AT COMMUNITY COLLEGE
}

\author{
COLUMBA MYRA GAYTAN-MORALES
}

\author{
A Dissertation Submitted in Partial \\ Fulfillment of the Requirements \\ for the Degree of \\ DOCTOR OF PHILOSOPHY \\ Department of Educational Administration and Foundations \\ ILLINOIS STATE UNIVERSITY
}


(C) 2017 Columba Myra Gaytan-Morales 


\title{
PATHWAYS TO A BRIGHTER FUTURE: NARRATIVES OF LATINO STUDENTS' PERCEPTIONS AT COMMUNITY COLLEGE
}

\author{
COLUMBA MYRA GAYTAN-MORALES
}

COMMITTEE MEMBERS:

Dianne Renn, Co-Chair

Pamela Hoff, Co-Chair

Guy Banicki

Santos Rivera 


\section{ACKNOWLEDGMENTS}

My education endeavors have been possible due to a wonderful support system that I have had throughout my life. I have wonderful role models that have influenced my educational path and who I am forever thankful to have had.

I would not be here without the support and love of Feliciano and Celia Gaytan, my parents. To my siblings, Dino Gaytan, Jesus Gaytan, Feliciano Gaytan, Ana Gaytan and Dolores Gaytan, nieces and nephews; Janet Gaytan, Daniel Gaytan, Roberto Lopez, Ivan Lopez, Chelsea Lopez, Guadalupe Mora, Jocelyn Gaytan, Victoria Gaytan, Feliciano Lopez, Leslie Lopez, Jesus Gaytan, Alejandro Gaytan, Valeria Gaytan, I also extend a lot of gratitude for their support. To my husband, Nelson Morales, and my precious daughter, Edith Paloma Morales, both of whom have been my coaches and inspiration!

To all of my friends and mentors who have become part of my family and support system, I am forever grateful to your friendship, Lynne Reynolds, Melba Rivera, Ennedy Rivera, Santos Rivera, Suleyma Perez, Rodolfo and Theresa Ruiz-Velasco, Juan Arenas Hernandez, Alicia Hernandez, Darl Drummond, Hilary Ward Schnadt, Gary Grace, Mytzy RodriguezKufner, Claudia Rodriguez, the nine participants of this study, the University Center of Lake County, Lake County Latino Scholars, Birthday Club Sisters and my Ph.D. Cohort.

Finally, very special thanks go to my advisor-chair, Dianne Renn, my co-chair, Pamela Hoff, and my committee members Guy Banicki and Santos Rivera. Thank you for guided me through this process. 
For Edith Paloma Morales, Janet Gaytan, Daniel Gaytan, Roberto Lopez, Ivan Lopez, Chelsea Lopez, Guadalupe Mora, Jocelyn Gaytan, Victoria Gaytan, Feliciano Lopez, Leslie Lopez, Jesus Gaytan, Alejandro Gaytan, Valeria Gaytan, Gustavo Gaytan, Carla Castro, Anahí Gonzales, Raul Flores, Esther Garcia, Miguel Guerrero, Christa Sanchez, Carla Villagomez.

C. M. G. M. 


\section{CONTENTS}

Page

ACKNOWLEDGMENTS

CONTENTS

CHAPTER I: THE LATINO NARRATIVE

$\begin{array}{ll}\text { Introduction } & 1\end{array}$

$\begin{array}{ll}\text { A Latina Narrative } & 2\end{array}$

$\begin{array}{ll}\text { Statement of the Problem } & 18\end{array}$

$\begin{array}{ll}\text { Purpose of the Study } & 21\end{array}$

$\begin{array}{ll}\text { Research Questions } & 21\end{array}$

$\begin{array}{ll}\text { Definitions } & 23\end{array}$

Limitations of the Study $\quad 25$

$\begin{array}{ll}\text { Assumptions } & 26\end{array}$

$\begin{array}{ll}\text { Significance of the Study } & 27\end{array}$

$\begin{array}{ll}\text { Summary } & 30\end{array}$

CHAPTER II: LITERATURE REVIEW 32

$\begin{array}{ll}\text { Introduction } & 32\end{array}$

Demographics $\quad 32$

$\begin{array}{ll}\text { Community College } & 34\end{array}$

$\begin{array}{ll}\text { College Readiness } & 35\end{array}$

$\begin{array}{ll}\text { College Completion } & 36\end{array}$

History of Latinos in the U.S. Higher Education System 38

$\begin{array}{ll}\text { Discrimination } & 39\end{array}$ 
$\begin{array}{ll}\text { Theoretical Frameworks } & 44\end{array}$

Critical Race Theory (CRT) 45

Latino Critical Theory (LatCrit) 48

CRT and LatCrit Counter-storytelling $\quad 54$

$\begin{array}{ll}\text { Community Cultural Wealth } & 57\end{array}$

Latino Students Community College Attendance $\quad 59$

$\begin{array}{ll}\text { Summary } & 63\end{array}$

CHAPTER III: METHODOLOGY 65

$\begin{array}{ll}\text { Purpose of Study } & 65\end{array}$

$\begin{array}{ll}\text { Research Design } & 66\end{array}$

$\begin{array}{ll}\text { Procedures and Data Collection } & 67\end{array}$

$\begin{array}{lr}\text { Data Analysis } & 69\end{array}$

$\begin{array}{lr}\text { Research Questions } & 69\end{array}$

Role of the Researcher $\quad 70$

$\begin{array}{ll}\text { Participant Sampling } & 71\end{array}$

$\begin{array}{ll}\text { Facebook Group Discussions and Interviews } & 73\end{array}$

$\begin{array}{ll}\text { Participants Profile } & 74\end{array}$

$\begin{array}{ll}\text { Alma } & 74\end{array}$

$\begin{array}{ll}\text { Ariana } & 75\end{array}$

$\begin{array}{ll}\text { Cassandra } & 76\end{array}$

$\begin{array}{ll}\text { Ivan } & 78\end{array}$

$\begin{array}{ll}\text { Jocelyn } & 79\end{array}$ 
$\begin{array}{ll}\text { Leslie } & 81\end{array}$

$\begin{array}{ll}\text { Marcos } & 82\end{array}$

$\begin{array}{ll}\text { Roberto } & 83\end{array}$

$\begin{array}{ll}\text { Victoria } & 84\end{array}$

$\begin{array}{ll}\text { Summary } & 85\end{array}$

CHAPTER IV: FINDINGS 86

$\begin{array}{ll}\text { Introduction } & 86\end{array}$

$\begin{array}{ll}\text { Family-Support } & 87\end{array}$

$\begin{array}{ll}\text { Ariana } & 87\end{array}$

$\begin{array}{ll}\text { Cassandra } & 88\end{array}$

$\begin{array}{ll}\text { Jocelyn } & 89\end{array}$

$\begin{array}{ll}\text { Leslie } & 90\end{array}$

$\begin{array}{ll}\text { Marcos } & 90\end{array}$

$\begin{array}{ll}\text { Roberto } & 92\end{array}$

$\begin{array}{ll}\text { Peer Support } & 93\end{array}$

$\begin{array}{ll}\text { Alma } & 93\end{array}$

$\begin{array}{ll}\text { Leslie } & 93\end{array}$

$\begin{array}{ll}\text { Marcos } & 94\end{array}$

$\begin{array}{ll}\text { Victoria } & 95\end{array}$

$\begin{array}{ll}\text { Cultural Mentoring } & 96\end{array}$

$\begin{array}{ll}\text { Alma } & 96\end{array}$

$\begin{array}{ll}\text { Ariana } & 97\end{array}$

$\begin{array}{ll}\text { Cassandra } & 98\end{array}$ 
Ivan

$\begin{array}{ll}\text { Jocelyn } & 99\end{array}$

$\begin{array}{ll}\text { Marcos } & 100\end{array}$

$\begin{array}{ll}\text { Roberto } & 100\end{array}$

$\begin{array}{ll}\text { Resilience-Resistance } & 102\end{array}$

$\begin{array}{ll}\text { Alma } & 102\end{array}$

$\begin{array}{ll}\text { Ariana } & 103\end{array}$

$\begin{array}{ll}\text { Ivan } & 104\end{array}$

$\begin{array}{ll}\text { Jocelyn } & 106\end{array}$

$\begin{array}{ll}\text { Leslie } & 106\end{array}$

$\begin{array}{ll}\text { Marcos } & 107\end{array}$

$\begin{array}{ll}\text { Roberto } & 108\end{array}$

$\begin{array}{ll}\text { Victoria } & 109\end{array}$

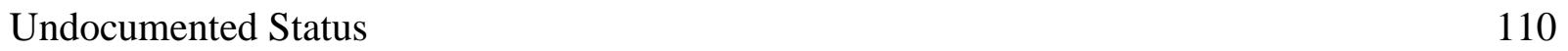

$\begin{array}{ll}\text { Roberto } & 111\end{array}$

$\begin{array}{ll}\text { Victoria } & 112\end{array}$

$\begin{array}{ll}\text { Summary } & 113\end{array}$

CHAPTER V: SUMMARY AND CONCLUSION 116

$\begin{array}{ll}\text { Introduction } & 116\end{array}$

$\begin{array}{ll}\text { Success Factors } & 116\end{array}$

$\begin{array}{ll}\text { Family Support } & 116\end{array}$

$\begin{array}{ll}\text { Peer-Support } & 117\end{array}$

$\begin{array}{ll}\text { Cultural Mentoring } & 118\end{array}$ 
$\begin{array}{ll}\text { Resilience-Resistance } & 118\end{array}$

$\begin{array}{lr}\text { Implications } & 120\end{array}$

$\begin{array}{ll}\text { Recommendations } & 123\end{array}$

$\begin{array}{ll}\text { Taste of College } & 124\end{array}$

Free Application for Federal Student Aid (FAFSA) completion workshops 124

$\begin{array}{ll}\text { Family Conference } & 125\end{array}$

$\begin{array}{ll}\text { Cultural College Student Banquets } & 125\end{array}$

$\begin{array}{lr}\text { Taskforce Board } & 126\end{array}$

$\begin{array}{ll}\text { Future Research } & 127\end{array}$

$\begin{array}{ll}\text { Conclusion } & 127\end{array}$

$\begin{array}{lr}\text { REFERENCES } & 130\end{array}$

APPENDIX A: Recruitment Letter 155

APPENDIX B: Letter of Consent 157

APPENDIX C: Demographic Data Sheet 160

APPENDIX D: Letter of Consent (Skype Interview) 161

APPENDIX E: Interview Protocol (Face Book-Dissertation Group Discussion) 163

APPENDIX F: Individual Interview Questions 164 


\section{CHAPTER I: THE LATINO NARRATIVE}

"No hay rosa sin espinas. There is no rose without thorns" (Munoz-Ryan, 2000, p. 14).

\section{Introduction}

The researcher found that Latino students come to the post-secondary experience with the requisite skills and abilities necessary to successfully complete their post-secondary studies. In particular, the research provides insight in which institutions can be culturally responsive to Latino students. Community colleges are important institutions for the educational advancement of non-traditional students having diverse needs. They are the first entry to higher education for over seven million people in the United States and provide cost-effective educational opportunities with programs and services (Krogstad \& Fry, 2015). While, community colleges have played a vital role in the success of many Latino students who later became great assets to this nation, there are still areas of concerns regarding the success of Latino students (De los Santos \& De Los Santos, 2005). Community colleges provide primary points of entry into postsecondary studies for Latino students, creating communities of cultural wealth that support Latino students' navigation of the post-secondary terrain. The nine participants who took part in this narrative study started their postsecondary education at a community college due to the location, tuitions cost, open-admission policy, flexible-classes schedule, and the variety of academic and adult education programs offered. The factors that contributed to the success of the associate degree completion of the nine participants were as follows: family support, peer support, cultural-mentoring, and the participant resilience-resistance skills.

There are many reasons why Latino students enroll at community colleges and they are as follows: (a) some wish to pursue an associate degree and later transfer to a four-year institution to complete a bachelor's degree; (b) some enroll to complete a few language or math courses; 
and (c) others enroll to take courses to obtain or retain employment. The aforementioned reasons and others leave the students in awe as they finish their college degree (Espinoza, 1990). Students may feel that transferring from a community college to a four-year institution is an unreachable goal since it takes $11.6 \%$ of the students about six years to finish (Baum \& Kurose, 2013; Camacho, 2012; Contreras, 2011; Fry, 2011). Additionally, the perceptions, experiences, and reflections of successful students' attitudes are based on resisting the norms and overcoming them and creating change.

The narrative that you are about to read is one of the stories of the $11.6 \%$ of students who started their post-secondary education in a community college and graduated with an associate degree, transferred into a four-year university, and completed their bachelor's degree. The person's story illustrates the purpose of this research study and helps to reveal the voices, experiences and cultural consciousness of Latino students who have successfully completed an associate degree among the oppressive challenges they faced while attending college. A particular focus will be placed on those students who began their postsecondary careers at community colleges.

\section{A Latina Narrative}

“Abuelita smiled, reached over, and pulled the yarn, unravelling all of Esperanza's rows. Do not be afraid to start over," she said" (Munoz Ryan, 2000, p. 38).

A lonely rebellious young girl stood looking defiantly at her mother. She had decided that she would no longer attend school. Her mother's pain written all over her soul was reflected in the strong words she chose to use with her mother. She was only 14, yet her lack of motivation and anger reflected her desire to be with her father, whom she loved with all her heart. She would be given that opportunity; this would mean that she would have to continue her education 
in a country that she knew very little about. All she knew was she wanted to be near him. Her actions were similar to so many young girls' who were trapped in the turmoil of family separation, not due to divorce, but rather a familiar story found in so many Mexican families: trying to find a better life in the United States. Many of these families are forced to make difficult decisions due to lack of employment and opportunities for low-income urban families in other countries. They have no choice but to give up all they have and embark to other countries for a better life.

This is my narrative, which is a reflection of my experiences. My personal story in some ways is similar to the story of many other Latino students who have come from other countries as children, having dreams of being the first one in the family to attend college. My narrative focuses on the opportunities and challenges found in starting the road to higher education at a community college. All of these desires for success tested my abilities and helped me become a strong and proud Latina. Within my story, I also highlight the many struggles evidenced by Latino families trying to get their children a brighter future.

At the age of fourteen years old, my father decided to bring me to the United States to be with him and my two brothers who had immigrated to the United States from Mexico several years prior. My father's decision to bring me during my adolescent years was due in part to my rebellious attitude, which was attributed mainly to experiencing the separation from him. I had stopped listening to my mother and dropped out of my first semester of secundaria school in Mexico, which would be considered eighth grade in the American school system. My father understood the importance of bringing a young rebellious teen with no hope for a bright future in Mexico to the United States, especially his daughter's. Therefore, my parents' decision, although a difficult one, was for me to leave Mexico and live abroad. Similar to stories of so many others, 
mine highlighted the sacrifice and hardships young immigrant children face traveling to the United States. I left behind my mother and three other siblings, yet I knew that it was the best decision my parents made for me. And although I had rebelled against my mother, it was very painful to leave my mother behind. My family was very important to me. I left Mexico with a broken heart. I cried because I did not know if I would ever see my mom and siblings again. For me not having my family as a whole unit, caused a great deal of grief.

Upon arriving to the United States and seeing my father, I knew that I had been granted a new beginning and I did not want to mess it up. This experience is similar to that of many Latino immigrants' who come to this country. We feel that coming to the United States is an opportunity to shine and reach our full potential. This is one of the reasons why we work so hard and take pride in our work. As a mother, I understand the types of sacrifices that my family and my own mother made. Pride is also the other feeling I share towards my parents for seeking a better life for me and my brothers. I am also grateful for fully supporting my decision to attend college and not placing me in a traditional woman's role. As I reflect, I also realize how hard it must have been for them not understanding the American educational system.

Two weeks after I arrived in the United States, my father, with very limited English and no knowledge of the American education system, managed to enroll me in seventh grade at a middle school. Having one of his children receive an American education was a big deal to him, as he understood the importance of providing me with the best he could. After all, I was the first in my family to have come this far. Both my father and mother have very little formal education, having only completed third grade and first grade respectively. As for the rest of my siblings, my older brothers only completed their $6^{\text {th }}$ grade education, my older sister has an equivalent of high school education in the United States and completed her terminal degree as an accountant in 
Mexico, my youngest brother and sister attended and completed their high school education in the United States. In addition, my younger sister attended the local community college only to become frustrated due to being placed in remedial education where she felt she did not progress. To add to her frustration and the reason she withdrew was that she was unable to provide the proof of family income and apply for financial aid because my dad was self-employed and did not know how to file his business taxes at the time she signed up. For me, this would not create any issues as I was old enough to file as an independent student and my father's tax dilemma would be irrelevant to my financial aid needs. It was unfortunate that my younger sister gave up on her higher education dream and that my parents could not help her because they did not know how. My family's struggles are still evident today; highlighted in the experiences of other Latino parents who want to see their children become successful. As Brown, Santiago and Lopez (2003) point out, this is due to a lack of knowledge about the higher education system, which creates barriers and prevents children of immigrants reach their goals.

Upon my arrival to the United States, I was determined to succeed in school. I was given the opportunity to attend a good school and loved my new school, friends and teacher; yet, I remember that my friends and I were treated differently from other students. While I felt safe and was provided with a teacher who made us feel loved and protected, there was a lack of education that I would notice as I got to high school. Both my seventh and eighth grade years passed without me learning to speak English and, as I was new to the country, I did not know any different. My experience with integrating myself to the U. S. culture occurred during physical education and lunch time.

The field of bilingual education has never been truly understood by school districts and thus, many schools during the time I went to school provided a free and attainable education in 
the most isolated and segregated manner possible (Acuña, 1998; Garcia, Wiese, \& Cuellar, 2011; Menchaca, 1997; San Miguel \& Valencia, 1998). At the time of my attendance, I was acclimating to my new country and feelings of dismay or ingratitude would not have been evident. I see the inequalities now, as my classroom was placed outside of the school building in a trailer behind the school's back parking lot and the only students in this mobile classroom were Latinos. Additionally, our caring teacher, who spoke Spanish, was not certificated or endorsed in bilingual education. This meant that we were not instructed with English language learner methodologies and strategies used today. As a newly arrived student, I really struggled to understand the reason as to why so many native English speaking and American-born Latinos were also placed in this classroom. My classmates and I spent most of the school-day in the mobile classroom, playing board games, building puzzles and hanging out. At my young age, I inherently knew that learning to speak and write in English would help me do well in school, yet I felt that there were some inequalities I could not yet define. Today, some of these inequalities are still evident in many schools, pre-kindergarten through college. Although it may not be as clear as before, the type of inequalities found presently at the college level are masked within different aspects of professors' rights, such as: 1) not teaching certain classes, 2) not offering differentiated classes for English language learners, or 3) refusing to do something because it has always been done a certain manner (Gandara \& Contreras, 2009; Valencia, 2009; Villalpando, 2004).

When I began high school, I was placed in an English as a Second Language (ESL) program, where I finally started to learn the basic structure of the English language. My passion for learning encouraged me to receive good grades as well as challenge myself to taking classes beyond the ESL classes where I saw many of my Latino peers remain. As a quick learner, I 
found myself excited about receiving better instruction. I excelled and jumped from advanced ESL classes to 'regular' classes such as speech, literature, geometry, math, and health.

Unfortunately, my good grades would not be enough to prepare me for college. For some reason, the high school counselor or other adults never advised me or my family about college planning and the importance of going to college. Fortunately, there were college entrance exam registration posters about the ACT on the high school hall walls. I went to see my high school counselor and asked to be registered for the test because I felt this test was important for my future. I would not understand the relevancy of the test in helping me achieve my college dream until much later. Interestingly, my counselor assumed I had an understanding of the reason for taking this test, therefore she did not go into the details over the process; I was too afraid to ask for clarification and so I missed out on important information. Thinking back to this time period, my perception was that my counselor was unaware of the limited knowledge that first-generation immigrant students and their parents possessed about the higher education process. Perhaps this person had never worked with students in a similar situation as myself and was unaware that my parents had little formal schooling, very limited English skills and that they had never put a foot in my high school because they were intimated by the whole education system. The process of schooling at a higher level was all new to my parents and the individuals at the high school did not make any efforts to reach out to them. Additionally, there were no parent meetings set up for parents who spoke another language.

When looking through the lenses of the Critical Race (CRT) and Latino Critical (LatCrit) theory it becomes evident that my counselor was only doing her job. Her actions were part of the social norm led by the dominant culture (Valencia, 2010; Yosso, Smith, Ceja, \& Solorzano, 2009). Perhaps she had low expectations about English Language (EL) learner students and that 
is why she did not want to learn about my goals and aspirations or push me towards higher education. I felt that being just another number to her, it did not matter whether I went to college or not. I felt as if my gender and national heritage dissuaded her from explaining the process of going to college to me because she thought I would be unsuccessful during my first year of college. Students who looked like me did not attend college because society expected Latinos to get a job after high school graduation, get married and have children. Regardless of my high school experiences and what society's expectations were about students like me, I was determined to go to college. I did not know how, but I knew where, when and why I wanted to go.

It was a Saturday morning when I took the ACT and I do not remember seeing any English Language Learners or Latino students taking the test, which appeared odd to me. Within a few months, I received the ACT scores, but not knowing the significance of the scores, I opened the envelope and placed it somewhere in my room. No one in my family or members of my immediate community had gone through the college process and my siblings were too busy trying to understand our new culture and language to help. Like so many Latino youths' experiences, I was very lost and embarrassed to ask questions because college was an unfamiliar experience to my family. I pretended to act as if I knew what I was doing. Latino Critical Theory explains this as a layer of oppression experienced in the area of identity that impacted my ability to advance within a Eurocentric environment. The oppression that I experienced was a result of the educational policies and practices which operated in a way that oppressed minority and Latino students and supported and maintained the status quo (Yosso, 2005; Valdes, 1997). In my situation, my father's advice, which he gave me upon arriving to this country, drove me to persevere and continue on my journey towards a college education. 
In the last semester of my senior year at high school, a community college counselor came to the high school to speak with Latino students about college. Secretly I wanted to be an attorney, but I was afraid to mention it to my family, as I was also afraid of their reactions, criticisms or comments. I was afraid of breaking the norm expected of Latinas, which was to get married and take care of the family. I had doubts about my ability to succeed due to my 'jaded' past, as a secundaria school out who had not been an "A" student. I was afraid that my family and friends would tell me that I was not smart enough to go to college and become an attorney. I felt as if I had no one who believed in me or who wanted to guide me through this path. At the age of 18 , I felt I was the only person motivating, coaching and mentoring myself. I did not feel that people would believe me or support me; thinking of me crazy for wanting to achieve this milestone. In sharing my precious secret, I felt that others would create walls of doubt within me and prevent my dream from coming true, so I kept it to myself. Yet, my goal was to become an attorney regardless of the hurdles placed before me.

My goal of becoming an attorney stemmed from my desire to educate and defend those individuals in my community who did not speak English or who did not have an understanding of the legal system. At that point in my life, acquiring a juris doctorate made for a perfect career path; and, being a native Spanish speaker would be an asset. Additionally, becoming a lawyer had been an idea borne from the experiences that my family members faced when not being able to adequately communicate with their attorney. I had a very challenging path placed before me, regardless of the advice given to me during the community college counselor's visit.

The college counselor advised me to take a few steps for successfully completing my journey towards accomplishing my dream, but I did not realize how hard this journey would become. She advised I attend a community college, earn an associate degree with a major in 
Criminal Justice, transfer to a Catholic private college and finally attend law school. I followed most of the steps this counselor provided, but with an ACT score of a 15 in reading and writing and a 17 in the area of Math, I did not fully realize how much effort I would have to put in reaching my goal than had been described to me. Similar to my sister's experience, I would have to take remedial classes in college. Perhaps it was because the counselor was unaware of my ACT scores or perhaps it was her lack of understanding of the struggles that Latino students in my situation faced, which led me to receive advice on being told what to do rather than how to get there. Product and processes are two different variables in helping people achieve their goals, after all. The CRT and LatCrit theory provide lenses into why Latino students achieve low ACT scores and lack college-readiness compared to their peers; when educational institutions marginalize students of color and low-income students, they rob them of the necessary academic skills to succeed later in life (Brown et al, 2003; Garcia, 2009; Solórzano, Villalpando \& Oseguera, 2005; Villalpando, 2004; Yosso, 2005; Yosso et al, 2009). It was not entirely my fault I lacked the high ACT scores necessary to succeed at college or that I was not college-ready. I was not even aware that the school system I had attended had failed me, yet as Esperanza's abuelita, grandmother, told her in the story Esperanza Rising, "No hay rosa sin espinas [There is no rose without thorns]" (Munoz Ryan, 2000, page 14). I was determined to succeed amongst these barriers placed before me. I knew that with hard work anything was possible and in spite of all the challenges I faced, I would achieve my goals and aspirations, no matter how thorny the path.

I graduated high school, knowing that I had three barriers to overcome to reach my goal of a college degree. I had to break my family norm, improve my immigration status and work with my low ACT scores. The first barrier was easier to accomplish than the other two. In order 
to appease my parents and to save a little money in the process, I decided to live at home. While the money was not as big of an issue, I was also not ready to break my parents' hearts with the news that I was about to leave the house to go to college. The only time Latino children leave their homes is when they get married (Chapa \& Schink, 2006; Fry \& Taylor, 2013; Santiago \& Stettner, 2013). My father had the hardest time letting me go into the world and get a college education, as I was his daughter and una mujer, a woman. While it was difficult for him to allow of me to achieve my 'outrageous' idea, he also thought about my future. Especially when he saw my determination and understood the importance of supporting me in achieving my goal. With that challenge out of the way, the next challenge was to overcome my undefined immigration status.

The one variable that worried me about the possibility of ever attending college was my immigration status. Within LatCrit theory, immigration status marginalizes Latinos in the United States and makes them feel subordinate to the American society (Solorzano \& Delgado Bernal, 2001; Yosso, 2005). According to Garcia (1995, 2011), this is one way that the dominant society keeps control by exercising Eurocentric culture and limiting Latino's greater participation in the American society. An immigrant's status is a category created to discriminate against people who are not from European descent (Garcia, 2009; Garcia 2011). This is how the dominant culture exerts the power of the American society. My family and I had fallen under such an immigration status, so we needed to provide the U.S. Department of Homeland Security and the Community College with proof that we were worthy of living in this country and that I had the right to attend the college campus. At the time of my arrival, five years earlier, my father had applied for me to become a permanent resident, since he also had permanent residency. My father handed a letter to the college from the lawyer indicating that the immigration application 
was in process. I was admitted to the college and was able to pay the in-state tuition as, "[g] enerally, a student with at least one parent who is a resident of the state for period of at least one year before the student matriculates in college can expect to pay an in-state tuition rate" (Perez, 2014, p.5). Yet, this was not enough of a reprieve, since I could not apply for any type of financial aid until I had a resident card, the "green-card," and a social security number. Within a year of starting college, I received my social security number and my work permit. I was now able to legally work and attend college. At this point, I want to emphasize I was one of the few fortunate immigrants who are able to receive permanent residency in this manner. My dad had permanent residency and he was able petition me and the rest of my family. For many other students who attend college and are undocumented, out-of-state fees apply. Yet, the hardest part for individuals who are undocumented and attend college is knowing that when they finish with all the requirements they will not be allowed to practice their career due to not having a legal work permit and a social security number. These young professionals become known as dislocated professionals.

The term dislocated professionals is being used to refer to individuals who in this case are not allowed to work in this country because they do not have a green-card and a social security number. The social security number is granted by the social security administration after it has been verified that these individuals are approved by the department of homeland security and are candidates for a work permit or a green card. This aforementioned information is a brief description of one of the paths to residing in the United States with permission as a resident or a lawful non-resident. The process of legalization is very difficult, expensive and long, depending on the country of origin of the person requesting citizenship (Contreras, 2011); Social Security Administration: U.S. Departments of Homeland Security, 2016). For students and their families 
who are in this country without a visa or residency, fixing their legal situation is extremely hard. Because of this situation, immigrant students who have grown up in the United States education system find it helpful to meet their dreams of attending college through immigration reform (Contreras, 2011). Currently, the immigration status of students and their families are subject to the political turmoil in legislation (Perez, 2014). An explanation for this can be provided using the LatCrit theory in which the dominant culture maintains the status quo by marginalizing Latinos. Therefore, it is evident that the immigration status of Latinos is a way to discriminate and subordinate Latinos within this Eurocentric society. Consequently, the Eurocentric community resists accepting or acknowledging the new population of Americans known as Latinos (Acuna, 2007; Garcia, 1995). LatCrit theory focuses on the types of discrimination and subordination that Latinos face on the basis of immigration policies (Garcia, 1995). In my situation, it took over six years to receive U.S. residency, yet for some families it may take longer, or they may never be as fortunate as I, since those family members need to return to Mexico or their country of origin before receiving legal residency (Perez, 2014; U.S. Department of Homeland Security, 2016). There are many families and students who do not have any legal sponsors and go through life living in the shadows in fear of being deported at any time.

Oftentimes, people ask how college student can live with the fear and stress of deportation on a daily basis and still attend school.

In comparison to all of my Latino friends, I received good grades in high school, finished all of my assignments, attended class every day, stayed out of trouble, concentrated in school, and held an after-school job; however, all of this preparation that I perceived to have received was not sufficient enough to prepare me academically for college. A lack of preparation for college, according to the CRT and LatCrit theory, is a systemic issue within the education system 
(Villalpando, 2004). Under the lens of these two theories, the school system failed to provide the rigorous curriculum and academic support for students like me needed to succeed in college. This issue persists due to the manner in which school systems operate and are designed to served minority students. African-American and Latino students tend to be placed in less rigorous courses and have less academic support than students from affluent families (Gandara \& Contreas, 2009; Ramirez, 2009; Villalpando, 2004). The majority of Latinos graduating from high school and who are not college-ready are more likely to be the first person in their family to go to college (Santiago \& Calderon-Galdeano, 2015). This means that they are less likely to demand that the school system provides them with advanced classes, which would equip them with the knowledge and skills to be successful within the higher education process (Gandera \& Conteras, 2009). In my case, I was assigned to classes, not English-based instruction, which did not prepare me to be college-ready and as a result my ACT scores were very low.

Once I arrived at my local community college, the college counselors had a difficult time placing me in the right academic program, thus preventing me from being placed in a traditional path to an associate degree. My options, according to the college counselors, were to either take remedial education classes or ESL classes. I was advised to take the college placement test or the ESL placement test. I took both placement tests and qualified for both; however, I was placed into the remedial program, because at that time the college did not have any more openings in ESL classes. In order to take college level courses for my major in Criminal Justice, I needed three remedial courses. Taking these developmental classes turned out to be easier than the challenges I had faced during the application process for attending community college. The college process caused a great deal of confusion within me due to its unfamiliarity and newness. To make matters worse, I saw two different counselors at different starting points. After going 
back and forth between both counselors, I finally found a good counselor who had better advice and understood how to serve Latino students.

The inconsistency and lack of cultural awareness from college counselors and staff becomes problematic to the success of first-generation college students. As part of CRT, institutional racism leads to educational disparity, which may be intentional (Solorzano et al., 2005). Minority students are expected to understand the unwritten rules and behave in a manner similar to the dominant society's. Institutions of higher learning need to be sensitive to the needs of minority and Latino students. A student should not have to actively seek a person that understands the challenges that Latino students undergo within the college application and college attendance process, such as and individual like myself. During my fourth visit to the counseling department, I finally met the person who took the time to explain the college process and the requirements needed to graduate so that I could receive my associate degree and then be able to transfer. He was a very compassionate person and helped me to register for my three remedial classes. This counselor believed in every students' potential. He was not from a Latino background and did not speak Spanish, but with his sweet smile and guidance, he became a great mentor who always made time to speak with me and always made me feel welcomed. Even so, there were times that I felt defeated and overwhelmed because I could not see the end of my journey.

I always felt like I was walking on an endless road. I felt overwhelmed because I felt I was responsible for paying my own tuition and contributing financially to my household, even though my parents never asked me for help. I worked tirelessly towards paying for my own schooling and being a successful college student, yet I saw that my father's minimum wage was not enough to cover all of the household expenses. I worked to pay for my college tuition after 
school and during school breaks. Yet, working long hours, prevented me from reaching out to others for additional help and support. When school was in session I studied long hours at home after work and thus I did not have enough time to visit the tutoring center, because I would go to work right after my classes ended.

One day during my community college career, I was invited by a good friend to attend a student organization called the Latino club. Thanks to my friend, Dina, I found the encouragement and cultural support that I desperately needed during those years. The club advisor took the time to acknowledge each member of the club. She also spoke Spanish and was very familiar with Latino culture, in particular the Mexican culture. I had found a sense of familismo --a strong identification and attachment to one's primary relations, such as family and peers (Cerezo, McWhirter, Peña, Valedez \& Bustos, 2013). Cerezo et al. (2013) described familismo as that which "...underlies and explains the importance of building community and support on college campuses" (p. 2). The feeling of familismo helped me to feel safe within the college environment as if I was home. I was no longer invisible or felt out of place. As a result, I felt accepted, valued and welcomed at this community college for the first time. I was encouraged by the support that I received by the friendly counselor, the club advisor and my new friends. They helped me graduate from a community college and transfer into a four-year university.

After completing my undergraduate degree, I decided to follow a career in higher education. I wanted to help the next generation of Latina/o's stay engaged at their college and eventually graduate. I felt it was my responsibility to give back to my community by making a career within higher education. The college process was very complicated and frightening for me, as I was a non-native English speaking student. I had a very heavy accent and I felt that 
many people at the college judged my intelligence based only on my accent. I wanted to support every student who needed guidance within this complicated community college system. It took over four different visits to finally register for classes and find the right counselor to guide me through the process.

My story is similar to that of so many Latino children with dreams of aspiring a college education. I was blessed to have had so many people who supported me in spite of all the obstacles that were presented to me as an immigrant. I courageously pursued my dreams in spite of the Eurocentric ideas that pulled me back in an oppressive manner and which impeded my success. These obstacles manifested themselves through isolation, misinformation, confusion, and having to take remedial classes that added to the cost of college. It took me four years to complete my degree and acquire the knowledge to help others overcome these obstacles. My perseverance and resilience in finding the right person to guide me, allowed me to become a spokesperson for and guide first generation Latino students through their struggles. Because of this, I would like to create change and help more Latino students graduate with an associate degree, which allows them to pursue a higher degree and in turn help influence others.

As a college employee, I currently provide recommendations to my peers and supervisors on how to streamline the processes and procedures to embrace the needs of our diverse student body. Throughout the United States, there are many stories like mine; stories about staff at community colleges making it possible for many Latina/o students to obtain an associate degree and then a four-year college degree when it otherwise would have been impossible. It is very important to me, personally and professionally, that I reveal the voices and experiences of Latino students who have completed their associates' degree and pursued a higher degree. Likewise, it is especially important to learn about the stories and experiences that incoming or current Latino 
students bring, helping them find appropriate resources to successfully complete an associate degree. These narratives provide insight into the types of cultural communities that foster Latino student's academic success and provide the necessary recommendations for changes in higher education.

\section{Statement of the Problem}

Many Latinos rely on community colleges as an educational stepping-stone to fulfill personal and professional aspirations, yet many who begin their associate degree programs do not realize their goals. Latinos make up over 17 percent of the nation's total population; the U.S. Census Bureau estimates that by the year 2020, one in four college students will be of Latino descent (Camacho Liu, 2012; Patten, 2016; Santiago \& Calderon-Galdeano, 2015). There are approximately 56.6 million Latinos in the United States population, with one out of every six people in the United States being Latino, and 17.9 million being younger than 18 years of age (Patten, 2016).

Making community colleges work for Latinos aspiring to receive an associate degree and then a baccalaureate degree will require an understanding of the experiences of Latinos who have succeeded in achieving these goals, as a critical first step. This study seeks to understand the experiences of Latinos in community colleges by listening to their narratives, increasing the number of Latinos who succeed at completing this segment of the educational pipeline.

As stated previously, Latino success in higher education is vital for the nation. Latinos are the largest minority within the higher educational system in the United States, yet they are the least studied (Krogstad \& Fry, 2015; Solórzano et al., 2005). The pace of Latino college enrollment has already seen a sharp increase by $201 \%$ from 1993 to 2013 , compared to the college enrollment of African-Americans at $78 \%$ and Whites at $14 \%$ over the same time period 
(Krogstad, 2015). This increase broke the record of Latinos enrolled in higher education and it made Latino students the largest minority group on U.S. college campuses (Krogstad, 2015). It is estimated that two-thirds of Latinos who completed high school began their post-secondary education at a community college. But, only $20 \%$ of the students who began their education at a community college and had aspirations to transfer to a four-year institution actually transferred (Solórzano et al., 2005). National degree attainment, such as an associate degree or higher for Latinos was $23 \%$ compared to $42 \%$ of all adults (Santiago, Taylor \& Calderon-Galdeano, 2016). This college attainment gap is due in part to the fact that Latinos are less likely than some other groups to enroll in a-four-year college, attend academically selective colleges and enroll fulltime (Camacho Liu, 2012; Krogstad, 2015; Santiago et al., 2016).

In Illinois, the attainment for a higher education for students from public institutions is above the national average at $43.6 \%$, but when it comes to degree attainment for Latinos, Illinois lags behind despite its sizable Latino population. Demographically, degree completion rates do not favor the Illinois Latino residents. Within the 25 to 64 age bracket, only $19.38 \%$ of Latinos finish compared to other groups such as, African-American at 29.6\%, Asian/Pacific Islander at 72.4\%, Native American at 32.9\%, and White at 48.9\% (Lumina Foundation, 2016). Given the minimum requirement for employment in many fields and for upward economic mobility is a baccalaureate degree, it is alarming to see that only $23 \%$ of Latinos have an associate degree or higher in the U.S., compared to that of other ethnicities (Camacho-Liu, 2011; Lynch \& Engle, 2010; Santiago et al., 2016). Therefore, it is essential for higher educational institutions to redesigned their practices by eliminating the discriminatory policies that consistently create ethical and racial disparities in education (Santiago et al., 2016; Solórzano et al., 2005).

A college education is an important tool for the social justice system. Society needs 
educated individuals who can rationalize and strive for a fair society. Education can be used as a tool to create freedom from ignorance, helping individuals demand equal opportunities for all members of society. Equal opportunities reduce and eliminate marginalization between minority groups and the White population (Santiago et al., 2016; Solórzano et al. 2005; Villaneda, 2011). Therefore, hearing the voices of Latinos who have achieved their college degrees unveils the discriminatory policies and practices, which are embedded in the higher education system. Latino students' narratives highlight the struggles and experiences, hoping for the creation of change in a way that makes education equitable for future generations. The institutions of higher learning need to take into consideration the students' struggles and make the necessary systemic changes for Latinos to graduate at the same rate as they matriculate in college (Camacho Liu, 2012; Krogstad, 2015; Santiago et al., 2016).

Institutions of higher learning should strive to understand each student's values, culture and dreams in order to better help every student reach his or her full potential as part of their responsibility. While the work of the student club advisor and the counselor at my community college was admirable, they could only impact a small percentage of Latina/o's who would benefit from a higher education degree and who went on to contribute to the community. In order for students, such as myself, to be successful, everyone in the institution should help make a difference in the lives of students (Brown et. al. 2003; Contreras, 2011; Gandara \& Contreras, 2009; Valverde, Baltazar, Acevedo, \& Perez, 2008). The Latino community and the community college system need to work together to increase the Latino representation in an American society, so as to dismantle racism, segregation and poverty in the U.S. (Santiago et al., 2016; Solórzano \& Delgado Bernal, 2001; Villalpando, 2004). 


\section{Purpose of the Study}

The purpose of this study was to collect the narratives of Latino students who earned associate degrees at community colleges and to understand the role that resilience-resistance played in their successes. The postsecondary education community must hear and understand the voices and experiences of successful associate degree-completing Latino students who began their postsecondary careers at a community college. Furthermore, this study will be a step toward understanding what postsecondary institutions could do to end deficit-thinking to help Latina/o's find their voices, identities and critical consciousness (Valencia, 2010).

It is also important to find ways to link the higher education system with the Latino community (Rendon, 2016). Linking together higher education with the Latino community allows for a natural flow between the two contingencies and for Latino students to add valuable contributions (Brown et al., 2003; Delgado, 2013; Solórzano \& Delgado Bernal, 2001; Solórzano et al., 2005). By including the voices and experiences of Latino students into education policies, the institutions of higher learning can eliminate the ethnic and racial disparities in the field of education (Solorzano \& Delgado Bernal, 2001).

\section{Research Questions}

The following research questions helped investigate the experiences and voices of Latino students who graduated from a community college and matriculated in four-year institutions. Using a narrative framework, students' voices provided answers to the following questions:

1. What do Latino narratives reveal about successful completion of the associate degree?

2. What do narratives or stories reveal about how voice, self-consciousness, and culturalconsciousness contribute to resisting deficit-based stereotypes and dominant cultural norms, overcoming obstacles, and successfully completing the associate degree? 
3. What actions emerged from voice, self-consciousness, and cultural-consciousness that helped Latino students resist deficit-based stereotypes and dominant cultural norms, overcome obstacles, and complete the associate degree?

To answer these questions, a qualitative study was planned, and narrative methodology used to value the experiences and voices of Latino community college students as a primary data source. In this study, nine narratives represented the experiences and challenges of Latino students in which these nine students experienced. Personal stories were drawn, first from Facebook discussions and then by personal interviews. The narrative-story qualitative research method provided a means to collect and reveal the voices, experiences and particular knowledge of marginalized people who have faced numerous challenges and obstacles to succeed at completing the associate degree (Merriam, 2009). Personal narratives from the students were collected through interviews, discussion boards on Facebook and through personal narrative from the author. The stories and voices of students illuminated how the successful students understood and responded to barriers and obstacles to their community college completion (Merriam, 1998).

Since this researcher's personal experience is that of a first-generation community college Latina alumnus, the reader should be aware of the opportunity for bias that may be evident from which this research is conducted and analyzed. The advantage of the narrative-story methodology is that it validates and centers the Latino community college students' voices and experiences, which may lead to their academic success. The revealing of their voices creates a platform for the stories, explanations and underlying assumptions of Latinos that often times are counter to those developed and sustained by the dominant cultural discourse (Cerezo et al., 2013; Delgado, 2013). 


\section{Definitions}

Throughout this study the following terms will be used:

Counter-story: It is a story from the perspective of a subordinated or oppressed person or group that reflects on their everyday challenges and life experience. This type of story challenges the dominant discourse about people of color or minorities (Delgado, 2009, 2013).

Critical Race Theory $(C R T)$ : This is a theoretical framework originated within legal studies and examining the educational practices and policies that systematically exclude people of color (Solórzano, 2013).

Cultural deficit thinking (or Deficit thinking model): Within this framework, there is blame placed on students of color and their families as well as the communities they live in and the low academic performance; it also implies that students of color and their families are culturally deficient, and are not capable of scholarly learning and professional achievement (Valencia, 2010).

Cultural-consciousness: This is the knowledge and appreciation for which an individual has about customs, language and family background; knowing and understanding where and family came from (Ramirez, 2011).

Cultural-Mentoring: The informal role of mentoring, in which people who are culturalconscious assume to guide students who have similar backgrounds. Students are naturally attracted to professionals who look like them because they feel culturally validated and appreciated by professional and ethical individuals (Rendon, 2016).

Chicano: This term is a political term that represents the movimiento Latino, also known as the Chicano Civil Rights movement of 1960s and 1970s (Aguilar, McGillivray \& Walter, 2003). The term Chicano is used in a scholarly work (Solórzano, Delgado Bernal, 2001) that is 
referenced often in this study. Although the term Chicano has largely been replaced in more recent studies by the term Latino, which is considered to be more inclusive and representative (Garcia, 1995).

Hispanic: This term was created by the U.S. Office of Management and Budget 1977, in order to identify people from Puerto Rican, Mexican, Cuban, Spanish-speaking Caribbean, Central American, and South American countries. This term is considered inappropriate because it was imposed, is inaccurate and has marginalized those who had a history of Spanish colonization by associating New World peoples with Spain because of linguistic ties (Nunez, 2014).

Latino: The term Latino will be used to include people from several nationalities and ethnic groups such as Mexicans, Puerto Ricans, Cubans, Central and South Americans (San Miguel, 2005). The term Latino is a plural term that refers to the entire population of this ethnic group. Latino is a female and male term, and in this paper the term Latino will be used to include all the people whose origins are Latin American. In addition, this term is appropriate to use because it was socially constructed. This term evolved from grassroots origins and tends to be perceived as less marginalizing and more determined by population than the term Hispanic. It is also more accurate because it acknowledges the community's origins in the Americas through the terminology used by the population group itself (Nunez, 2014). Latinos is a plural term and will be used to refer to the entire population of this ethnic group or those who have identified themselves as Latino.

Latina: This term will be used to define a female who is of Latino decent.

Latino Critical Theory (LatCrit): This theory focuses on layers of oppression that are attached to immigration and documentation status, linguistic community, accent, and identity, 
building on Critical Race Theory and making explicit applications to the Latino experience. All of these layers of oppression impact Latinos' educational advancement in the United States (Valdes, 1997).

Successful students: This term will be used to define students who have completed an associate degree from a community college.

\section{Limitations of the Study}

This study revealed and analyzed the stories of successful community college Latino students. There were several factors that limited the findings. First, the framework for this study assumed counter-stories emerged as the voices of Latina/o associate degree graduates. The study draws upon narratives, but there were limited occurrence of counter-stories. A fair assumption that counter-stories would emerge guided the study in each phase. Second, the number of students who participated in this study did not represent all the successful Latino community college students in the United States. The sample of students were primarily from the Chicago metropolitan area, which may not necessarily reflect the collective voices and stories of Latinos throughout the U.S. Third, the role of the principal researcher conducting this study was that of researcher, mentor and former college advisor, which may have influenced the research. The researcher was networked to the study participants through social media and various social and cultural connections. This may have resulted in a sampling bias and required vigilance on the part of the researcher throughout the study. Finally, the sample size was small and limited in its ability to accurately capture all successful community college Latino students' voices and narratives. However, the study provided rich contextual information and narrative data that is often not found in the professional literature related to community college student outcomes. 


\section{Assumptions}

The assumptions of this research study were as follows: 1) Narrative-story was the best method to understand the students' resistance to dominant norms that include deficit thinking about Latinos; 2) the associate degree graduates honestly answered the questions and used authentic voices to do so; 3 ) the selected methodology was appropriate for this type of study because social media is an efficient method to collect the necessary data quickly ; and 4) the number of selected subjects were sufficient to collect the necessary data for this research study.

First, the use of narrative-stories provides a better means to understanding the students' resistance to dominant norms that include deficit thinking about Latinos. Hearing the narratives provided insight on how resistance was used to draw conclusions about successful Latino community college graduates. This assumption is held because sharing narratives -stories is part of the process to build communities and understand people's racial subordination and discrimination. This assumption is a way to value and acknowledge the students' voices and experiences (Delgado, 2013).

Second, the graduates receiving an associate degree were able to honestly answer the questions by using their authentic voices. This assumption was held because many of the students who were selected to be part of this study knew the researcher and knew how important it was to represent their voices and experiences authentically. The assumption was that they were honest and open to answering the questions and that the personal relationship with the researcher enhanced, rather than impaired open and honest responses. Because there is a strong connection, the level of authenticity is higher due to individuals feeling honored and committed to portraying their voices (Solórzano \& Yosso, 2009).

Third, the selected methodology was appropriate for this type of study, because social 
media is an efficient method to collect the necessary data. Facebook, email and phone conversations were familiar and the nine participants were comfortable using this efficient method of data collecting through social media. Since we live in a global society, many participating students reside out-of-state or out-of-country, making the use of an on-line social media venue an efficient means to include the voices of successful students that might otherwise be excluded (Davenport, 2010).

Finally, personal connections created a safe environment where students felt at home and free to speak from their hearts. Looking at the small percentage of individuals interviewed, it was important for the personal connections to be present. The number of selected subjects were sufficient to collect the necessary data for this research study. The personal connection between participants and the researcher is important as they recognized the researcher's commitment to the community and the higher education system.

\section{Significance of the Study}

The significance of this study helps to create an understanding of the experiences and community cultural wealth that Latinos draw upon in order to survive and succeed in postsecondary education. Latino college success is not only related to social justice, but also towards supporting a successful American democracy which factors economic success. Latinos have become one of the largest groups in the college-aged population; therefore, this timely study alleviated the low college completion rate among Latinos (Aguirre Hernandez, 2010: Patten, 2016; Santiago \& Calderon-Galdeano, 2015; Santiago et al., 2016). Additionally, this study is important because it fills current gaps in the literature regarding Latino students who successfully complete an associate degree at a community college (Jain, 2009; Ramirez, 2011; Villalpando, 2004). 
There is a need to understand how Latinos first imagine their college experience will be and how they aspire to reach their goals so as to make them successful at community colleges. By listening to the voices of people of color, we are better able to understand their communities and experiences (Ladson-Billings 2009). Critical Race Theory and Latino Critical Theory validate the experiences and restore the voices of marginalized people (Solórzano \& Delgado Bernal, 2001; Solórzano \& Yosso, 2001a). My story expresses experiential knowledge. It is appropriately legitimate, critically analyzing my learning and understanding about the racial subordination that Latino students face within the educational system (Yosso, 2005; Yosso, Villalpando, Delgado Bernal \& Solórzano, 2001). This knowledge draws explicitly from my community cultural wealth that many students of color possess. My personal story follows the methods as narrative-storytelling, family history, biography and personal scenarios that contribute to understanding individual and collective experiences. Therefore, it is validated under CRT and LatCrit theory. Because many of these stories are often ignored and undervalued, the experiences of students of color told in stories similar to mine, are important in order to have a better understanding of how they empower and validate other students of color and allows for them to take action to eliminate racism and other forms of subordination (Yosso et al., 2001). Therefore, having Latinos in positions of higher ranks in various professions allows for these individuals to not only help other Latinos, but also other minority groups.

I was able to achieve my educational goals because I drew strength from my family, cultural knowledge and gained the skills necessary in overcoming earlier structural barriers to education. My story can be deemed a success story because as a part of the largest growing ethnic community in the United States, I overcame the many extraordinary challenges presented by both being a member of this group and by my own unique circumstances. But, this story 
would not have been a success story if not for the support mechanisms that were provided to me by a community college with a culturally sensitive staff, open access policies, convenient location and low tuition cost. Latino students are more likely to succeed in college when there is a strong infrastructure of support, which includes cultural responsive policies and practices, supportive peer networks, staff networks, and institutional resources (Contreras, 2011).

The new economy is based on knowledge and it requires a highly skilled and informed workforce. Community colleges are critical in addressing the educational and skills gap that are present within minority groups. In addition, community colleges remain affordable compared to four-year institutions; therefore, they become a natural choice for nearly half of America's undergraduate minority students (Baum \& Kurose, 2013). The open-access found within community colleges is pivotal in restoring peoples' efforts to reach the American Dream (Baum \& Kurose, 2013). As a result, community colleges enroll about nearly half of Latino collegestudents in the United State (Krogstad \& Fry, 2015). For all of the above reasons, community colleges have become vital to Latinos' higher education advancement, not because it is their only choice, but because they are accessible, affordable and flexible.

Community colleges are important because for nearly half of the Latinos in the United States who attend community college, it is their first access to post-secondary education. Latinos who are able to complete their associate degree are able to transfer in a more natural progression to a postsecondary education. For me, a college degree meant breaking deficit-thinking and creating a path to social justice for upcoming generations. A college degree is a resource that will influence the individual's consciousness and that will lead to social change and social justice or transformational change (Berger \& Luckmann, 1966; Rendon, 1992). Latinos with a college degree have the potential to become role models to others who may feel vulnerable or out of 
place. Professional Latinos would have the opportunity to recommend changes to the higher education system so they could become culturally-responsive and inclusive institutions to all the students.

The voices and experience of successful Latino students are presented in this study. Their voices provide alternative points of view that challenge a dominant cultural narrative about Latinos in education (Jain, 2009; Delgado, 2013; Solórzano \& Yosso, 2009; Valenzuela, 1999). In addition, this is an opportunity to send a message to Latino students and their parents that it is acceptable to be Latino and that the Latino culture and its language are not inferior. The cultural community wealth which Latino students bring to the higher education system helps them to succeed in college but colleges needs to value these attributes that Latinos bring to their classrooms (Valencia, 1998; Yosso, 2005).

\section{Summary}

Community colleges are very important institutions in providing the educational advancement of non-traditional students having diverse needs. They are the first entry to higher education for over 7 million people in the United States and provide cost-effective educational opportunities, programs and services (Krogstad \& Fry, 2015). While, community colleges have played vital roles in the success of many Latino students who later became agents of change and advocates for social justices, community colleges are still areas of concerns regarding the success of Latino students (De los Santos \& De Los Santos, 2005). It is important for successful Latino college graduates to share their stories. Through these stories, students who come from similar backgrounds and circumstances can see their reflection in the successes of these graduates, which motivates them to strive for better lives as they complete their education and feel proud of who they are and what they represent. The narratives that are told by the individuals will impact 
the community college graduation rate because Latino students will see that finishing a degree is attainable.

The next chapter is composed of an overview of rich literature in community cultural wealth, which includes the following: (a) Latino demographics in the U.S.; (b) frameworks and theories of Critical Race Theory (CRT) and Latino Critical Theory (LatCrit); (c) and, counterstories. These aspects of the literature are used in this study in order to value and unveil the voices of Latino community college students. 


\section{CHAPTER II: LITERATURE REVIEW}

"She turned away, thinking that if Isabel could learn English, then maybe someday she could learn it, too" (Muñoz Ryan, 2000, p. 58).

\section{Introduction}

This chapter provides an overview of the higher educational attainment of Latinos who are living in the U.S., the roles of how community colleges in Latino community are developed, and the theoretical framework that was used to guide this study. The theories used include the following: (1) the Critical Race Theory (CRT); and (2) the Latino Critical Theory (LatCrit Theory) counter-storytelling, which depicts community cultural wealth as a means to understand and validate the voices of students. Additionally, the chapter highlights an overview of community colleges and a brief discussion of the most recent research studies on Latino community college students.

\section{Demographics}

Latinos make up $17 \%$ of the total U.S. population, making them the largest, fastest, and youngest ethnic minority group living in the United States. They are also the least studied ethnic group within institutions of higher learning, in particular the community college system (Covarrubias, 2011; Santiago \& Calderon Galdeano, 2015; Solorzano et al., 2005; Villalpando, 2004;). Additionally, Latinos are the largest ethnic group yet have the lowest percent when it comes to college education or degree attainment, lagging behind their peers. Therefore, it is important to have a better understanding about the needs of the Latino community in order to improve their higher educational attainment (Covarrubias, 2011).

Latino college enrollment continues to be significant, but college completion continues to be lower among Latino adults (Santiago \& Calderon-Galdeano, 2015). Despite the educational 
attainment that Latinos reached during the years 1993 through 2013, in which there was higher college matriculation and higher high school completion, Latinos continue to lag behind the White population in a number of key higher education measures within the areas of degree completion and college readiness (Fry, 2011, Krogstad, 2015;). The gap between the Latino and White populations completing an associate degree or higher is 24 percent points (Santiago \& Calderon Galdeano, 2015; U.S. Census, 2016). It is a significant gap that needs to decrease and create a just society. At the same time, it is important to understand how Latinos experience the beginning of their post-secondary education in the community college system since the community college is the primary entrance to post-secondary education for over $46 \%$ of Latinos (Krogstad \& Fry, 2015; Santiago \& Calderon Galdeano, 2015; Santiago et al., 2016).

Furthermore, in Illinois, higher education enrollment among residents ages 18 to 54 is above the national average of $45 \%$; but the Latino minority student college enrollment and degree attainment still lags behind and there is still have a long way to go before closing the higher education attainment gap. In Illinois, Latino student college enrollment is 11.8\%, compared to $14.2 \%$ of African-American students, $30.9 \%$ of Asian/Pacific Islander students, $13.9 \%$ of Native American students, and $16.1 \%$ of White students. Degree attainment of postsecondary education such as, certificates, associate degrees, bachelor degrees or higher with adults between the ages of 25 and 64 years of age in Illinois is $49.6 \%$. Latino students have the lowest percentage of postsecondary education attainment at $19.4 \%$, compared to $29.6 \%$ of African-American students, $72.4 \%$ of Asian/Pacific Islander students, 32.9\% of Native American students, and $48.9 \%$ of White students. Furthermore, Illinois will need to increase the degree attainment by 29.6 percent points for Latino students since $64 \%$ of all new jobs in Illinois will require postsecondary education by the year 2018 (Lumina Foundation, 2016; Merisotis, 2014). 
The state of Illinois still lags behind in narrowing the achievement gap by race at all stages of the education pipeline and needs to increase college attainment for persons of color (Lumina Foundation, 2016). So as to reduce the discrepancy, the Illinois Board of Higher Education, has highlighted three goals to increase educational attainment, they are as follows: (1) match the best-performing U.S. states schools to that of the world's countries; (2) narrow the educational achievement gap by race at all stages of the education pipeline; and, (3) increase college completion rates for students of color and for those with disabilities (IBHE Public Agenda, 2013).

\section{Community College}

Community colleges are the gateway to higher education and provide ease of access in many areas. Community colleges typically are closer to home, have an open- door policy, have flexible schedules, and are affordable. This makes community colleges the most logical place for Latino students to attend after completing their secondary education (Chapa \& Schink, 2006; Fry, 2011; Krogstad \& Fry, 2015; Santiago \& Stettner, 2013). When half of all Latino students who begin post-secondary education at open access public institutions never graduate, it becomes a problem (Santiago et al., 2016). An examination of the CRT and LatCrit theoretical frameworks provides a reason as to why Latinos have not benefited from the educational system at this level. These theoretical frameworks use counter-storytelling as a tool to reveal the voices of Latino students who attended community colleges and had graduated. There is a paucity of professional literature that covers this topic and this research study provides necessary additional information (Contreras, 2011; Santiago \& Stettner, 2013; Solórzano et al., 2005; Villalpando, 2004). 


\section{College Readiness}

College-readiness is a combination of academic skills and soft-skills that allow students to be successful in a college or university setting and is typically seen as a standard of whiteness (Covarrubias, 2011). Student academic skills include the formal education that takes place in the kindergarten through 12th grades educational system and those academic skills measured by the American College Testing system (ACT). Academic skill or academic achievement has a clear relationship to student college achievement (Conley, 2007). According to Brown and Roodan (2016), students who are academically ready are more likely to enroll in four-year institutions, and attain their postsecondary degree within four years compared to students who are less academic ready and enroll in two-year colleges after high school. For students who have low college-readiness the opportunities appear to be limited (Santiago et al., 2006). The good news is that the number of Latinos entering postsecondary institutions has grown and they are making progress toward college and career-readiness. However, the bad news shows many Latino students graduating from high school at about 25 percent points lower on their ACT scores in the area of college readiness when compared to white students' college readiness levels. When the ACT test results of high school graduates of the class of 2015 were compared by race and ethnicity over the 2011 to 2015 school years, it was found that the ACT scores of the following three minority groups continued to be similar in 2011, they are as follows: African-American at $10 \%$, American Indian at 21\%, and Latino at 23\%. The percentage of ACT scores from high school graduates that meet the three or more benchmarks by race and ethnicity are as follows: African American at 12\%, American Indian at 18\%, Asian at 59\%, Hispanic at 25\%, Pacific Islander at 26\%, and White at 50\% (Brown \& Roodan, 2016; Santiago et al., 2016). When students arrive at postsecondary institutions and are under-prepared or not college ready, they are 
more likely to take remedial education courses, which reduce their chances of completing a college degree (Camacho Liu, 2012). According to Santiago et al., (2016) approximately 30 to $47 \%$ of Latino students needed remediation when they started their postsecondary education. Remedial education contributes to low community college completion and low transfer to fouryear institutions (Mejia, Rodriguez \& Johnson, 2016). Remedial education is also known as developmental education. "Developmental education aims to provide underprepared students with the foundational skills they will need to succeed in college-level courses" (Mejia, Rodriguez \& Johnson, 2016, p.5). However, the structure of remedial education is not effective because it is too long and costly. Many students who are placed into remedial education and complete their courses never enroll in college level courses (Mejia et al., 2016). Students become discouraged when they arrive at college and learn that they must take remedial education courses, therefore being less likely to return the following term. Latino students and low-income students are disproportionately placed in remedial education. It is critical to enhance the college readiness of Latino students and low-income students in order for them to graduate from college at the same rate as their college matriculation (Brown \& Roorda, 2016; Fry \& Taylor, 2013; Mejia et al., 2016).

\section{College Completion}

Understanding the college completion rate of Latino students provides a means to enhance the rate at which this happens. Fry and Taylor (2013) mentioned that, "[a] record of seven-in-ten (69\%) Latino high school graduates in the class of 2012 enrolled in college that fall..." (p. 1). This is two percentage points greater than the White population of students at 67\% (Fry \& Taylor, 2013). This increase in college attendance broke the record for Latino students enrolled in higher education (Cerezo et al., 2013; Fry \& Taylor, 2013). While Latino 
students are entering college in record numbers, Latino college completion numbers are dramatically lower, as only $15.5 \%$ of Latino population in the United States had completed a postsecondary degree compared to $22.5 \%$ of the African American population , $53.9 \%$ of the Asian and Pacific Islander populations, and 36.2\% of the White population (Bryk \& Toch, 2012; Cerezo et al., 2013, Lederman, 2013; Merisotis, 2014; Pew Hispanic Center, 2013; U.S. Census, 2016). Latino students have the lowest level of completion when it comes to a bachelor's degree. These numbers are troubling, since a college education is critical for Latinos to advance in life and to ascend the social mobility ladder (Cerezo et al., 2013; Contreras, 2011; Fry, 2011). It is crucial to hear Latino students' voices in order to understand what works and does not work when it comes to college completion. Latino students have indicated that a college education is critical to their success by showing that they are motivated to earn a college education (Brown \& Roorda, 2016; Mejia et al., 2016). If this is true, then why are there so few Latino students completing their postsecondary education?

In understanding the obstacles that prevent students from finishing their degrees, there is a better understanding of how to improve the assistance provided to them. Understanding the Latino student experience, not only allows for better assistance in getting Latino students to complete their education at the community college level, but it also helps other minority students who may be facing similar challenges (Cerezo et al., 2013; Contreras, 2011; Fry, 2011). Santiago and Calderon-Galdeano (2015) asserted that Latino students have not been able to graduate at the same rate at which they enrolled in places of higher learning due to lack of support. While raceconscious efforts may provide racially-neutral equal treatment of students and are well-meaning, they create color-blind policies and practices that are counterintuitive to the advancement of the institutions of higher learning when adopted. Another reason is that institutions of higher 
learning attempt to serve all students, but are afraid to directly serve Latino and other minority students. This is evidenced when attempts are made to not show any bias or favoritism toward any student within the policies found in the institutions of higher learning, yet hinder the success of Latino students and other minorities. While this practice appears to be fair on the surface, evidence shows there has been an opposite effect for the college attainment of Latino and other minority students. These practices also appear to be substandard, showing evidence of the persistent educational attainment gap between White and non-White student groups. Therefore, the recommendations provided for college systems are to adopt policies and practices that are clear and direct, intentionally consider the needs of Latina/o students, and can be evaluated for substance. "Studies have clearly shown that for every $\$ 1$ invested in higher education a state can expect to gain \$4 in return” (Santiago \& Calderon-Galdeano, 2015, p.19). This information strengthens the argument that Latino student degree attainment is not only vital for the students and their families, but it is also vital for the nation's economic future. It is a matter of public good and private benefit (Carlson, 2016; Santiago \& Calderon-Galdeano; Santiago et al., 2016).

\section{History of Latinos in the U.S. Higher Education System}

In recent years, the presence of the Latino population in the United States has prompted much attention toward the growth and educational attainment of this population. Even though Latinos have been part of this nation since its inception, only in recent years has the American society put more emphasis on their presence (Acuna, 2007; Contreras, 2011; Gonzales, 2011; Perea, 2013; Valencia, 2010). In addition, the Latino population is very diverse. Over 64\% of Latinos are of Mexican descent, 9\% are Puerto Rican, 4\% Cuban, 3\% from El Salvador, 2\% from the Dominican Republic, and the remaining contributing countries make up less than $2 \%$ of the total population (Gandara \& Contreras, 2009). It is important to note that the majority of Latinos 
living at the United States are of Mexican descent, which is not surprising given the history between Mexico and the United States. Latino communities have been and remain an integral part of U.S. history, culture, and language. From a historical perspective, the long relationship between the U.S. and Mexico has been troubled and that has created resentment among the dominant culture toward any person who has skin color that is brown and/or identifies as being Latino or Hispanic (Delgado, 2013; Haney Lopez, 2013). Nevertheless, in order for Latinos to be fully integrated into the American society, there needs to be an understanding and awareness of resistance theories, such as Critical Race theory and Latino Critical theory. These theories emphasize the need to respect and value the Latino population for their contributions and assets they bring, such as, language, culture, and heritage (Acuña, 1998; Geron, 2005, Gonzales, 2011; Solórzano \& Delgado Bernal, 2001).

\section{Discrimination}

The United States was founded on tolerance and freedom for a certain group of individuals, mostly from European background; yet, for many ethnic backgrounds these two areas have not always been available. Latinos have been suffering discrimination since the beginning of U.S. history (Acuña, 1998; Geron, 2005; Gonzales, 2011; Perea, 2013). According to Krogstad and Lopez (2016), about 52\% of Latinos in the United States have experienced discrimination or have been treated unfairly because of their race or ethnicity. Although a large number of Latinos became part of the United States at the end of the Mexican-American War, they were not able to fully participate in American society as citizens of this country (Haney Lopez, 2013; Perea, 2013). They were subjects of racial and immigration discrimination because of the color of their skin and the language they spoke (Acuña, 1998; Geron, 2005; Gonzales, 2011). Latino citizens were viewed by many as second-class citizens who had a lesser claim to 
membership in the American community due to the stereotypes placed on them, such as "undocumented immigrants" (Acuña, 1998; Garcia, 1995; Perea, 2013). Latinos were restricted from participating in public places such as restaurants, theaters, and public schools even though the treaty of Guadalupe Hidalgo guaranteed Mexican-American civil rights and preservation of their language and culture. The treaty of Guadalupe Hidalgo was not honored by the American government. This was seen through the closure of many public schools with bilingual programs and through the placement of bilingual students into English only segregated schools (Acuña, 1998; San Miguel \& Valencia, 1998). In addition, Latino children had teachers who did not possess professional training in the teaching of bilingual students and harsh punishment often ensued when students spoke in a language other than English (Acuña, 1998; Garcia et al., 2011; San Miguel \& Valencia, 1998). As a result, students were not engaged by their teachers and many Latina/o's and Black students felt demoralized and exited the school system without a diploma (Acuña, 1998; Gonzales, 2011; San Miguel \& Valencia, 1998). For these students, education did not equate to freedom and tolerance.

Today, one may think that as a nation we have made significant progress in dismantling discrimination in the educational system. However, looking at the achievement gaps among Latino students and their peers, it becomes clear that Latinos continue to be marginalized and discriminated against (Carlson, 2016; Krogstad \& Lopez, 2016; Santiago et al., 2016). Latino students continue to have the lowest educational attainment and are still stereotyped as unauthorized immigrants (Krogstad \& Lopez, 2016; Lederman, 2013; Valencia, 2010). The level of marginalization and discrimination that Latinos experience today is not as visible as it was prior to the Civil Rights Act of the 1960's. The marginalization and discrimination experienced by Latinos is created by postmodern, color-blind, neutral immigration policies and practices 
embedded in the educational structures (Carlson, 2016; Covarrubias, 2011; Solórzano et al., 2005; Valencia, 2010).

It is hard to prove that the educational policies and practices discriminate minority students, since the educational institutions were created under the auspices of providing equal opportunities to all Americans (Lederman, 2013). However, Latino students and AfricanAmerica students are more likely to attend under-funded and low-performing schools than are White students; Latino students are more likely than white students to graduate from high school under-prepared when they begin their college or careers (Carlson, 2016). These examples of structural postmodern discrimination are factors contributing to low educational attainment by the Latino population (Bryk \& Toch, 2012; Carlson, 2016; Contreras, 2011; Lederman, 2013; Taylor \& Linchtenberger, 2013; Valencia, 2010). CRT and LatCrit theories assert that postmodern structures, policies, and practices are the educational race-neutral equivalent of the failure of the Treaty of Guadalupe Hidalgo. When immigration policies are added, it becomes evident that educational institutions use these variables to camouflage discrimination against people of color in order to maintain the status quo (Acuña, 1998; Santiago \& CalderonGaldeano, 2015; Solórzano et al., 2005). Postmodern policies can be seen in the confounding matrices used by the school systems such as, college tuition policies and college admission policies (Baum \& Kurose, 2013; Lederman, 2013). Change can be accessed for Latino and other people of color by demanding postmodern discrimination practices and policies (Carlson, 2016; Santiago et al., 2016). However, people must become agents of social change by educating themselves about the issues that are affecting minority students

Providing an education to people of color becomes problematic when they feel that they are being controlled by labels and stereotypes. This is an indication of a society's' control over a 
group of people (Haney Lopez, 2013; Ladson-Billings, 2009; Lederman, 2013). Latinos are more likely to be categorized as low educational achievers and blue-collar workers. These stereotypes not only impact their academic achievement, but also impacts their socio-economic status (Gillborn, 2009; Lederman, 2013). High numbers of Latinos are more likely to occupy low wage jobs that require manual labor which do not provide benefits and makes it to both have a better life and to climb the social ladder. As a result, their lives are occupied with a daily struggle for survival (Haney Lopez, 2013). Given that a Latino's focus is on the life's basic necessities, it is difficult for them to consider other options such as an education and or career. This focus does not allow them to contribute to society at more professional levels.

Furthermore, Latino college students are less likely to attend highly selective colleges due to the high tuition cost. They choose to attend community colleges because these institutions cost less than four-year institutions (Krogstad \& Fry, 2015). Therefore, CRT and LatCrit theories challenge the social constructs of higher learning, claiming that institutional policies place minority students and their communities at a disadvantage. There is a need to deconstruct the higher education system by recognizing race and ethnicity by ending the pretense that it does not exist or matter. In so doing, there would be an elimination of discrimination and social subordination (Ladson-Billings, 2009; Lederman, 2013; Solórzano \& Yosso, 2001c; Valencia, 2010). CRT and LatCrit highlight the insensitivity towards Latinos and students of color when the aforementioned institutional policies are put in place. The disproportional underrepresentation at the college level by Latinos is affected by the policies which make it difficult for students to attend (Santiago et al., 2016; Solórzano et al., 2005; Solorzano \& Yosso, 2001a). 


\section{Undocumented Students}

An undocumented student is one who is foreign born and does not have a social security number and U.S. identification card (Contreras, 2011; Perez, 2014). Many students are brought to the United States as children without their consent or their ability to grant such consent as they are only minors. The parents or guardians are either not aware of the necessity to obtain legal status for their children or have come to the county illegally themselves and are unable to obtain legal status for their children. The laws of the United States allow for the education of all children through high school; however, the lives of these undocumented children become very challenging when it is time for them to plan for higher education, due to higher education requirements such as having a social security number and residency status (Carlson, 2016; Contreras, 2011). According to Perez (2014), in 1982 the Supreme Court granted the right to access free public K-12 education to all students regardless of immigration status, in Plyler $v$. Doe. However, higher education was not part of this court decision; as a result, "[u] ndocumented students have to navigate through a complex web of federal, state, and postsecondary institution polices in order to achieve a postsecondary education" (Perez, 2014, p. 4). The Personal Responsibility and Work Opportunity Reconciliation Act of 1996 prohibited all undocumented people to receive any federal public benefit and that included postsecondary education. There is an estimate of 1.7 million undocumented students under the age of 30 who are enroll in elementary, middle school, high school or have graduated from high school; of these, approximately 65,000 undocumented students graduate from high school every year (Perez, 2014). In August of 2012, President Obama signed an executive order to defer deportations for eligible undocumented minors and granted them a social security number and two-year work permit called the Deferred Action for Childhood arrival (DACA). In order to be 
eligible, students needed to be between the ages of 15 and 30. Overall, undocumented students lack financial assistance because they do not qualify for federal student aid, and, depending on the state they reside impact the number of college admission for this population (Perez, 2014). Santiago and Calderon-Galdeano (2015) asserts that there are small numbers of undocumented students in the U.S. of which the majority of them are Latino and mostly enrolled in a community college. Therefore, there is important to better understand their needs to be able to help them be successful in their educational goals (Perez, 2014; Santiago \& Calderon-Galdeano, 2015). Burton (2012) found that often times undocumented students feel subordinate because of their race and language skills mostly due to their immigration status. On the other hand, Poetker (2015) found that the frustration and intimidation that undocumented students felt was overshadowed by their self-determination guided heavily by the institutional agents and peers they relied on for support and guidance. As a result, undocumented students faced roadblocks when trying to reach their college dream (Contreras, 2011). The recommendation from these scholars emphasized inclusivity, sensitivity for, and knowledge of immigration policies and processes amongst higher education institutions; providing better support and services to the undocumented students that are part of their college campuses (Covarrubias \& Velez, 2014; Santiago et al., 2016; Shelton, 2014).

\section{Theoretical Frameworks}

In the past ten years, there has been an increase in the number of research studies about Latino college achievement and experience. Given the number of Latinos who matriculate through community colleges, there is a need for additional studies that increase the wealth of knowledge about this particular ethnic group. It is also critical to adopt a theoretical framework that specifically examines the complexities of Latino identities, such as those determined by 
Critical Race theory and Latino Critical theory. Due to the limited research about Latino first generation college students using a Critical Race Theory and Latino Critical Theory framework, these two were used to create a better understanding of the higher education journey of Latino students.

These theories take the interconnectedness of both the educational and social impacts of Latino's identity into consideration. For this study, these two theories were combined and informed this study allowing for a useful critique of race, ethnicity, culture, language, immigration status, and the education system. These variables create educational oppression for Latinos and students of color forcing them to abide by the status quo of the dominant group (Covarrubias, 2011; Ladson-Billings, 2009; Solorzano, et al., 2005; Solorzano \& Yosso, 2001b). Therefore, it is critical for more research studies to be conducted using CRT and LatCrit in order to provide new ideas that improve the higher education system for all students and to remove unnecessary barriers to earning a degree. The following two sections depict in more detail the impact that CRT and LaCrit in understanding college completion from a theoretical perspective (Solorzano \& Yosso, 2001a).

\section{Critical Race Theory (CRT)}

Critical Race Theory (CRT) was created from critical theory and critical legal studies during the 1970's. The critical legal scholars advocated for equal treatment and social justice for people of color. The CRT foundational thinkers, Bell, Crenshaw, Delgado, and Williams, argued that the experiences of people of color mattered and should be part of racial discourse. CRT was incorporated into the education field to examine the color-blind, race-neutral policies and practices using the guidance of five tenants; such that CRT:

1. Acknowledges the different layers of discrimination and subordination on the basis of 
race, gender, class, immigration status, surname, accent, and ethnicity and racism is endemic in U.S. society and educational institutions (Solórzano, 2013; Yosso, 2005).

2. Challenges white privilege and alleges that race-neutral, color-blind policies are acts of camouflage to protect the interest of the dominant group (Solórzano, 2013; Yosso, 2005).

3. Commits to social justice by eliminating racism, poverty, sexism, and empowers minority students.

4. Centralizes and recognizes experiential knowledge of people of color as a legitimate, appropriate and critical knowledge to understand and analyze racial subordination.

5. Provides an understanding of the needs of students of color through the transdisciplinary perspectives in an historical and contemporary context (Solórzano, 2013; Yosso, 2005).

These CRT tenants help individuals understand and analyze how racism is embedded in the American education system and the actions that must be taken in order to eliminate them, providing social justice for all.

The CRT rejects color-blind and race-neutral policies and practices that students of color are subjected to (Solórzano, 2013). The color-blind and race neutral policies and practices are not fair to students of color, because many times students of color have been placed into lowperforming school systems that do not provide the opportunities and preparation necessary for college success. These policies avoid taking the struggles and backgrounds of students of color into consideration for college admissions or standardized test results. Furthermore, CRT scholars refuse to ignore the differences between class and race oppression, and they argue that class oppression is not the same as racial oppression. CRT scholars defined racism as a, "... system of ignorance, exploitation, and power used to oppress African-Americans, American-Indians, Asians, Latinos, Asians, Pacific Americans, among a few populations on the basis of color, 
culture, ethnicity, and mannerism (Bell, 2009; Ladson-Billings, 2009; Taylor, 2009; Yosso, et. al., 2005, p. 72; Yosso \& Solórzano, 2009).

Researchers assert that race has been socially constructed by micro-aggression and stereotypes in order to keep nonwhites at a disadvantage while protecting the advancement of the dominant group (Delgado, 2009; Haney Lopez, 2009; Ladson -Billings, 2009). They affirmed that CRT and LatCrit are powerful social tools that deconstruct social structure and reconstruct human agency in order for non-whites to be able to advance in life and have equity. Berger and Luckmann (1967) argue that individuals from the dominant society develop and sustain that social construct by creating social structures that are organized and controlled by the dominant society. The dominant society is controlled by people in power who find benefit in controlling the social structures in order to maintain the status quo. In this way, social structure becomes tacit and invisible to individuals in their everyday life. Therefore, when a child is born, that child's social structure is already determined by those individuals from the dominant society, whereby the child may not realize that the current social norms are fixed by those in power.

As a result, the social structure in which that child was born has already determined the child's social status, type of schools the child will be attending and the type of life the child will live. The social structure is also controlled and supported by the education system (LadsonBillings, 2009). The education system is a contradictory system. Educational institutions operate based on social structures as a way to maintain the status quo; at the same time, the educational institutions provide hope to oppressed individuals who wish to be free from oppression and have a better life. Yet, these individuals have to work harder than their peers because they are fighting the status quo and the social structure. This does not mean that they are unable to be successful, rather that they will face many obstacles that will be too great for some to overcome; however, 
others will be able to succeed (Berger \& Luckmann, 1967). CRT challenges the dominant discourse on race and racism as it relates to the field of education. In legal terms, CRT asserts that affirmative action is the only path to increasing authentic educational experiences for minority students because of the endemic racism in U.S. society (Solórzano \& Delgado Bernal, 2001).

In addition to its legal insights, CRT examines how education theories, policies, and practices are used to oppress certain racial and ethnic groups by using deficit thinking models that are mainly from the dominant ideology (Delgado, 2013; Solórzano \& Yosso, 2001c; Yosso, 2002). Together, CRT and Latino Critical Theory (LatCrit) specifically illustrate how race and racism impact the experiences and consciousness of Latino students (Yosso, 2002). CRT and LatCrit challenge the dominant ideology, the traditions, and the educational system's claims of objectivity, meritocracy, color-blindness, race neutrality, and equal opportunity (Garcia Torres, 2009; Solórzano, Delgado Bernal, 2001; Solórzano \& Yosso, 2001a; Yosso et al, 2001). It is important to study the use of these theoretical frameworks within this study to highlight the experiences and voices of Latino community college students. Therefore, it is critical to fully adopt LatCrit theory.

\section{Latino Critical Theory (LatCrit)}

LatCrit emerged from CRT in the early 1990s. The founders of LatCrit include the following: Harris (2013), Trucios-Haynes, Valdes, Haney- Lopez, Perea, Espinoza, Delgado, Garcia, and Acuña. LatCrit brings not only race to the forefront but also addresses multiple layers of racialized subordination that directly impact Latinos in their individual and collective struggles for social justice (Espinosa \& Harris, 2013; Johnson, 2000; Solórzano \& Delgado Bernal, 2001; Solórzano \& Yosso, 2009). Specifically, the racialized layers include: ethnicity, 
class, nationality, immigration, gender, sexuality, language, culture, accent, and identity (Espinosa \& Harris, 2013; Johnson, 2000; Solórzano \& Delgado Bernal, 2001; Solórzano \& Yosso, 2009).

Espinoza and Harris (2013) affirmed that CRT and LatCrit theories differ because Latinos and Blacks do not experience racism in the same way. CRT tends to focus more on the Black and White discourse, while, LatCrit solely examines the issues that impact the educational structures, process and policy discourse, which affect Latinos' academic achievement and advancement. Therefore, focusing solely on race and not on a nexus of characteristics that include language and immigration status limits an understanding of the educational experiences within Latino communities; thus, preventing critical analyses that highlight particular challenges or an advance to potential responses (Espinoza \& Harris, 2013; Garcia Torres, 2009; Solórzano et al., 2005).

In addition, LatCrit scholars assert that educational institutions' structures and practices are contradictory because, while offering an open-door policy, the same educational system oppresses and marginalizes students of color and in particular Latino students. These same structures and processes produce the result that Latino students graduate in smaller numbers (Jain, 2009; Olivia, Perez, \& Parker, 2013; Solórzano \& Delgado Bernal, 2001; Solórzano et al., 2005; Solórzano \& Yosso, 2001a; Valez, 1992;).

Solórzano et al. (2005) examined the educational pipeline data from elementary to college level by using the CRT framework and they found that out of 100 Latino students who started elementary education, only 52 would graduate from high school, 31 would enroll in college, 20 of the 31 would go to a community college, 11 of the 31 would go to a four-year university, and two of the 20 who started their post-secondary education at a community college 
would transfer to a four-year university. Additionally, Solorzano et al. mentioned that a

combined 11 students who started at a four-year university with the two students who transferred from a community college only 10 will complete a bachelor degree, four of 10 students who graduated with a bachelor degree would actually graduate with a professional degree, and less than 0.23 would complete a doctoral degree. When using the CRT and LatCrit theoretical framework to analyze the Latino educational pipeline, it is evident that more work needs to be done in this area. It is imperative that higher education institutions adopt more explicit raceconscious practices to truly enhance the success and achievement of Latino college students. There are many factors that impact the low academic achievement of Latino students but the most critical ones include racialized structures and policies and practices, which guide the higher education systems. As a result, only a small number of Latinos have been able to make it through the educational pipeline. The Latino students within these pipelines have been adopting their own support systems in order to resist all of the racialized structures and policies and practices in order to graduate from college. Latino college graduates need to reflect upon the educational inequalities to be able to recommend changes to the higher education institutions, which may make colleges more culturally responsive to all the students Yosso (2002) used critical media literacy to understand the influence that media has on Chicana/o's community college students by using 25 Latino students to highlight micro-aggressions. Historically, racial relationships between black and white led to the development of this terminology during the civil rights era (Solorazano \& Yosso, 2001b). Micro-aggressions are labels or stereotypes about a particular ethnic group based on utilizing social constructions of race such as, class, gender and immigration status to separate people and assign them a disparate value. The participants were exposed to different clips of Hollywood films that perpetuated negative images of Latinos. Yosso 
et al. (2009) found that these negative images motivated the participants to take a stand in their social reality by "prove wrong" (p.661). Participants became critically conscious and wanted to prove others wrong by overcoming micro-aggressions about Latinos. The labels that Hollywood film-clips used to portray Latinos were very disrespectful and offensive to the Latino youth and community; the Hollywood clips stereotyped Latinos as criminals who were disrespectful and had low academic achievement. The "others" in the film portrayed the dominant society and the people who made those films, in this case the story of the master (Yoso, 2002). The Chicano participants mentioned that not all Latinos were bad and that Latinos had the potential to become academically successful, but these participants also believed that whites were superior (Yosso,2002). This is an example showing how the experiences throughout their lives had allowed for the participants to become victims of racialized social constructs lives, and so they thought that they had to change themselves in order to become succeed in life. The outcomes of this study showed that the participants became critical of their social and educational inequalities and they were determined to be successful in life (Yosso, 2002). They wanted to "prove" to those with low expectations of Latinos wrong by working hard in school and becoming successful. They understood their potential and acknowledged their community cultural wealth skills, which included knowing two languages, as an example. They wanted to succeed so they could create a positive change for their community (Yosso et al., 2009).

Villalpando (2004), provided a discourse to the higher education system about improving college achievement for Latino students. He argued that there is a need to develop policies and practices that will specifically address the academic and social needs of Latinos and students of color. He stated that higher educational institutions have been trying to address the needs by implementing traditional programs such as, new out-reach and recruitment and academic 
advising programs, but this is problematic when all of the programs are based on the traditional models and not the ones under the CRT and LatCrit frameworks. Individuals using the CRT and LatCrit frameworks would do a better job in addressing the academic and social needs of Latino students by analyzing the Latino multidimensional identities and addressing the interconnected issues of race, immigration status, gender, classing, and other forms of oppression. Villalpando (2004) recommended a unique framework that would help the institutions of higher learning better address the interconnected issues of Latino college students, these are as follows:

1. CRT and LatCrit contest dominant ideology. Under this lens, CRT and LatCrit are used to argue about how race-neutral and color blind polices and practice are driven by selfinterest, power, and privilege of the dominant group in American society. This ideology prevents Latino college students from attending four-year colleges. Furthermore, fouryear institutions have admission policies and practices that promote the advancement of white students by using an alumni legacy practice that places Latino students at a disadvantage for admission, thus limiting the rate of completion of Latino students compared to white students.

2. CRT and LatCrit focus on social justice and social justice practice. Under this lens, CRT and LatCrit recommend that all institutions and individuals strive toward achieving educational equality for all students and that they develop and adopt programs, services and practices that explicitly support the holistic student development and social justice approach.

3. CRT and LatCrit recognize experiential knowledge. Institutions need to centralize Latinos' experiential knowledge by incorporating the idea that this knowledge as an asset found from within the community. Additionally, institutions of higher learning should 
develop culturally relevant programs and services that build support services based on these experiences and knowledge making sure not to adopt a one-size-fits all model.

4. CRT and LatCrit focus on historical context. It is important to know the student's story, whereby the institution is able to provide the support that reflects an awareness of the historical and regional differences within each student group.

All the arguments within the framework are appropriate when taking steps to implement change within an institution of higher learning. It lays the groundwork for using a community's cultural wealth, which Latino students bring to the higher education system (Yosso et al., 2009) When the CRT and LatCrit theories are used together, they challenge the existing deficit models and the traditional paradigms and demonstrate that Latino students possess community cultural wealth that helps them to resist racialized policies and practices that are found at traditional higher education institutions. Educational policies and practices often-times make Latino students feel out of place when they arrive at their campuses. Latino students often feel as though they do not belong in the higher education system and they experience the "imposter syndrome," often times questioning their intellect due to their surname, identity, and accent (Garcia Torres, 2009; Jain, 2009; Solórzano \& Delgado Bernal, 2001; Solórzano \& Yosso, 2001; Yosso, 2002; Yosso et al., 2009).

Latino students possess community cultural wealth that help them become successful, despite dominant cultural beliefs (Solórzano \& Delgado Bernal, 2001; Yosso, 2005). Despite all of the negative stereotypes associated with Latinos, many Latinos have been able to resist negative stereotypes linked to deficit thinking (Yosso et al., 2009). Deficit thinking theory supports the social structure systems that are used to oppress and subordinate non-whites and emphasize the continuity of the status quo (Bell, 2009; Brown et al., 2003; Gandara, 1995; 
Ladson-Billings, 2009; Pacheco, 2012). Therefore, the CRT and LatCrit models use narrative storytelling as a tool to unveil the voices and experiences of Latino college students. Narrativestorytelling is a methodological, conceptual, and pedagogical tool for hearing and then analyzing the stories of people of color that may challenge dominant social narratives, and perceptions (Delgado, 2009; Solórzano \& Delgado Bernal, 2001). The CRT and LatCrit frameworks can be used to acknowledge experiential knowledge, which helps to reveal and recognize the voices and experiences of Latino community college students by using narrative-storytelling methodology. Narrative-storytelling is a tool that highlights the students' community cultural wealth used by CRT and LatCrit to challenge the dominant discourse.

\section{CRT and LatCrit Counter-storytelling}

Counter-storytelling allows for the highlighting of the lived experiences of Latinos and people of color (Covarrubias, 2011). This type of story challenges deficit thinking and the dominant societal norms, revealing alternate points of view of the realities of subordinated people. The purpose of this counter-storytelling method is to honor the stories of marginalized people, build community and alliances within a shared common culture, and depict the experiencces of people of similar ethnicities, history, and racial subordination (Delgado, 2013; Solórzano \& Delgado Bernal, 2001; Solórzano \& Yosso, 2001c; Yosso et al., 2001).

Counter-stories, as a critical pedagogical methodology, may move Latinos through levels of consciousness unto a critical stage (Yosso, 2002), facilitating social action (Johnson, 2000). Social action is an indicator of higher levels of consciousness (Solórzano \& Yosso, 2001a). Some examples of higher levels of consciousness experienced by Latino students is their participation in the UCLA protests of the 1960's called walkouts (Solorzano \& Delgado Bernal, 2001). During the Chicano student movement at UCLA, Latino students were conscious of their 
low academic performance and the poor support they received when compared to non-Latino students. They demanded educational changes and social justice. They organized hunger strikes and marches in order to have equal opportunities, "prove wrong" (Yosso et al., 2009, p661), and take a stand and be determined to succeed. They became critical of the way they were being educated, demanding equal learning environments and confronting negative ideas and images of Latinos; in this way they demanded structural and institutional changes so they could approve upon academically (Solórzano \& Delgado Bernal, 2001; Yosso, 2002).

Counter-stories validate the students' experiences and culture by helping them to be proud of who they are. The CRT and LatCrit counter-storytelling encourages students of color to be natural leaders, therefore rejecting the humiliation encountered throughout their college careers (Solórzano, \& Delgado Bernal, 2001). Many Latino students enter college with selfdoubt, disconnected from sources of individual and cultural strength and a belief in the dominant discourse instead (Espino, 2008; Rendon, 1992). As a result, students doubt their intellectual capacities and question themselves as to whether they belong in higher education and ignore the community cultural wealth available to them (Espino, 2008; Garcia Torres, 2009, Rendon, 1992; Solórzano \& Yosso, 2001b; Yosso, 2005; Yosso et al., 2009). Through the counter-storytelling method, students are able to understand that educational institutions are part of a fixed social structure, which students resist in order to be able to graduate from college and eventually become an agent of social change (Solórzano\& Delgado Bernal, 2001). The CRT and LatCrit counter-storytelling values, acknowledges, and validates characteristics of the students of color and their community cultural wealth (Espino, 2008; Pacheco, 2012). Ramirez (2011) examined the stories of 85 Latino community college students under the CRT and LatCrit counter-story frameworks. He found that Latino students from community colleges were able to successfully 
transfer to a four-year university because of the assets they possessed as community capital and community cultural wealth. His findings challenged deficit thinking and suggest that leaders in institutions of higher learning and institutional agents of change need to re-examine and reform the higher education structures, policies and practices in order to create an inclusive higher education system; a that acknowledges and supports the experiential knowledge and community cultural wealth that Latinos bring to the education system.

Community cultural wealth emerged from CRT and LatCrit. Yosso (2005) challenged the cultural capital discussion by presenting the community cultural wealth, which minority students bring to the higher education system, and argued that community cultural wealth is valid and important to the well-being of minority students. This type of community cultural wealth challenges the cultural capital, which profits affluent students. Yosso states that all students possess capital, but the findings of her study show the higher education system only acknowledged individuals who acted a certain way, possessed certain knowledge and demeanor, and disregarded others who looked different than the traditional affluent students as either unprofessional or less than the others. Community cultural wealth is a set of characteristics that students of color bring to the higher education system. These characteristics are what helped them to succeed in their college education (Yosso, 2005). Community cultural wealth helps students to develop skills in order to resist racial subordination in school structural systems and achieve their academic goals despite the challenges not faced by the dominant group. This set of cultural knowledge is known as "community cultural wealth" and is comprised of six overlapping areas that include: aspirational, linguistic, familial, social, navigational, and resistant capital (Yosso et al., 2009). 


\section{Community Cultural Wealth}

According to Yosso (2005), community cultural wealth is a set of assets or resources that Latino students and students from a community of color possess. De la Riva (2012) examined the persistence of second-generation Latino language community college students. The participants of this study were Latino students who were raised in Spanish speaking households. This study found that participants were very individualistic and their academic success were supported by a sociocultural context enabling them to cross both cultural and linguistic boundaries. Valdez (2015) studied the characteristics of community wealth among Latino students and their community. Valdez found that students were able to succeed in college due to their cultural asset and cultural wealth by challenging higher education policies and practices; therefore, succeeding in college completion. This study used CRT and LatCrit as critical lenses, and focused on community cultural wealth in order to recognize the racial challenges, which students overcame.

Community cultural wealth challenges the traditional cultural capital that the dominant group considers. These resources strengthened Latino students by helping them resist and overcome racism, discrimination, and subordination. The community cultural wealth consisted of aspirational, navigational, social, linguistic, familial, and resistance capital. All of these characteristics function similarly. Traditional capital refers to an accumulation of abilities, cultural knowledge, and skills that are possessed and inherited by privileged groups in society. Traditional capital could also be inherited through an accumulation of specific forms of abilities, knowledge, and skills that are valued and validated by privileged groups in society. Community cultural wealth characteristics are drawn from the knowledge that students of color bring from their communities to the classroom. Often times this knowledge is ignored by the educational system because it is not part of the traditional cultural capital possessed by the dominant groups 
(Valdez, 2015). Valdez (2015) found that community cultural wealth helped Latino students to successfully move through the higher education system. The resources that students brought in the form of family and community knowledge made it possible for the students to succeed in college. In addition, Artiaga (2013) found that the support and influence that Latino students received from their families and community were major factors in contributing to the success of a group of women at their community college.

Lodmer (2008) examined the characteristics of 10 Latino males who were children of immigrant parents and were ready to transfer or had transferred to a four-year university. Students were able to proceed through the education pipeline due to their resilient characteristics and support from family members, mentors and teachers. These findings resemble Yosso's model of community cultural wealth (2005). The resilient characteristics Latino college students bring to higher education are part of their community cultural wealth. It is important to know that these findings are very important to the success of Latinos in higher education, yet there is still a need to centralize and acknowledge the experiences and assets that Latino students bring to the college setting.

Family influence and support are parts of the assets included in community cultural wealth. Furthermore, Villanueva (2015) found adult Latino community college students traced their identity to the concept of community cultural wealth in order to overcome oppression and discrimination to become successful in reaching their goals. The number of studies using CRT and LatCrit counter-storytelling recognizes community cultural wealth as a tool to recognize the experiential knowledge of students of color, yet they are limited and even more so when applied at the community college level. 


\section{Latino Students Community College Attendance}

Community colleges were established in 1901 to respond to the quickly developing social changes and demands that were present at the turn of the century and that the four-year institutions could not meet (Cohen, 1998; Thelin, 2004). Today, community colleges have become a natural path for nearly half of the Latinos in higher education. It is estimated that $46 \%$ of Latino higher education students attend public two-year community colleges, compared to $34 \%$ of African-American students, $32 \%$ of Asian students, and $30 \%$ of White students (Krogstad \& Fry, 2015). However, Latino students who began their higher education careers at two-year public institutions were less likely to graduate with an associate degree or transfer into a four-year institution (Fry, 2011; Solórzano et al., 2005). Furthermore, Latinos were more likely to attend community colleges and less likely to attend four-year universities due to financial issues, lack of information about the higher education system processes, and cultural reasons (Chapa \& Schink, 2006; Covarrubias \& Velez, 2014).

The percentage of Latino students in higher education who attended four-year universities is 52\%, compared to $63 \%$ African-American, 67\% Asian, and 69\% White students (Krogstad \& Fry, 2015). As a result, Latinos have the lowest higher educational degree attainment, an associate degree, as seen by the percentage of $22 \%$, compared to $46 \%$ of the White population, $32 \%$ of the African-American population, and $60 \%$ of the Asian population (U.S. Census, 2016). At the baccalaureate level, the Latino degree attainment is $15 \%$, compared to following populations: African-Americans (32\%), Asian (53\%), and White (49\%) (U S. Census, 2016). Although Latinos are heavily represented on the college campus, the representation does not translate into degree completion. Therefore, CRT and LatCrit scholars argue that low degree attainment is a result of racialized policies and practices of the higher 
education system that redirect Latino students to community colleges instead of four-year institutions (Santiago \& Calderon Galdeano, 2015; Solórzano et al., 2005; Yosso et al., 2009).

Often times, first college generation college students are unaware of other options and think of a community college as their only option. Since more than half of the Latino students who attend a community college are the first person in their family to attend college, they are unaware all of the financial aid opportunities available to them. The cost of college attendance has become a major decision factor for Latino students. As a result, Latinos are highly concentrated at community colleges due to tuition cost and selection process of some colleges and universities. Highly selective higher education institutions have higher completion rates, but they are more expensive and have very selective admission requirements (Krogstad \& Fry, 2015). Unfortunately, Latinos are disproportionately found at the lowest socioeconomic levels and are more likely to base their decision of college on the college price (Chapa \& Schink, 2006; Krogstad \& Fry, 2015). Financing a college education is a tricky endeavor for Latino students because many of them are unaware of how to complete the Free Application for Federal Student Aid (FAFSA) form or even seek additional scholarships; as a result, they are less likely to apply for FAFSA or scholarships, and choose to work while attending college in order to fund their college education (Fry, 2011; Lederman, 2013; Solórzano et al., 2005). Therefore, the community college becomes a natural choice, since that is what they can afford.

Another reason that Latinos tend to matriculate at community colleges is due to the lack of information. Approximately $60 \%$ of undergraduate Latino students who may have attended a selective college or university went to non-selective institutions. This "under-matching" results in high-achieving low-income students not applying to highly selective colleges where they would have likely been accepted (Chapa \& Schink, 2006; Lederman, 2013; Stratford, 2013). In 
addition, Latinos tend to select community colleges for cultural reasons. Many Latino students are the breadwinners of their families, so they often attend college on a part-time basis and work more than thirty hours per week (Fry, 2004; Fry \& Taylor, 2013). Furthermore, it is part of the Latino culture for the children to contribute to the well-being of the family, and to live with their parents until they marry (Chapa \& Schink, 2006; Fry \& Taylor, 2013; Santiago et al., 20016; Santiago \& Stettner, 2013). For all of these reasons, the natural choice for Latino students is to continue their education at community colleges (Covarrubias \& Velez, 2014; Yosso et al., 2009) There is a disconnect between college attendance and college completion. This disparity creates social issues that must be attended to, especially when less than half of Latinos, who are the "largest and most rapidly growing ethnic group" (Gandara \& Contreras,2009, p.1), start their education at a community college and graduate or matriculate in a four-year institution (Chapa \& Schink, 2006; Fry, 2011; Solórzano \& Yosso, 2001a). Because Latinos have the lowest educational attainment of any other ethnic group in the United States when nationally compared to the 25 to 64 -year-old working group bracket, it is easy to see why they lag dangerously behind (Bryk \& Toch, 2012; Gandara \& Contreras, 2009; Krogstad \& Fry, 2015; Lederman, 2013; Merisotis, 2014; Ryan \& Bauman, 2016; Yosso et al., 2009).

The low college completion rate of minority students requires a deep examination by the higher education organizations (Yosso, et al., 2001). According to a report from Georgetown University (2013), higher education reinforced the inter-generational reproduction of White racial privilege (Lederman, 2013). Highly selective higher education institutions produce higher college completion rates among white students, which in turn allows for higher earnings, and those higher earnings result in the privileges that have been passed down by highly educated parents from generation to generation (Lederman, 2013). Race does matter, especially when it 
comes to equity and college completion (Covarrubias \& Velez, 2014; Delgado, 2013; Lederman, 2013). The over-representation of Latino students in community colleges and their continuing under-representation in four-year institutions are the effects of the ongoing manipulation of selfserving notions of racial neutrality and meritocracy by higher education institutions (Yosso et al., 2009). Arguments using the CRT and LatCrit show that these policies and practices adopted by higher education purposely maintain a racially segregated educational environment and continue to benefit and protect the interest and the advancement of non-minority students. Some of the policies and practices that negatively impact Latino students are academic tracking, ineffective counseling, negative racial climate, standardized admission exams, and tuition costs. These policies and practices are the main factors or 'landmark victories' that direct Latinos to community colleges (Gillborn, 2013; Mejia et al., 2016; Solórzano et al., 2005). These 'landmark victories' protect the racist status quo by ensuring "just the right amount of racism" and have therefore become additional weapons against further reform as they allow business as usual to continue (Gillborn, et al., 2013, p.136; Solórzano, et al., 2005).

The low rates of Latino students' college completion provide an alarming picture of the American future, since Latinos are the largest and youngest minority in this country (Fry \& Taylor, 2013). The Latino students' lack of degree attainment will have significant impacts within the American democracy (Chapa, Schink, 2006; Gandara \& Contreras, 2009; Merisotis, 2014). Higher education is guided by racialized structures, polices, and practices, which help four-year institutions keep the majority of Latino students from being admitted to their institutions due to Latino students being perceived as unprepared and unmotivated students (Covarrubias, 2011; Covarrubias \& Velez, 2014; Solórzano et al., 2005). As a result of those perceptions, Latino students are highly concentrated at community colleges (Solórzano et al., 
2005). Higher education has embraced a meritocratic objective and color-blind system, maintaining the current race, class, gender and sexuality privileges, while clearly devaluating and marginalizing Latina college students (Covarrubias, 2011; Covarrubias \& Velez, 2014; Solórzano et al., 2005).

\section{Summary}

The issues found within CRT and LatCrit studies acknowledge racism as socially constructed and supported by micro-aggression, stereotypes, and labels that the dominant groups in society created to protect the status quo and continue the oppression of people of color. White superiority is so embedded within the national, political, legal, educational policies and practices that it is virtually invisible and normal, but still present in our society (Taylor, 2009; Villalpando, 2004). The educational disparities between minorities and White students is clearly evident in how educational institutions of higher learning continue the impact of White supremacy or whiteness (Covarrubias \& Velez, 2014; Lederman, 2013; Solórzano \& Yosso, 2001a; Villalpando, 2004). The CRT and LatCrit theories challenge higher education practices and demand equity for people of color (Yosso et al., 2009)

Taking the notion of equity in higher learning more seriously allows the conversations to delve deeper with the help of the LatCrit theory, which emphasizes the importance of language, immigration status, and Latino identity. LatCrit theory encourages Latinos to feel proud of their roots and challenges deficit thinking by helping them question the status quo, which draws from their community cultural wealth and helps them overcome racial oppression. When using CRT and LatCrit theories, the counter-story method can be applied as the tool of preference to unveil the marginalized and oppressed community college students' voices. By sharing their stories, community college students feel validated by their successes. This helps them understand how 
resistance transforms education (Chapa \& De la Rosa, 2006; Contreras, 2011; Fry, 2002;

Gandara \& Contreras, 2009; Rendon, 1992; Valencia 2010; Yosso et al., 2009; Yosso et al., 2001). 


\section{CHAPTER III: METHODOLOGY}

\section{Purpose of Study}

The purpose of this research study was to use Critical Race Theory (CRT) and Latino Critical theory (LatCrit), in particular narratives, as a fundamental framework to recognize the voices and experiences of successful Latino students who began their postsecondary careers at community colleges. CRT and LatCrit scholars have argued that when the experiences and cultures of students of color are highlighted and validated by academia students of marginalized communities are more likely to be successfully engaged in their college careers (Rendon, 1993; Santiago et al., 2003; Solórzano \& Yosso, 2001a). The framework of this study draws together insights from two theoretical strands that use counter story-telling as a way to hear the voices of Latinos who have successfully navigated community colleges to achieve their associate degrees, they are as follows: (a) Critical Race Theory, and (b) Latino Critical theory.

Delgado (2014) asserts that CRT and LatCrit counter-storytelling is a cure or healing method used by people of color who have been marginalized, oppressed, and devalued. This type of counter-storytelling helps to create bonds among marginalized students, and it also authentically represents the experiences of Latino students in community colleges. Dominant groups create their own stories too and those stories are told within the group and remind them of their identity and core relationships, affirming their superior position over that of people of color. The dominant group's stories become part of reality and are seen as natural or normal within society. The people of color, rarely have an opportunity to share their stories, voices, history and experiences, because stories from the dominant group portray people of color as inferior and abnormal (Solórzano \& Yosso, 2009). Therefore, it is essential to this study to highlight the stories and experiences of Latino students who started their higher education journey at a 
community college (Solórzano et al., 2005).

Narrative inquiry is well represented in this research study by the use of counter-story methodology. The role of a counter-story is to show the student's experience as interpreted by their experiences and how those experiences influence their college graduation or completion (Johnson \& Christensen, 2012; Merriam, 2009). This method was effective in understating the voices, experiences, and perspectives of the nine participants from this study (Merriam, 2009). The narrative -story approach described the experiences of participants by highlighting participants' voices through personal narratives (Lester, 1999; Merriam, 2009). The primary focus of this type of study is the experience itself; interpreting how these experiences transform the individual's consciousness and guiding them in their everyday lives helps to provide an understanding of how they view their worlds and their social actions (Johnson \& Christensen, 2012; Lester, 1999; Merriam, 2009).

\section{Research Design}

In order to explore the essence of the Latino community college students' experiences, the CRT and LatCrit frameworks were used. This research involved an online demographic survey, online discussion, and online and face-to-face, 30 to 60 minute interviews, with nine participants during a period of two months. The interviews were audio recorded. An online discussion with nine participants and an in-depth online and face-to-face interview with eight participants followed. Qualitative data was gathered from Latino students who had or were attending community colleges or those who had graduated from a community college. Participants were solicited to participate in this study via Facebook with a recruitment letter found in Appendix A. Data was collected from the Facebook group discussion and critical incident interviews. Then, data was coded and categorized into common and repeated themes 
that helped to answer the research questions (Coffey \& Atkinson1996; Wholey, Hatry \& Newcomer, 2010).

\section{Procedures and Data Collection}

This research study was conducted in three different stages, having all the questions approved by the University Institutional Review Board (IRB) prior to conducting each step. Stage one was the recruitment of the participants from August 16, 2015 through August 25, 2015, following the approval of the recruitment questions. Stage two was the Facebook discussion group from August 31, 2015 through September 15, 2015. Stage 3 consisted of the individual interviews from December 17, 2015 through December 29, 2015. To ensure that all participants met the research study requirements, an online demographic survey was created. This survey was created using Googledocs. This link was only shared with people who had expressed interest in participating in the research study and who had sent a signed consent form in an email back to the researcher (See Appendix B). This online survey entitled, "Demographics Data Survey", included 13 demographic questions found in Appendix C. These participants were recruited via Facebook. I posted the research recruitment participant's letter on my Facebook status, found in Appendix D. Facebook friends were asked to share my status, recommend any possible participants, or to contact me if they were interested in participating in this study (Davenport, 2010).

Thirteen people showed interested, but only 11 met the general research study requirements. Ten out of the 11 participants completed the demographic online survey and consent form. After they completed the demographic survey and consent form, they were sent an email with the instructions to join the Facebook private page called Dissertation Group, which served to have online group discussions. Eight out of the 10 participants participated in the 
Facebook group discussion. One of the 10 participants who had completed the demographic survey and signed the consent form withdrew from the group due to a death in her family; she felt that she was not going to be able to keep up with the group discussion. Another participant, who completed the demographic survey and signed the consent form decided to participate in this study phase only via email instead of the Facebook discussion group. She sent me all of her answers to the fourteen questions that were prompted to the Facebook private group. A copy of the questions the participants received can be found in Appendix E. She did not feel comfortable sharing her story with the Facebook group because she felt that her information would be compromised.

After four weeks of the online group discussion, the students' stories were recorded and critical incident interview questions were prepared and presented to the IRB for their approval. After IRB approved these critical incident interview questions, the participants were again contacted via Facebook instant messenger, text, and email. All nine of the participants agreed to participate in the second phase of this study. I asked them to sign the second consent form (See Appendix B) and email it back to me. The interview arrangements were made and the individual interviews began. The participants had different options for being part of this study phase. They could choose to be interviewed via Skype, Facebook Video Conference or face-to-face interview methods. There were a set of nine individual interview questions that were asked, these are found in Appendix F. Eight of the nine participants participated in individual interviews. One of the nine participants who participated in the Facebook online group discussion and who had agreed to be interviewed was not able to participate in the individual interview due to her complex schedule. Although all of the possible accommodations were made available to her, none of the options were viable. 


\section{Data Analysis}

Facebook group discussion and interview data was analyzed by using step-by-step process of coding as a means of data reduction. Coding is part of the qualitative data reduction method that allows finding key themes associated with participants' stories and align with the research questions (Coffey \& Atkinson, 1996; Wholey et al., 2010). Coding began as the initial step to reduce and eliminate unnecessary data. Then, categories at the second level of coding, known as axial coding, were formed. At this level of coding, similarities or themes among the different responses from the participants were examined and codified. Finally, another round of analysis was conducted and the constant comparative method was used on the collected data in order to answer the research questions of the study (Johnson \& Christensen, 2012; Lester, 1999). This analysis was significant because it assisted with the elimination of any personal bias or prejudice (Wholey et al., 2010).

\section{Research Questions}

Three research questions framed this study of how Latino students voice the identity and cultural consciousness that helped them to graduate from a community college. Using CRT and LatCrit theories, students' voices gathered from Facebook discussions and interviews helped answer the following questions:

1. What do Latino's narratives reveal about successful completion of the associate degree in a community college?

2. What do narratives reveal about how voice, self- consciousness, and culturalconsciousness contribute to resisting deficit-based stereotypes and dominant cultural norms, which help the students overcome obstacles, and successfully complete the associate degree? 
3. Are there any actions that may emerge from voice, self - consciousness, and culturalconsciousness that may help Latino students to resist deficit-based stereotypes and dominant cultural norms by overcoming obstacles, and completing the associate degree?

These questions were formulated in order to recognize the students' own voices, experiences, and cultural consciousness to understand the factors that might have contributed to their degree completion. Qualitative data was coded and categorized with common and recurring themes that explained and addressed the research questions (Coffey and Atkinson, 1996; Wholey et al., 2010).

\section{Role of the Researcher}

It is possible that in qualitative research the researcher could occupy positions which make them "insiders" and "outsiders." Therefore, it is important for the researcher to declare their own position in order to avoid ambiguity and ensure the validity of the research study (Merriam, 2009: Wholey et al., 2010). In this study, I occupied both the "insider" position relative to participants because I am a first-generation college student, community college alumni, born in Mexico, naturalized U.S. citizen, and the daughter of working class parents. Likewise, I am the "outsider" to the participants because now I am a professional, middle-class and mentor to some of them. These two positions have provided the opportunity to work with the community and the higher education system. I have over 15 years of experience working with Latino college students in the advising, administration, and program development positions.

Prior to the narrative-story Facebook group discussion and interviews, I completed an assessment of my own experience in order to be aware of personal prejudices, viewpoints, and assumptions. Once I was aware and understood my personal prejudices and assumptions, I set aside those prejudices and assumptions, removing them from the research study in order to see 
the participants' experiences without the confounding personal input (Johnson \& Christensen, 2012; Merriam, 2009). The personal narrative is shared in Chapter I of this work. I often crossreferenced my writing with that of my participants to check for bias.

The advantage of this methodology was that it validated and centered the Latino community college students' voices and the relationship of their experiences to their perceptions and their academic success (Rendon, 1993). The revealing of the students' voices created a platform for their stories, explanations, and underlying assumptions that often times are developed by the dominant cultural discourse (Delgado, 2013; Solórzano \& Yosso, 2009). The narratives preserved authentic voices of Latino students who successfully completed their

associate degrees. The narratives of the dominant culture could be destabilized as "the way" to interpret community college experiences for all students (Delgado, 2013; Ramirez, 2011; Solórzano et al., 2005; Solórzano \& Yosso, 2001a).

\section{Participant Sampling}

For the purpose of the study, I used the networking or snowball sampling method. Participants who attended and graduated from a community college with an associate degree in the last five years were solicited. In the initial phase, the demographics and connections made through networking or snowball sampling identified participants for the Facebook data gathering. In the second phase, participants in the Facebook group and online discussion were invited to participate in individual interviews using a theoretical or purposeful sampling frame. These follow-up interviews sought further elaboration on the stories that emerged in the Facebook online discussion group. Follow-up questions were crafted based on these powerful counterstories in order to further reveal participants' voices and experiences. The process of eliciting interview participation was conducted using Facebook videoconference, Skype or face-to-face 
interviews. The method that was used in each case depended upon the participant's availability. The sample of participants consisted of nine Latino community college graduates and were identified as follows: a) all of the participants identified as first-generation college students, b) they were of Mexican descent, c) they were attending or had graduated from a community college within in the past five years, and d) who were pursuing or who had pursued a baccalaureate degree or higher. Network or snowball sampling was an appropriate tool to use for this type of qualitative research because it centered upon the ability to gather information relevant to the research questions based on the stories and experiences of specific participants (Merriam, 1998). To identify prospective participants, a message was posted on my Facebook status that solicited participants. Direct messages or private messages were also sent to the participants after the initial general post. Those participants who responded to the solicitation were sent the information about the research study. The information included the IRB-approved consent statement, selection criteria, and the researcher's contact information. Students who qualified for this study met the following criteria, they are as follows: (a) self-identified Hispanic, Latino, or Chicano descent, (b) first-generation college student from their families, (c) began their post-secondary education at a community college, (d) Completed their associates' degree at a community college within the past five years, and (e) pursued or had pursued a baccalaureate degree.

For the purpose of this study, developing a private Facebook Dissertation Group page was an excellent means to engage people and to create an avenue for them share their stories with others from similar cultural and ethnic backgrounds in a secure location. 


\section{Facebook Group Discussions and Interviews}

Facebook group discussions were used to learn about experiences of Latinos in community colleges who then matriculated in baccalaureate studies. Facebook was an appropriate and efficient method to collect data for this study because Facebook is a popular and reliable social medium that is used by over one billion people per day in the world (Davenport, 2010). Through Facebook, I was able to listen to discussions that highlighted Latino experience and allowed follow-up questions to answers that might need further clarification. Facebook group discussions replaced focus groups, while serving a similar function and provided a platform for sampling select interviews. Facebook provided access to several people at the same time in different and widely dispersed geographical locations (Davenport, 2010). Participants, whose geographical location and personal commitments would have prevented them from inclusion in this study were able to have their voices heard and provided useful and important evidence; evidence of distinctive nature of Latino experiences in community colleges.

During the second phase, the participants who participated in the Facebook and online discussion were invited to take part in the individual interview process and were given an opportunity to elaborate on their stories (Merriam, 2009). Therefore, it was possible to gather their full stories. The interviews were led by semi-structured questions. The questions were designed by the researcher and approved by the IRB of the university attended by the researcher. The length of the interviews was between 30 and 60 minutes. The interviews targeted Latino community college graduates who participated in the private Facebook Dissertation Group page, an online discussion. The interviews were conducted using three different methods. The interview method was determined by the participant's preference and availability. Three individual interviews were conducted using the Facebook video conference; three interviews 
were conducted using the face-to-face method, and two interviews were conducted via skype. By having more control of the interview setting, the participants appeared comfortable and provided feedback, sharing that they had a positive interview experience.

\section{Participants Profile}

There were nine participants in this study, three males and six females. Four of the nine participants were born in the United States and the other five participants were born in Mexico, immigrating to the United States between the ages of three and 16 years of age. Two of the nine participants identified themselves as undocumented students. Three of the five participants who were born in Mexico had acquired legal documentation for U.S. residency. All of these participants are of Mexican descent and identified themselves as Latinos or Chicanos. The average age of the participants during the study was 30 years old. Four out of nine participants majored in business, four out of nine majored in social work, and one out of nine majored in political science. All of these nine participants attended a community college, had continued their education at a four-year university, and were the first ones from their family to complete a college education. The following narratives show each of the participants' experiences. Their names have been changed in order to maintain confidentiality.

\footnotetext{
Alma

Alma described herself as an outgoing and caring person who wanted to make a difference in the community. Alma had completed her bachelor's degree in workforce education and development at the time of the study. She was a mother of two children and was married. She described her ethnicity as half Mexican and half Irish and Scottish. She was born in the U.S. While growing up, she was embarrassed to say that she was Latina because other children and their parents spoke so openly about not liking those who were not white. However, when she
} 
attended her community college she felt differently about her ethnicity and felt welcomed and accepted.

While attending community college, she learned more about her Mexican heritage through a Spanish course and by becoming a member of the Latino student organization. She learned how to speak Spanish and all of the different components that made Latinos a unique ethnic group. She loved her community, college faculty, and staff. She had positive experiences and received support from her peers and her advisor from the Latino student organization. Having a nurturing environment helped her to have more confidence in herself. Alma is a special needs student, but thanks to all of the support that she received throughout her college education, she was able to do well and at the same time she helped other students who had similar needs as herself. She felt that if it was not for the support that she had received from her student organization advisor, she would not have been able to graduate with her associate degree or to transfer to her four-year university.

\section{Ariana}

Ariana described herself as a very persistent and hard-working person. Her life philosophy was, "in order to get things that you never had, you have to do things you have never done". In other words, you have to earn what you receive with some risk-taking involved. She was a senior in college and her major was accounting and finance. She worked very hard to accomplish what she had. Since childhood, she had wanted to attend college, so she studied and worked hard to achieve good grades. She was included in the honors program at her community college. She found the faculty and staff at her community college to be very helpful to all the students, regardless of their ethnicity or race. She grew up in Mexico and moved the United States when she was 14 years old. She considered her biggest challenge as learning a new 
language and culture at such a young age. At the time of the study, she was attending a four-year university and scheduled to graduate at the end of May. She had a love of literature, but decided to major in accounting and finance. Ariana's main support was her family and boyfriend. She also said that her club advisors, faculty, and staff provided her with a great deal of support. She maintained friendships with some of the faculty and staff from her community college. She also found the college's staff to be very welcoming to Latino and non-Latino students, which was a different experience than she had when she was in high school. At her community college, several people spoke Spanish and were very friendly. In her opinion, some of the major issues that Latino students faced were financial challenges and immigration status. Ariana had to work multiple jobs to cover some of her education expenses even though she received scholarships to pay her college tuition because she still needed to pay for her books and travel expenses. She commuted to her four-year institution, every day. Ariana thought of herself as a change agent, since she was the first person from her family to attend college. She said that she was "planting the seed" for her siblings. She liked to tutor college students and provided advice, since many of the students that she tutored were facing similar challenges to the ones that she had experienced.

\section{Cassandra}

Casandra described herself as a friendly person. She was born in the U.S. and had completed her associate degree. She was a junior at a four-year university at the time of the study. For her, she felt that her two biggest accomplishments were her son and having finished her associate degree. Her greatest challenges were learning English and leaving her baby with her parents, while she went back to school. She decided to attend a community college because her sister had attended a community college and it had offered a variety of career options and was affordable. Her experience at the community college was very positive. When she started 
her career at the community college she wanted to be an architect. However, she changed her mind and pursued social work as a career after she became involved with the Latino student organization. She realized that the Latino community had many needs and that Latino children needed encouragement and role models to strive to do their best in school. She wanted to be a social worker and work with children in need to make a difference in their lives.

Her experience with faculty at the community college was a very positive one. She felt that they treated her well and the faculty became mentors and friends. She did not feel that she was treated any differently than non-Latino students and did not feel that she faced any stereotyping. The majority of the professors were friendly and helpful. Cassandra also received student support from both a support program that targeted first college generation students and the Latino student organization's advisors.

She gave the credit of her college completion all to her Latino student club advisor and the support program advisor. She said that they were always available to help and encouraged her to complete her associate degree and to stay focused on her studies. She emphasized that students should consider community colleges to begin their higher education careers because of the cultural support that she received. She said that the community college was affordable, helped students find the right career, and that faculty and staff were extremely helpful and supportive.

Her strategies to succeed were to surround herself with positive people who believed in her and to maximize the support services that her college provided. Her biggest challenges while completing her college degrees were being able to balance family and full-time work. In her opinion, the challenges that Latino students face are language barriers, lack of financial support, and families who do not understand the benefits of a college education. Her goal after 
completing her associate degree was to earn a bachelor's degree in an area that would help others in her community. She was successful and now she is engaged in the rewarding work of helping her community improve by providing education to the children.

\section{Ivan}

Ivan described himself as an immigrant who refused to follow the stereotypes about immigrants engrained in mainstream society. He had just graduated with a bachelor's degree in political science. He came to the United States at the age of 12 from Mexico to live with his brother and his family. At the age of 13 his brother's wife had him leave the house and he was sent back to Mexico. Ivan came back to the United States at the age of 26 and started his education at the community college. He chose a community college to learn English, but to his surprise he found people who motivated him to strive for more than English classes. As a result, he took college level courses after learning English and was able to complete an associate of arts degree in Criminal Justice. After receiving his associate degree, he transferred to a four-year university and successfully completed his Bachelor of Arts degree in political science. His goal was to complete a master's degree. Ivan's main motivation was to provide for and to set an example for his son. His biggest challenge was to believe in himself and to become a perseverant person. He lost his father at a very young age, which caused him to give up easily when things became difficult. He still had his mother, but she was living in Mexico. He felt that he did not have any family support while he attended college. His experiences at the community college were mixed. He had some great professors and advisors, but others were not. He felt stereotyped by some faculty members. He provided a few examples of how he was stereotyped in the classroom. For example, he was called José by one of his professors, even though he corrected the professor several times, she continued to call him José. Ivan decided to withdraw from the 
class due to this issue. Another professor made a comment about him drinking a lot, although he did not consume any alcoholic beverages. In addition, he had a negative experience with an academic advisor at the end of completing his associate degree. He was advised to take several additional courses, but Ivan consulted his student club advisor for a second opinion. That advisor advised Ivan to speak with someone from the division where he was completing his major, which he did and was told that he only needed one of the courses that the academic advisor had advised him to take in order to graduate with his associate of arts degree. Ivan was always very cautious about the number of courses that he would take during any semester since he was working to pay for his education. Ivan didn't qualify for federal and state aid due to his undefined immigration status. He was able to get some scholarships to pay for some of his education, but for the most part, he funded his college career on his own. Ivan saw himself as a change agent during his college attendance days. For example, he was very active at his community college by becoming president of one student organization and a board member for another student organization. He continued to be active in his community by serving as a board member to a Latino organization in his community. He felt that he was a strong role model to his son, nieces and nephews.

\section{Jocelyn}

Jocelyn described herself as a hardworking, friendly, and kind person. She was a senior in college, majoring in business administration. She was born in the U.S. and identified as Latina from a Mexican heritage. Jocelyn attended community college because she was not accepted at the University of her dream due to her low ACT scores and grade point average, which did not meet the four-year university's admissions requirements. Jocelyn's biggest accomplishment at the time of the study was to complete her associate of arts degree in two consecutive years. During her first year of her community college experience she started working because she 
needed to pay for her school expenses. She learned how to juggle school and work. According to Jocelyn, she felt that Latinos were all labeled as undocumented immigrants. She also noticed that when she identified herself as Mexican-American, people would immediately ask her if she was born in the United States or in Mexico and she felt that they implied that she might be undocumented. Another stereotype that she experienced was being told that Latinos did not graduate from high school or care about higher education.

Jocelyn felt that understanding her Latino culture and language helped her to complete her associate degree and overcame negative stereotypes. Her family understood the importance of higher education for advancement in life. She understood that speaking Spanish and being Latina were great assets. This allowed her better opportunities for her future. Her family was always on her side and provided her with financial and emotional support. She felt blessed to have them in her life. She was not an active student at her community college and she was not close to any of her community college teachers, but she was able to do well in her classes. Her experiences with student support services were tolerable. She did not find the academic advisors, counselors or financial aid staff to be very helpful. She felt that she was always chasing them to find the help in understanding her financial aid package or to answer her questions. She used the tutoring center and she found some of the tutors to be helpful. She also received scholarships based on her ethnicity. She felt that "being Latina worked in my advantage," she said. When she attended community college, her goal was to transfer to a four-year university and complete her bachelor's degree.

Overall, her experience at community college enriched her life because of the diverse experience that made her a better person. This diverse experience helped her to learn more about herself and her values and made her more open-minded to other cultures. 


\section{Leslie}

Leslie described herself as a "go getter," realistic, and a believer that putting forth effort helps you achieve in life. She was a senior in college at the time of this study. Leslie was the middle child and the first person from her family to complete high school and an associate degree. She emigrated to the United States from Mexico when she has 6 years old. Her biggest challenges were learning about a new culture and language and becoming a U.S. Citizen. Her experience at the community college was positive. She found many faculty and staff that were very helpful but her participation in the Latino student organization was what really helped her find herself. She felt that the Latino student organization helped her to feel very comfortable with her language and culture. The staff at this student organization was Latino and bilingual, which was very important to her. Leslie did not experience any stereotypical treatment during her years at college, but at her job she often times heard comments from other people about Latinos that were not correct, but preferred not to become involved with negative people. She was very satisfied with her community college experience, although she had not planned to attend a community college when she graduated from high school. She had wanted to go away for college, but being the first of the family to attend college did not allow for her father's blessing. Her father convinced her to stay closer to home, which also allowed him to help financially. Her father also motivated and encouraged her to continue her education. At the time of the interview, Leslie saw herself as a change agent. She was the main emotional support for her younger sister who had almost completed her associate degree, her younger brother who was in his second year of high school and also on the honor roll, and her step-daughter whom Leslie had encouraged to stay in school. Leslie transferred to a four-year university and was majoring in elementary education with a bilingual endorsement. She had recently married and was completing the last 
year of her undergraduate degree while working fulltime as a teacher assistant.

\section{Marcos}

Marcos described himself as person who never gave up, no matter what. He was a junior in college and his major was business administration. He became the father of a boy when he was a teenager but that did not stop him from dreaming big. Marcos said that his older brother and his son have been the individuals who have motivated him to continue with his college studies. Marcos looked up to his older brother, because his brother had completed his associate degree. Marcos was a U.S. Citizen, and the youngest of his family of three. He identified himself as Mexican-American and Latino, as his ethnicity. He completed his associate of arts degree and was attending a four-year University. His main goal was to complete a Master of Arts degree in business to provide a better future for his son. Marcos' biggest fear was failing his son. He wanted his son to be proud of all of the sacrifices that he made to obtain an education. His family was his main support. He saw his dad as a true role model and his mom as the main support. His parents were always there for him with financial and emotional support and he credited his success to his family. One of the services that he used while attending the community college was tutoring. He visited the tutoring center twice a week. He did not feel directly stereotyped or discriminated against during his years at the community college. He found that everyone at his community college was open to diversity. One of the strategies that he used to feel part of his college's community was to become involved with the soccer team. There, he had the opportunity to interact with different minority students and found that he had much in common with the members of his soccer team. He found that many minority students were facing similar issues that Latino's faced. Marcos said that all of his soccer team members worked hard to have a successful future, and they all shared the same goal of creating a better life for themselves and 
their loved ones. His advice to minority students was to help out as much as is possible. Marcos did not see himself as a social agent of change.

\section{Roberto}

Roberto described himself as a friendly, hardworking, responsible and family-oriented person. At the time of the interview, he had just graduated with his associate degree and was in the process of transferring into a four-year university. He majored in business administration. He emigrated from Mexico to the United States along with his father when he was 16 years old. However, Roberto did not start high school until he was 17 years old. At the same time that Roberto started high school his father returned to Mexico, leaving Roberto behind. Roberto also assumed financial responsibility for his family and himself. Roberto's family stayed back in Mexico. He obtained a fulltime job while attending high school, which was not an easy task, but he managed to graduate from high school. After his high school graduation, he realized that his English skills were not sufficient to understand the American culture, so he decided to attend his local community college and learn how to read and write English well. When he started taking English as a Second Language classes at his community college, he became involved with different student organizations where he found a very welcoming environment. This was because the advisors were of Latino decent, spoke Spanish, and Roberto felt safe and comfortable. His experience at his community college was a very positive one; he found the faculty to be extremely helpful and often times they went out of their way to help him to do well in their classes. Some of the challenges that Roberto had to overcome were learning English and learning about a new culture as well as paying for his college tuition while supporting himself and his family. His accomplishments he is most proud of were graduating with a high school diploma and an associate of arts degree in business administration despite his challenges. His new goal 
was to continue his studies at a four-year university and complete a bachelor's degree in business. Some of the strategies that he used to accomplish his goals were balancing life, persistence, and studying hard, while working at the same time.

\section{Victoria}

Victoria was a very optimistic person. She believed in hard work and kindness. She liked to treat others the way that she would like to be treated. She recently graduated with her master's degree in social work. Victoria and her mother emigrated from Mexico to the United States when she was 4 years old. She attended a community college because she did not know about other colleges or universities and the option was both affordable and close to home. Victoria had a very difficult time during her years at her community college because she did not have any student support. The only support during those years came from some of her old high school friends and her boyfriend. Due to her undefined immigration status, she did not qualify for financial aid and she could not major in the career that she wanted. At the end of her nursing program she was told that she could not sit for the licensure test and receive her license because she did not have a social security number. She was devastated and ready to give up, but thanks to the encouragement that she received from her boyfriend she stayed in school and changed her major to social work, which did not have the same requirements. She felt that she was still able to fulfill her dream because she was able to serve people in need, but in a different venue. She loved her career and she was able to complete an associate degree and transfer to a four-year university where she completed her bachelor's degree, followed by the completion of a master's degree in social work. Since then she has acquired documentation to be able to work. She enjoys helping and working for people who cannot help themselves. She felt that her social work career was the way that God called her to help others in need and that God works in mysterious ways. 
Victoria was a very spiritual person, which helped her to overcome obstacles and stereotypes. She said that she had experienced stereotypes based on her ethnicity, but she would rather not talk about those experiences, preferring to keep moving forward. She refused to be a statistic and worked hard to excel in every possible way. Victoria was the first person in her family to complete a college education and was very proud because her accomplishments were a result of her optimistic personally and hard work. She financed her entire college career and graduated at the top of her graduate class, despite the fact that she worked fulltime while attending graduate school fulltime.

\section{Summary}

This research study falls within the qualitative methodology tradition. The sampling population was designed to investigate the stories of successful Latino community college students and find out how they used their voices, experiences, and cultural- consciousness to complete an associate degree. This section provided background to the participants, which is useful in understanding their responses in the next chapter. Most of the participants had positive experiences to tell, but there were some areas that they expanded upon and that is where the four themes emerged. The following chapter creates the connection with the findings and the theories that support the findings. 


\section{CHAPTER IV: FINDINGS}

"This was not a gently rolling landscape like Aguascalientes. For as far as the eye could travel, the land was unbroken by even a hillock. Esperanza felt dizzy looking at the repeated straight rows of grapes and had to turn her head away” (Muñoz-Ryan, 2000, p. 77).

\section{Introduction}

Of the nine successful Latino community college graduates that comprised this study, six were females and three were males. There were four United States citizens, five immigrants undergoing citizenship level change, and two participants who identified themselves as undocumented students. Their stories were collected in two phases, they are as follows: a) phase one was a virtual private group discussion via the private Facebook page called Dissertation Group; and b) Phase two included one-to-one structured interviews using critical incident questions via various methods of social media, which included Skype, Facebook videoconference, and Face-to-Face interviews. The method used during the phase two interviews were customized to the individual participant's preference. The main findings or themes that emerged were linked with Yosso's (2005) community cultural wealth discussion are as follows: family-support, peer-support, cultural-mentoring, and the resilience-resistance characteristics, which the Latino group possessed and helped them overcome difficult experiences. All of these

attributes are validated by community cultural wealth. Community cultural wealth consists of at least six forms of capital wealth such as, aspirational, navigational, social, linguistic, familial, and resistant capital. Community cultural wealth helps Latino students and students of color to resist all of the challenges that they faced in the higher education sector (Covarrubias \& Velez, 2014; Ramirez, 2011; Rendon, 2016; Solórzano et al., 2005; Yosso, 2005; Yosso et al., 2009). The four themes of importance that emerged from this study are as follows: 
1. Family-Support: The family support and hopes that students bring to higher education.

2. Peer-Support: peer-support students build their own peer-network and communities where students' motives, guided and helped each other's'.

3. Cultural-Mentoring: Cultural mentoring is an unformal mentoring role, which a bilingual and bicultural college faculty or staff took to guide and encourage the participants. Participants identified these Latino people as someone who the felt natural connected because of their cultural background. The participants felt that these individuals were trust-worthy and understood the students' challenges. These cultural-mentors made the students feel welcomed and accepted.

4. Resistant-Resilience: Student were cultural-consciousness and kept moving forward despite the macroaggression comments, which they experienced. They were determined to complete their degree and nothing was going to stop them.

\section{Family-Support}

Family-support overlaps in the participants' stories. The majority of the participants in this study shared stories about the level of support they received from their families and how each family valued education and encouraged them to keep striving toward their educational goals. They used their parents' experiences and struggles as motivation to keep working hard in their college education, so they could provide better opportunities for their family members, parents, siblings and children (Yosso, 2005; Rendon, 2016).

\section{Ariana}

Ariana felt that her family cared and valued her education. She said that her family encouraged her to do well in school and worked hard to provide her with better opportunities. 
She felt that her family was very supportive of her education, and their struggles pushed her to keep going. She wanted to be able to help her parents, so they would not have to continue to work as hard as they had. "My family was a big part of my motivation. I wanted to finish my associate degree, even if I was uncertain about continuing with my education. I wanted to make them proud and help them in any way I could." Her dream was to help her family and have an education degree. She was not thinking of her future alone, but also wanted her family to be able to have a brighter future. Ariana's familial capital helped her to cope with negative comments that she heard at school. She knew that her parents cared for her education and credits them with being a part of her success. "When I hear negative comments about Latinos not caring for education, I know that is not true. My parents value education and [they] were doing their best for my dream to come true. I was also getting straight A's and doing better than English speakers. My parents assured me that I was capable of doing great things for myself, and I could persevere no matter what. Home is a safe place for me [going home] was a reward to me for working hard and having a high GPA. My parents taught me to be proud of my heritage, accent, and culture. I would not change it for the world." Ariana valued her family and felt committed to them. Therefore, she kept moving forward despised of the negative comments that she heard about Latinos not caring and value education.

\section{Cassandra}

Cassandra felt supported by her parents to continue her education after she became a mother of a "beautiful" boy. She knew that going back to college to complete her associate degree was not going to be an easy task, but that was the challenge which she was willing to take in order to provide a better future for her son. She knew that working long hours, taking night 
classes, and being away from her son were sacrifices that she needed to do in order to complete her education and provide a better future for her son. She was fortunate to have her parents, who provided her with childcare, while she went to work and attended night classes. She mentioned that one of her biggest challenge was being away from her son. "One of my major challenges was when I went back to school to finish my associate, leaving my baby with my parents, but I know it's for a better future". Her hope was to get an associate degree and to continue working on her undergraduate degree, and to eventually graduate with a master's degree in social work. She wanted to be a social worker and help children who may have needed guidance and motivation in their lives to become good citizens. Cassandra's parents understood and valued her higher education goals and they were willing to support her by providing assistance with childcare while she went to school and worked. This type of family support was very important to Cassandra's well-being because she knew that her parents supported her in every way that they could. She could relax and focus on her studies knowing that her child was safe with her parents.

\section{Jocelyn}

Jocelyn always felt that her family supported her college education. "My parents have been supportive of me going to college. They never denied me going to school. My mom and sometimes my dad would go on college visits with me. Whenever I kind of doubted myself, my family were always there pushing me." Her family believed in Jocelyn and knew she would be able to have a better future if she stayed and completed her college education. "For my parents, my school always came first; they also told me to cut my [work] hours. They told me that I could always stop working if I needed to spend more time at school, and that was very helpful for me, as well." This story demonstrates how Latino parents want their children to obtain a college 
education and to graduate from college. Jocelyn's parents were willing to do everything within their power to support her, so she could do well academically. Although her parents did not have a college education, they were by her side to make sure she felt encouraged to continue her education.

\section{Leslie}

Leslie's greatest influence on her higher education career was her family, especially her father. She felt that it was her responsibility to go to college and do well. She felt that it was at least she could do after all of the sacrifices that her father had made for her family. "My biggest influence personally was my dad; he doesn't know it. When I started this journey, I wasn't doing it for me, in my mind, I was doing this for my dad. He sacrificed so much for his family, so we could have a better life...he is definitely the one person that I truly admire. My mom, she is the most caring woman I have even met. And my younger siblings. I wanted to set a good example for them so they could finish high school and go on to college." Leslie felt that it was her responsibility to do well in college and to set an example and motivate her siblings to enter and graduate from college. She felt that it was up to her to create a smooth path to college so her siblings would not face as many challenges as she had. The challenges that she identified were not knowing how to navigate the college system and being the first person in the family to go to college. She felt that completing her college education would be a good way to make her family proud and at the same time become a role model for her younger siblings.

\section{Marcos}

Marcos said that he had always relied on his family for support. He knew he could always count on his family no matter what. He provided a story to illustrate his family's support. "One time I was short $\$ 500$ to pay for my tuition...I felt bad asking my dad for money, but at the 
end I did not have any other person or anyone else that I could ask for money, so I asked my dad and he helped me. He took out a loan to help me pay for my tuition.” Although his dad was struggling financially, he was able to help Marcos continue his college education. This gesture contradicts the deficit thinking model and the belief that Latino parents do not value or care about their children's education. Marcos' father went out of his way to find the funds that Marcos needed to pay for his college education. Marcos saw the struggles of his parents and he knew that their struggles were due to the fact that his parents did not have a college education, were immigrants, and they did not know how to access the college system. Marcos knew that he had more opportunities than his parents and felt that he must earn a master's degree in order to have a brighter future for his family. Marcos' main motivation to go to college was his love for his child.

Marcos became a father during his teenage years, which was a wakeup call for him. It was after he became a father that he took his education seriously and wanted to continue his higher education in order to provide a better future for his son. Marcos said that "He's been my greatest inspiration ever since he was born. Before him, I never considered post-secondary schooling. Today, I have an associate degree and am now working on my BA. Hopefully in the future I can pursue my MBA.” He also mentioned, "My father has always been a great role model." Marcos values the sacrifices that his family has done in supporting him in his educational journey. He is very grateful for his family's support. "My family had a lot to do with my success. They were always supportive every step of the way. They would support me financially, emotionally and anyway you can think about. Without my family, I wouldn't have been able to finish school." Marcos felt that having a family who cared for his education contributed to his success. It was their support that motived him to keep going to college and 
work hard to make his family proud of his accomplishment.

\section{Roberto}

Roberto described his family as emotionally supportive, especially his sister. "My sister has been my main support, my parents in Mexico too, but their support is more mentally, but here at the U.S. my sister has been very supportive." Although his parents were far away from Roberto, they cared about his education; and, his sister has provided him a place to live and food to eat, which means a great deal to Roberto's well-being. He valued the encouragement that he received from his parents in Mexico. He also mentioned that because his sister provided him with food and shelter, he used his money to pay for his college tuition and send money to his parents in Mexico. He had a cultural responsibility and commitment to provide for his parents with financial assistance. This is usually the case for so many immigrant children who have left parents in Mexico.

Family is very important to Latino students. Latino students valued and appreciated the efforts which their parents and family members do in order for to them to continue with their education. To these participants, having family support means commitment, encouragement, and keeping the family united. Some of the participants talked about how they influenced others to go to college, which created a ripple effect with their younger siblings and their own children.

The narrative stories portrayed in this study identify a culture of possibilities and hopes for attending higher education that help future Latino students break the cycle of poverty and struggle faced by parents and families. These values are characteristic of Latino and students of color. These stories also demonstrated how the participants were motivated by their family struggles and how they were willing to work hard to provide for their families, becoming role 
models to their younger family members (Rendon, 2016; Yosso, 2005).

\section{Peer Support}

The other important finding in this study was peer-support. The participants mentioned how significant and valuable it was for them to have peers who understood and encouraged them when they felt overwhelm with school, family and work responsibilities.

\section{Alma}

Alma felt that peer-support helped her to overcome academic challenges. It was helpful to know that she was not alone in her academic and cultural struggles. She associated herself with Latino students and became a member of the Latino club. At the Latino Club, she learned that many of the students were facing similar struggles, so she felt much supported by them. She learned how to form study groups and learned how to study. "I study with people who had good study habits. I was able to adopt new study habits and go from part-time classes to full-time, and graduated quickly". She felt naturally attracted to other Latino students, because they looked like her and it both encouraged her and made her feel culturally validated. It was her first time where she was part of a Latino group. She said that during her childhood she was afraid to say she was of Mexican descent because she had always heard negative stereotypes types about Mexican people. She was afraid of not being accepted because of the brown skin and eyes, but it was helpful to her that she no longer needed to hide her identity at the college. Most importantly, her peers accepted her and supported her during her community college career.

\section{Leslie}

For Leslie having the peer-support helped her to stay motivated in completing her college education, as well as, resisting societal oppression. "I think at [community college] I tried to surround myself with positive people. Always helping others, not thinking that you are better 
than everyone else, understanding others and trying to help. Being involved with other Latino students and the student club helped me to be more comfortable with my Spanish and helped me to understand my culture. The Latino Alliance helped me to get closer and better understand where I came from." She felt that by being involved with her college's Latino organization, she became better understood as a person and learned to value the struggles of her parents. "What they [parents] went through so we could be better off. And, basically I guess it was this time when I realized that there is no reason to be ashamed of where I came from". Leslie felt that being surrounded by other Latino students and college staff members helped her to feel more assertive of her identity. She felt that having this type of support helped her to be positive about her college experience and to value her family and culture.

\section{Marcos}

Marcos felt out of place when he began his college career. "The biggest barrier I encountered was the cultural aspect of things. I joined the soccer team from my college and got to meet many people from diverse backgrounds. Within the team, we made bonds that will never be broken. My team consisted of Mexicans, Salvadorians, White Americans, Bosnians, Croatians, and some Africans. This strategy helped me feel more comfortable at my school'. He also relied on his brother's advice. His brother had already completed his associate degree, so often times, Marcos would seek his brother's advice and support. For Marcos, soccer helped him to cope with the college environment. This sport also helped him to feel connected to his identity and nationality. Soccer is a sport that he had been practicing since he was young child. Soccer is very important within the Latino Community and that is how he was able to find a common bond between college and his culture. His social community cultural wealth helped him overcome the 
cultural barrier that he faced when he started his college career.

\section{Victoria}

Victoria felt that her peers' support played a critical part of her college completion. "Honestly, had it not been for my boyfriend and his eternal support, I don’t think I would have gotten to where I am. The Calendaria Martinez banquets were nice and made me feel 'part of something." Victoria relied on her boyfriend as well as a friend from high school to navigate the college environment and understand the college policies. "Once I found that I could major in Social Work, I clung to a high school friend, who I knew was in a very similar situation as I was. She was a couple of years ahead of me in school and as I discovered new things or as I needed information about what to do next, she was the one I turned to.” Another example of peer support was the scholarship banquet that her Latino club organized every year. Those events helped her to feel part of something. She also felt that having special activities that recognized Latino students' success, such as the Calendaria Martinez banquet, was an important part that provided her a sense of ownership, belonging, and being part of something, which celebrated her ethnicity. She relied on her friends to find the right major. She felt very supported from her peers, especially her boyfriend and her best friend. These two individuals helped her to stay focused and motivated to continue her education.

Peer-supported, community-capital wealth is a resource that Latino students draw upon to resist macro- and micro- forms of aggression. Social capital is one of six forms of community capital wealth (Rendon, 2016; Yosso, 2005). Social capital helped the participants of this study find networks of people and community resources that they utilized to feel emotionally supported, and which helped them complete their associate degrees. The social networks that the students found were Latino community college staff, Latino student organizations, and peer 
support. This social capital is another asset that Latino students bring to academia. They are able to build communities that foster their learning, motivation and success. But, the key point for the majority of these participants is that they looked for supportive environments that nurtured their ethnicity, identity, language and background (Datnow \& Cooper, 2009). For these students having Latino staff and peer-support at the community college was very important because they provided them support, encouragement and familismo. They also felt proud of their ethnicity and identity (Rendon, 1993).

\title{
Cultural Mentoring
}

Cultural mentoring helped participants feel culturally accepted in their community college. The role of cultural mentoring was an informal role in which Latino professionals guided, encouraged, and culturally supported the students. Participants commented that having people like these Latino professionals helped them in their college accomplishment. Cultural mentoring falls under the social capital category. Participants looked for cultural mentors and built their networks of people and community resources to feel emotionally supported, which allowed them to complete their college degree. The interesting part of the cultural mentoring aspect was that all of the participants found a caring, trusting, and bicultural and bilingual staff member that supported the as individuals while understanding the struggles they faced. They were naturally attracted to these individuals and felt culturally validated by these people.

\begin{abstract}
Alma
Alma's social capital wealth helped her do well in her college career. "[Alejandro], if it weren't for him asking me to join the Latino Alliance, I would have never known the opportunities available throughout the college. I may have not even completed it”. Alejandro was
\end{abstract}


a college Latino staff member who was the advisor of the Latino club at the community college that Alma attended. At the beginning of her college career she was married and had a child. She also had a learning disability. She knew that in order to succeed she would need to develop a support network. She met Alejandro and she felt comfortable seeking his support and guidance. She also mentioned that she went to him because she knew she could ask him anything and he would direct her to the right person. "I signed up for help at the Office of Students with disabilities...I had a lot of trouble with my statistics class, and I was spending as much time as was available with the tutors at the time I was learning how to solve specific questions, so they were very helpful. The Latino Club, many of the students are facing similar struggles, so I felt very supported. I learned how to study and to not waste too many hours studying. I study with people who had good study habits. I was able to adopt new study habits and go from part-time classes to full-time and graduated quickly. Alejandro, and the student services, they helped me to push myself and not give up, and things will always come up... So school was not necessarily easier to manage, but I was able to manage my family, and finished my school". At the time of the interview Alma had completed her bachelor's degree in workforce education and was working for a non-profit organization, helping minority families to get engaged in extracurricular activities.

\section{Ariana}

For Ariana, social capital characteristic helped her find the necessary peer support and build relationships with her college staff members. "I would go to see the advisor when I needed help. The advisor was always helpful. [Alejandro] has an open-door policy where I could go and talk to him every time when I was uncertain of something. Most of my friends were always there for me. When I wanted to transfer, I did not know where to go, and I did not understand the 
transfer process, but my boyfriend helped me to weigh all of the options, location, tuition cost, requirements. He has been a mentor and has pushed me to do well in my classes, and to complete my associate degree".

\section{Cassandra}

Cassandra found cultural mentors who understood her challenges and were always encouraging. "After my 1st year attending [college], I met wonderful and supportive staff that always encouraged us Latinos to be someone and to not give up and to continue with our education. Also, any struggle I had they were there for me, to hear me out and give me the best advice they had. Thanks to them I was able to finish and appreciate it a lot." She felt she was able to complete her associate degree due to the unconditional support and guidance of her cultural mentors.

\section{Ivan}

Ivan was a very conscientious person and he knew that for him to be able to fulfill his dreams he needed to find the right support system. When he went to his community college he was unsure of how to prepare for a career. He first attended the community college to take English classes. But, during one of his English classes, he learned from one of his English teachers that he could study for a career. At that moment he realized that he would need to build his support system in order to accomplish his new goal. "I got involved with Latino Club, International Club, and Met [Mr. Alejandro]. He did a lot of good things for me, but if it was not for [Maria Garcia], I would have not met all the people, like [Dr. Rivera, Francisco Villa, Dolores], and many other people, where they talked to you. Look at these people, they were good role models. I think it is very important to have role models. I did not go with my parents, because one is not alive and the other parent did not know. But, I went to other people instead 
and these people really helped me, because they were Latinos and were people who already lived this type of life and understand what exactly you go through or what it is like". He found the support he felt he needed at his community college. Ivan had the social capital characteristic, which was critical to achieving his academic goal because he felt that there were people who believed in him.

At the beginning of his college career he felt lost and he did not know how to navigate the community college system. However, once he was able to find the resources and support that he needed, he was able to successfully complete his associate degree and transfer to a four-year public university. At the time of the interview, he had graduated with his bachelor's degree in political science and opened his own business. He now mentors and guides his niece and nephew, who are currently attending a four-year university. He felt very lucky to have attended his local community college, because it had excellent Latino staff members who were always there to help him. "As a Latino student, I think we are privileged in [my local community college] because those Latinos who work there are always willing to extend a hand to us".

\section{Jocelyn}

Jocelyn was able to find the resources that helped her complete her community college degree. "I s[ought] out help a lot, especially financial aid, advising, a couple of times tutoring as well, and I found them very helpful.” Jocelyn's social capital wealth helped her find support to be able to complete her associate degree in two consecutive years. Now Jocelyn is mentoring her younger cousins by encouraging them to take the ACT, apply for FAFSA, and telling them to consider a community college as an option to save money. "I am the oldest, I was scared, but now all my cousins are scared about taking their ACT and financial aid. I guided them and told them that they always have to ask questions, that people are there to help you". At the time of the 
interview she was in her last semester of her undergraduate degree.

\section{Marcos}

He found a very competent college advisor who helped him to select the right courses. He was able to finish his community college requirements and graduate. "I had a very good advisor. She was a lady and she told me what I really needed. She helped me to take the right courses and at the same time she helped me to save money by not taking the unnecessary courses." Another person who was instrumental to Marcos' academic success was his soccer coach. His soccer coach was Latino and he taught Marcos the importance of giving back to his community, and caring for others. "My goal at college was to be part of the varsity team at college. He told me the areas that I needed to improve upon in order to be a player and a leader. He did not give me an opportunity to take a leadership role until I was ready to be a leader. He provided examples of this leadership. I looked after my team members. I was also in charge of a fundraiser. I coordinated a breast cancer fundraising campaign. My coach helped me to reach my goals, and educational and soccer." Marcos' social capital characteristic helped him to seek the right student supported, which he needed in order to complete his associate degree.

\section{Roberto}

Roberto, found his network with Latino professional college staff and peers who motivated him to continue his education. He says, "While attending the community college I met wonderful people that helped me grow as a student and as a person, they became my mentors. They (my mentors) were not afraid to speak Spanish to you and make you feel welcomed. I went back to college to finish my associate degree because my mentors pushed me to go back and finish." "When I first went to the USHLI conference I met so many people who were in my place and I felt that I could be one of them in the future, if I finish my degree. People who I hang out 
with and people like [Mr. Alejandro], he has been a mentor for so many students from Latino Alliance. I also surrounded myself with people who motivated me, [you, Francisco, Eduardo], I know that if you did it why not me." Social capital wealth is an asset that Roberto had throughout his college career and that helped him to stay motived in his college studies. College was challenging for him, but he knew that in order to cope with those challenges he needed to surround himself with positive people who could help him to overcome those challenges, not the least of which was being the first person in his family to go to college. For him, not being able to qualify for financial aid and not having his parents close to him was very difficult. But, having mentors and peer support meant a great deal. His mentors and support system guided him on the right path and helped him to stay on track.

Cultural-mentoring helped the participants feel connected with their cultural identity, making them feel acceptance within their college campus. The participants were aware of the underlying Eurocentric and cultural expectations at their community college, but they never mention it, yet, they implied how helpful it was to have people they culturally identified with and whom they could seek guidance from. They knew that these cultural-mentors did not always have the answers, but they knew where or how they could go to get the support they needed for whatever question they had. Their starting point of reference for the most part was with a cultural-mentor who they felt culturally connected to.

Social capital wealth helped Latino students to find the support and motivation that they needed to navigate through their community college experience. They were able to build communities that fostered learning, motivation and success. But, the key point for the majority of these participants was that they looked for supportive environments that nurtured their ethnicity, identity, language and background. Their peers provided a culturally safe place to each other's 
and that feeling of safety helped them to persist and graduate from their community college.

\title{
Resilience-Resistance
}

Resilience-resistance was the characteristic that the majority of the participants had in common. Solórzano and Delgado Bernal (2001) redefined resilience-resistance as a skill that minority students used to survive and succeed through the educational pipeline as a response to the visual micro-aggressions. The participants did what they needed to do in order for them to succeed in their college studies, surviving and exiting as intact individuals. They used the microaggressions directed towards them to push themselves and finish their associate degree. They knew their associate degree was just a stepping stone, which they needed in order for them to reach their final goal-- their bachelor's degree or higher. They also understood that in order for them to give back to their community they needed to prepare themselves socially (Solórzano \& Delgado Bernal, 2001). They realized the oppression that Latino students experienced, but they did know how not to criticize the system. They took the responsibly of social justice upon themselves. Their desire was to help other students and give back to their community. None of the participants blamed the system for their challenges. They decided to keep moving forward and focused on their academic goals. They knew that they could prove those individuals that made negative comments or perceptions wrong and felt empowered by their potential and belief in themselves (Yosso, 2002; Yosso et al., 2009).

\begin{abstract}
Alma
At the time of the interview Alma had completed her bachelor's degree in workforce education, and worked for a nonprofit organization helping minority families get engaged in extracurricular activities. Alma did not feel discriminated during her college years, but she experienced discrimination while growing up. "So, school was not necessarily easier to manage,
\end{abstract}


but I was able to manage my family, and finished my school." Due to those negative experiences, she learned to resist any type of oppression and learned to advocate for herself at an early age. "Growing up, I grew up in a community that was not diverse. I am Mexican, Irish and Scottish, and I do not resemble my Caucasian side, so it was very difficult for me growing up. I always felt ashamed. I did not understand anything, except for negativity that I heard while growing up, of Mexicans. I remember trying to avoid talking to anyone. I remember being sent to another school because of my nationality, it was not a good place for me to grow up, so when I became a teenager I moved out and took care of myself. I did not know anyone. I did not know anything positive. It was very refreshing going to college and I learned that it was okay to be Mexican. I never knew that it was okay.” Her childhood was very painful and now she works hard to help other children to have a positive childhood and feels proud of their identity and ethnicity. It was very refreshing to find people in her life like Alejandro, who helped her to believe in herself, and to be proud of herself. She made it because of the positive people she met during her college career and also because at early age she developed resistance capital wealth, which helped her to survive the micro-aggression that she experienced at her early age.

\section{Ariana}

She felt that it was important for her to succeed in college and not fall under the status quo. "All of my experiences as a first-generation college student, people looking down on us because of our accent made me a stronger person. Nothing is going to stop me from getting [to] my goals. I have always been interested in international business, and I chose this career [path] because I liked working with international people and to also prove the others wrong. I want to prove to them that I can do this type of major, that I could climb the social ladder by getting a prestigious career. I could have any job not just the typical stereotype jobs that society expects us 
to take." Ariana valued her parents' hard work, but she felt that her college education would help her to break the cycle of hard labor and minimum wage. Her resilience-resistance characteristic helped her resist the oppression that Latino students faced in the college campuses. Ariana shared in her interview that she feels excluded from society because of her ethnicity, but she has to and knows that has to overcome those macroaggressions in order to move forward. "As already mentioned, the sense of belonging and acceptance is necessary for all human beings. By being Latino we know we are a minority in the country and we know we are labeled with many stereotypes sometimes I have felt that I do not belong in certain places because society makes it look that way". Being self-conscious helped her to resist the type of oppression that she experienced and despite all the negative judgments that she had felt, she was determined to graduate with her associate degree and continue her studies and be a role model for her siblings

\section{Ivan}

He was determined to complete both associate and bachelor degrees despite his language and immigration challenges by working hard to reach his goals. Ivan mentioned that, "I describe myself as an immigrant who refuses to follow the stereotypes that society puts on us." He is referring to the deficit-thinking models where Latino students are expected to drop out of college because they do not possess college capital knowledge (Yosso, 2005). He experienced several incidents of prejudicial treatment, micro-aggression, due to his ethnicity and nationality. $\mathrm{He}$ shared with the Facebook discussion group that his college friends and one of his professors thought that he liked to drink only because he was Mexican and had an accent. "Some Friends I made in college even asked me 'how come I didn't drink if I was Mexican?' One professor also said to me 'I can tell you like to drink a lot' when I do not even drink at all. However, the one that really made me angry was when a professor called me José for more than half of the 
semester. I explained to her several times that I was Mexican and my name was not José, but she kept calling me José until I dropped the class". He did not allow those stereotypes to determine his destiny. It is important to note that he dropped the class when his professor kept calling him José, but he enrolled in the same class with a different instructor the following semester. Ivan was determined to reach his goals, but he refused to waste time with ignorant people, so he always looked for different ways to navigate the community college to avoid unpleasant experiences. His resistance capital helped him to continue moving forward and he felt strong and confident.

Ivan felt that he had a great support system, which helped him to resist oppression when he faced it during his community college years. He became very involved in many different student organizations and as a result of that he became a strong student leader and a president of two different student organizations at his community college. Yet, when a college staff member, who was also a minority and a co-chair of a male minority student organization, appeared to be intimidated by Ivan's leadership, Ivan was not afraid to speak up. According to Ivan, that college staff member did not want him be the president of that student club because Ivan was an immigrant student and had an accent. This college staff member did not want a person with these characteristics to be the leader of the African-American and Latino male students. This person tried to remove Ivan from his leadership position, because it appeared that he felt Ivan was incompetent due to his accent and background and opined that Ivan would not be successful. "At the Men of Vision Conference in Indianapolis I was very sad because of that, and it was Mr. [Francisco] who said, 'Ivan, the best revenge against those people who do not believe in you is to become successful, and don't argue with him, just become successful'." He was able to resist that oppression and thanks to the encouragement that he received from his mentors he became a 
successful person. He was able to successfully finish his tenure as president of that student group, graduate with his associate degree, transfer to a four-year university, and graduated a year ago, with his bachelor's degree.

\section{Jocelyn}

She also experienced micro-aggression and comments against immigrants. She said that often times she was the only Latino or Mexican American student in her class and people often made very negative comments. In English class, Jocelyn found her classmates' comments to be very offensive and cruel and her teacher did nothing to help to diffuse the situation. "In my English class, it was a writing topic and obviously, some people shared their thoughts, we talked about immigration. A lot of people said mean stuff, I did not say anything...I did not want to get in to it". She did not want to get involved, because she felt intimidated by the classmates, and she felt that she did not have the support of her teacher to back up her argument. Jocelyn is a very conservative and quiet person and does not like confrontational discussions, so her way to resist this type of stereotypical discussion is to ignore those negative comments and work hard on her studies and to keep moving forward. She is focused on reaching her goal of helping others by giving back to her community. "I think by just not giving up and not losing hope, everything ends up working out. I got my associate degree and transferred".

\section{Leslie}

Leslie did not recall being stereotyped at college, but did share a few stories where she had witnessed stereotypical treatment outside of the classroom. "I think outside the classroom we faced them all the time, but I think I learned to put stuff on the side because I am better than people who make racist comments. I used to get really mad when people would make racist 
comments, but I am not going to lower myself to your level or play your game... another example, was at school where I worked. A teacher said, oh I am getting a new student, oh someone else said, what is the last name, it is a Hispanic name? And my friend and I were like what does the last name has to do with it. Like a last name does not mean if they speak English, are they smart or not smart? So, those comments are just ignorant comments and I tried to ignore them". The negative comments remind Leslie of why she is studying and why she feels she needs to be the person who can motivate students to fight for their dreams and not to let negative stereotypes hold them back. At the time of the interview she was about to start her last semester of her undergraduate degree. She will be completing her degree in general studies and eventually purse a master's degree in social work. Leslie also used her resilience-resistance capital when she refused to give up her college dream. It was hard for her because her father was in favor of her college education when she began, but he was not able to support her financially as time went on. She did not understand the process of higher education, but her peers helped her to navigate college politics.

\section{Marcos}

Marcos experienced micro-aggression comments against students of color on his college campus, but he decided to ignore them and to keep moving forward. He was determined to meet his college goals and nothing negative was going to stop him. "In most of my classes I am the only Mexican or maybe two or three more...so usually teachers will make negative comments about minorities, but I don't think that they know what they said is offensive to the students like me, perhaps, they do not mean it that way. They make comments like 'those people' comments like that make you feel very uncomfortable, but they are not directed to you." He thinks that such negative comments were innocently said, but they still made him uncomfortable, especially since 
his professors made them. He also shared another story where he felt directly discriminated upon based on his nationality and ethnicity during his high school years. He went to play soccer with a team at an affluent community and the other team was losing the game, so they became very aggressive. The audience started yelling names at his team, names like "Spics" and "Wetbacks". "Hearing those comments made me so uncomfortable, I also started talking back to those people...my coach was Latino. He was from Honduras, but he kept the team together. He taught me a lot. I want to be a soccer coach, too". "Sports helped me to be a leader. Being a leader it taught me to care for other people." He also learned to move on and not to waste time with people who were negative and racists. He learned from his coach that acting professionally and focusing on what matters is the way to handle difficult and unpleasant experiences. It is a way to resist the status quo and not to be caught in the negative stereotypes.

\section{Roberto}

Roberto also experienced negative comments based on his ethnicity, but chose to ignore them. Roberto is very culturally conscious, proud of his identity and one who does not waste time with people who think less of Latinos for having an accent. He knows his potential and works hard to meet his goals. What has also helped him is to surround himself with people who value him and see his potential. He mentioned that he likes to be around people who speak Spanish, people who motivate him, and people who validate his experiences and assets. "I felt that if you confront negative people it is waste of time. I do not like to argue or put myself at their level. People have made me feel uncomfortable because of my accent, but I ignored them and kept talking. I figured [that] if they have an issue with my accent they can walk away. I feel that having an accent does not make you less, but instead it makes you smarter, because if you have an accent it means that you know a second language. I do not let my accent stop from what 
I want to accomplish; I am equal to any other person.”

\section{Victoria}

Victoria also recalled being a victim of stereotypes or micro-aggression by a community college counselor, and used that negative experience to prove him wrong. "I absolutely felt that I was stereotyped based on my ethnicity and continue to feel the same way. There are too many experiences to list but [I] can say that I now use those times to propel forward. I am proud that I not only refused to be a statistic but also achieved my education goal with a triumph graduating on top of my class all while working full time and completing an internship." Victoria's resistance community wealth helped her to overcome her challenges. She learned from her mother that if you want something badly, you have to work hard and believe in yourself because there will be times when no one else will believe in your potential. "Yes, I feel that I cannot give up. I haven't come this far to give up. In my first year, I said I did not get here to give up. I think I used experiences that were hurtful, such as that advisor or an uncle who believed that I would never get there, in order to push me through those hard moments and to prove them wrong; and my mom said that if I work hard enough I will get there. I think it was definitely that."

It is very unfortunate that some people in this country, especially in academia, still have negative stereotypes about Latino students and the community. It is important to note from these stories that accent, ethnicity and immigration status did not define the student's potential or success. Through these negative experiences Latino students gained knowledge and skills to challenge inequality and the status quo (Rendon, 2016; Yosso, 2005). They developed an attitude to prove them wrong (Yosso, 2002) to show them that Latinos can succeed, and that Latinos are good people. "We are not rapists or drug traffickers, we are good people, and I am Latino, too." Latino students are able to succeed academically because they are determined and focused on their 
goals. Drawing from their resistance capital helps the students overcome the oppression that they face in their daily lives.

The Latino students knew that for them to complete their associate degrees they would have to ignore the labels often created by deficit-thinking models; they also had to draw from their resistance capital to survive the oppression and prejudice that they faced during their community college careers (Yosso et al., 2009). They needed to be strong and work hard so they could reach the dream of completing the associate degree and transferring to a four-year university. They wanted to prove society that they can go to college and graduate too and they are assets to society. Latino students are able to succeed academically because they are determined and focused on their goals. Drawing from their resilience resistance capital helps the Latino students overcome the oppression that they face in their daily lives (Yosso, 2005).

\section{Undocumented Status}

An important issue that was identified throughout the narratives of three participants was their undocumented status. The student stories revealed the struggles and subordination that the Latino students faced in higher education due to their undocumented status (Contreras, 2011; Perez, 2013; Poetker, 2015). These students were limited in their career options, and financial aid. They did not qualify for federal student aid or state funds to pay for their college education. They had a dream of earning a college education and they knew they had to work harder than the rest of their peers in order to achieve their goals. In addition to working hard, they also had to be very strategic as to which program to pursue since some fields such as nursing, criminal justice, political science and education require background checks. Legal documentation of the students is another impediment that is highlighted in the LatCrit as revealing how Latino students are disenfranchised due to their immigration status (Garcia, 1995; Haney Lopez, 2013). 
The participants mentioned how difficult it was for them to be undocumented. For Victoria, it meant disappointment because her legal status prevented her from majoring in nursing. She felt humiliated and self-defeated because she was forced to change her major to another career field that did not require her to produce a social security number-- at least not while she is was a college student. Being undocumented made it very difficult for the following three participants-- Victoria, Roberto and Ivan. All three participants worked long hours at their jobs in order to be able to cover their college tuition and also support themselves and their families.

\section{Roberto}

Roberto worked very hard to finish his community college education, but due to his legal status he did not qualify for financial aid. He worked long hours in order to pay for his education and support his family and himself. "For the financial aid barrier, I applied for scholarships and worked more hours." He worked long hours, attending college part time. After a long journey, he was to graduate with his associate degree, and at the time of the interview he was planning to transfer to a four-year university. "I knew my family couldn't help me financially so I had to find ways on my own to finish it." Not having his legal papers held him back and it took him longer to complete his two-year degree.

Roberto's biggest challenge was his legal status. He came to the United States when he was only a teenager and he was not able to file for legal status. This created a situation that required him to personally finance his college education. "I could not get any financial help. But mainly I had been doing it on my own that is why it has been taking me this long." The lack of available financial assistance creates additional roadblocks to undocumented students, which often prevent them from pursuing higher education. Determination and focus on the broader 
long-term goal is also required of those undocumented students who are able to continue and complete higher education degrees. It may also require the skill of compartmentalization of the different aspects and requirements to meet the goal. "I also feel that I am living two different lives; school where I could do everything and be all I can be, and all I need to do is to study hard. And the other life was my working life. I need to work hard and that I feel it is my other reality, working. 'Two separate lives'.”

\section{Victoria}

Victoria was very disappointed because she could not pursue her dream career due to her legal status. "During the hard moments of not being able to major in nursing and trying to explore alternative careers, I met with a Latino counselor in hopes of getting support and guidance. But, I remember coming out of the meeting feeling even more discouraged as he told me that being undocumented would really hold me back and that there was no career I could really pursue. He also told me that I could major in Social Work because I wouldn't need a valid social security number until I got to graduate school. But, since he knew I'd never get as far as obtaining a master's degree that this would not be something I should be concerned about." She felt discriminated by this counselor when he told her that she could not continue with her studies because of her legal status. "That broke me, but I did not give up."

Victoria came to the United States as a young child. She had a dream of being a nurse because she liked to take care of people. She was an excellent student but did not have legal documents. She felt that the college counselor, whom she went to seek support from, did not give her any other options because he did not believe in her potential despite her good academic standing, due to legal status. To his surprise, she completed her associate degree, transferred into a four-year university, and graduated not only with a bachelor degree but also with a master 
degree in social work. In addition to that, she graduated with high honors from her graduate program. Eventually, she was able to obtain legal documents to work and live in the U.S. She had a dream and she was not afraid to pursue her dream of getting an education, even though she felt that no one believed in her potential due to her legal status.

Students with undefined legal status have very limited resources, however, they work very hard to have good grades and stay focused on their goals. The students' legal status was an obstacle that they were able to overcome by negotiating their options and working hard to make it happen. Undocumented students had to work harder to pay for their college tuition and to do well in their studies. They could apply for private scholarships, but some of them were afraid to unveil their legal status to the college system. "I could not get any financial help. But mainly I had been doing it on my own that is why it has been taking me this long" (Roberto). The lack of available financial assistance adds additional roadblocks to undocumented students that often prevent them from pursuing higher education (Contreras, 2011). Determination and focus as the broader long-term goal is also required of those undocumented students who are able to continue and complete higher education degrees (Poetker, 2015).

\section{Summary}

This study focused on the Latino students' voices and experiences that each of the students brought. According to the findings of this study, each student brought familial, social and community capital that helped them to resist the deficit thinking models in the community college (Yosso et al., 2009). These experiences are validated and centralized by CRT and LatCrit. These findings illustrated the experiential knowledge that people in higher education need to regard and respect the voices of Latino students. These voices and experiences narrate stories that show that higher education structures are not friendly towards Latino students, yet 
with the support from Latino professionals and others who are there to help it becomes easier to navigate. While the type of support that Latino students receive is not the norm, as seen in the literature review, it becomes necessary for institutions of higher education to increase the graduation rate of Latino students by becoming culturally responsive to the needs of students of color (Yosso, 2005; Rosales, 2006). The students' stories were collected in two phases as described above. These stories are narrated from the students' perspectives and the findings mirror the community cultural wealth characteristic (Rendon, 2016; Rosales, 2006; Yosso, 2005). The findings of this study are presented through the lens of Critical Race Theory (CRT), Latino Critical Theory (LatCrit) and the narratives method. The frameworks within CRT and LatCrit were used to affirm the voices of Latino students or students of color, which are not typically heard, analyzed or questioned, especially when it comes to their college experiences (Jain, 2009; Ramirez, 2011; Yosso, 2005). Furthermore, Latino students, in building communities that foster their learning, motivation and success found supportive environments that nurtured their ethnicity, identity, language and background. Institutions of higher learning need to take a proactive role to foster Latino students' cultural assets such as community cultural wealth (Yosso et al., 2009).

The students' responses from the Facebook dissertation discussion group, individual Facebook phone conferences, Skype and face-to-face interviews are woven together as a form of narratives (Delgado, 2013; Yosso, 2005). Family-support, peer-support, cultural-mentoring and resilient-resistance characteristics are some of the variables that students possess. An analysis of these stories under the CRT and LatCrit lenses illustrates how Latino students continue to experience, respond to, and resist racism and other forms of oppression at the community college level (Covarrubias \& Velez, 2014; Espino, 2008; Ramirez, 2011; Solórzano et al..). The use of 
CRT and LatCrit reveals the layers of subordination that Latinos continue to experience based upon immigration status, cultural differences, language challenges, phenotype, accent and surname (Espino, 2008; Yosso, 2005). Community cultural wealth is an amalgamation of assets that a student brings to the academic arena and also helps to resist oppression (Rendon, 2016; Yosso, 2005).

The narratives highlighted the importance of family support, peer-support, cultural mentoring, and resilient resistance, yet also of the dizzying struggles in a landscape that can be vast and flat. Like Esperanza's experience seeing the grape vines for the first time, the students in these narratives feel that the "land" they have cast their eyes upon is "unbroken by even a hillock..." and they too feel "...dizzy looking at the repeated straight rows... and [have] to turn [their] heads away." (Muñpoz-Ryan, 2000, p. 77). Like the rows of dizzying grapes, racism is a combination of ignorance, exploitation and power that is used to oppress African-Americans, Latinos, Native-Americans, Asians and others based on their ethnicity, culture, color, and socialstatus which can cause confusion (Yosso, 2005). 


\section{CHAPTER V: SUMMARY AND CONCLUSION}

"She pressed closer to the ground, until her body was breathing with the earth's. And with Papa's. The three hearts beating together" (Munoz-Ryan, 2000, p. 15).

\section{Introduction}

The results found within this research indicate that Latino students come to the postsecondary experience with the necessary skills and abilities to successfully complete their postsecondary studies. The purpose of this study was to highlight the voices of Latino students who

enter and successfully completed their associate's degree in a community college. In this study, I used Yosso (2005) to frame these skills and abilities. The nine participants who took part of this narrative study started their postsecondary education at a community college due to the location, tuitions cost, open admission policy, flexible classes schedule and the variety of academic and adult education programs. The factors which contributed the success of the associate degree completion of the nine participants were family support, peer support, cultural-mentoring, and the participant resilience-resistance skills which students poised.

\section{Success Factors}

\section{Family Support}

A student's web of support allowed for Latino college students to overcome the challenges they faced in attending community college. Participants talked about the meaningful family support and relationships that they had with their families, including offers to help in any way possible, so they could successfully complete their goal of obtaining an associate degree. Seven of the nine mentioned that their families valued and supported their college goal. They wanted to complete a college degree and make their families proud. Their parents were making every possible effort to support their college dreams. Even when the parents did not know how to 
support them when it came to the college process, the participants knew that their parents wanted the best for them, because their parents made it clear that they valued and supported their college education goals. The parent support that these students experienced went beyond the physical and financial; the spiritual and mental support that they received was significant. The simple words such as, “don’t worry mijo/a o "echale ganas, tu puedes”, "keep going”, and "yes you can!" gave them the fortitude to continue. Their families' hard work also had an influence on their college success. The participants saw how hard their parents worked and how difficult life was for their family members who did not have a college education. The participants hoped that their college education would help them have better job opportunities to reduce the burdens they had faced and help their family members not face them.

\section{Peer-Support}

Peer support was a significant factor to the success of these participants within a community college setting (Datnow \& Cooper, 2009). Eight out of the nine participants mentioned how helpful it was for them to have friends who understood, supported and respected their goals. Some of the participants developed study groups and those study group members became their main support. They encouraged each other to stay focused in their college goals and completed the assignments on time. Some of them also mentioned that they relied on their peers for guidance when needing transfer information or as they were completing college. These participants were proactive and found the services that they felt they needed in order to excel in their college careers. This social capital wealth helped them to build learning communities as they became more proactive in reaching their academic goals. (Rendon, 2016; Yosso, 2005). 


\section{Cultural Mentoring}

Cultural mentoring is an informal mentoring role in which a bilingual and/or bicultural college faculty or staff take upon themselves. For the most part, individuals in these types of people identified themselves as Latina/os. These types of mentors were identified throughout this study.

The cultural-mentors determined the students' needs and took the initiative to guide, empower, and motivate the participants of this study. The participants felt naturally connected with these Latino professionals. The participants highlighted the importance of having faculty and staff who were bilingual and who understood their backgrounds. The participants felt that having a cultural-mentor was critical to their success, because they felt motivated and supported and they trusted this person. The participants were able to relate to these Latino professional and were inspired by their passion to help students succeed. They felt that a mentor who had a similar background was better able to understand their challenges and could provide the appropriate type of support and encouragement which they needed to complete their associate degree.

\section{Resilience-Resistance}

Resilience-Resistance- was another characteristic that participants demonstrated through their narratives. Five out of the nine participants mentioned they experienced negative stereotyping during their community college careers, but they never took action. They chose to invest their energy and time on their studies by ignoring the negative stereotypes and the people who made negative comments. These participants were confident and self-conscious of who they were and how they would persevere despite the deficit-thinking comments they experienced. These participants felt marginalized in their classrooms and sometimes on their college campuses, but that did not deter them from achieving their dreams. They mentioned that there 
were very few Latinos in their classes and at times they were the only one in a class or on the college campus. They worked hard to prove others wrong and at the same time they surrounded themselves with positive peers and mentors. They knew they had the academic talents and skills to reach their dreams. This level of resistance made them stronger and resilient and despite the challenges they continued moving forward. No matter the difficulties in each of their stories, they embraced the challenges and made each situation work to their advantage. Eight out of nine participants mentioned that they wanted to have their college education and give back to their community. The notion that they could succeed by studying hard was evidence by the importance they placed on their education. Their idea of giving back to their community and help the next generation to be better prepared for college. These participants refused to engage in deficit thinking; they knew they could succeed in their college education regardless of where they came from. They were confident of their academic and personal potential.

The findings of this study provided further information on the areas focusing on CRT and LaCrit theories; such findings included family-support, peer-support, cultural-mentoring, and resilience- resistance. It was evident that community college attendance can help Latina/o students reach their potential if the institutions become culturally responsive to Latino and other minority students and their community.

The findings of this study will help me continue to advocate for social change by making recommendations to college leaders and legislators in the adaptation of policies and practices that promote Latino college completion. The policies and practices should emphasize the following factors: family involvement, cultural mentoring, community support programs, and recognition of individual students' stories. I am planning on continuing to build relationships with community college leaders, community leaders, parents and legislators. Additionally, I 
would like to use the findings of this study to inform, motivate, and mentor families and students. Presenting the findings of this findings at the local, state and national conferences can also help me bring about positive social change. Working together we can make a difference in the lives of first-generation students. It is our responsibility to give back to our community and lift the upcoming generations

\section{Implications}

Community colleges are important to the success of first-generation college students and need to work closely with their communities. Community colleges are the best places to foster community cultural wealth, since nearly fifty percent of Latinos in higher education are in community colleges (Krogstad, 2015). Community colleges could become a cultural responsive institution by valuing students and their community cultural assets, helping them to become advocates for social justice. By getting a college education, these students are not only helping themselves but becoming role models for their communities.

Community college faculty and administrators need to remind themselves that the higher education system was created with Eurocentric ideals and their policies and procedure might not serve in meeting the needs of Latina/os and other minority students. Since there will be more Latino students attending college in the near future, there is still time to make structural changes that make community colleges more culturally responsive to their students, in particular students of color and low-social economic students. The values and cultural knowledge that Latino students and minority students bring to the classroom validates their success in higher education. Therefore, community colleges should become more culturally diverse. Community colleges can be areas where Latino students learn to become proactive and make meaningful connections to the society and communities in which they live. Acquiring information from the students they 
serve allows for community colleges to better both the students and communities students live and work.

These findings also indicated that community colleges need to make necessary systemic changes to better serve first-generation college students, in particular Latino students. The narratives of the participants highlighted the importance of having staff that understands their students' culture and backgrounds. Individuals at the community colleges need to put forth more efforts to build strategies, bringing together faculty, staff, students, families, and community stakeholders to provide a holistic approach; this helps to highlight the importance of college graduation for Latino students.

Latino community college students already possess several resources that they bring as they work towards completing their education. An understanding of the values that Latino students bring to community colleges provides a vast amount of cultural wealth, which is an asset for the college. Listening to the voices of the participants in this study helps guide the colleges in redesigning their policies.

The participants of this study mentioned how important their family was to their success. This means that community colleges need to work on strategies to connect families and the college campus. There must be assurances by the individuals within community colleges to include programs on campus that make families feel part of the campus. Allowing students to share their experiences makes them feel valued.

These nine narratives supported the importance of having Latino professionals as part of their success at the community college level. Ivan mentioned that, "As a Latino student, I think we are privileged at [my local community college] because those Latinos who work there are always willing to extend a hand to us." Community colleges should hire more Latino 
professionals and train their staff about Latino and minority student experiences. Community college staff need to understand and value the community culture wealth, which students of color bring to their campus. Students appreciate culturally sensitive events that help them feel connected with their community identity, which adds to the college community.

It was highlighted through the study the need to see Latino students as assets rather than burdens not only in higher education but also throughout society. Latino students have dreams and work hard to achieve their dreams. Latino students are culturally conscious and desire a college education in order to give back to their community and help others succeed. They see their success as a public good and not just a personal achievement. All of the nine participants worked juggling different facets of their lives while also working and going to college. The participants not only studied a profession and worked to cover the expense of the full tuition, but also committed themselves to providing for their families.

The participants felt a sense of pride to be Latino and knew also the importance of the Latina/o professionals who helped them reach their college dreams. Because they felt supported, they knew that they could accomplish their goals. Yet, the participants also noticed a need for additional Latino staff and faculty at the college level, which is evidenced by the lack of a large number of bilingual and bicultural staff. Additionally, the colleges should not rely on only a few bilingual faculty and staff to comply with meeting the quota. It is not fair to those faculty and staff, as it is likewise not fair for the students and the community. If community colleges want to increase the number of graduates in their institutions they have to change their mission, strategies and polices. They need to require training for all their staff and faculty regardless of their background. The communities around the community colleges have to take ownership of student achievement and work together for one common goal: student graduation. After all, a community 
college is present to serve the needs of its community and as such should stay true to their communities.

Another implication of this study is the high value placed on education by the families. These participants wanted to succeed, so they could provide and have a better future for their families and themselves. Four of the participants have young children and they wanted to succeed in college because they knew they would be able to provide a better future for their children. Latino students are smart, motivated, positive, and they are facing discrimination on their college campuses. There is a need to embrace college-wide cultural sensitivity training in order to dismantle deficit-thinking across in all areas.

\section{Recommendations}

There were several recommendations that came out of this research study, providing institutions committed to diversity and social justices with ideas. Community colleges are the best places to foster community cultural wealth, since almost fifty percent of Latinos in higher education are at community colleges. These ideas would strength the college culture and would create a welcoming college campus. Developing partnerships and programs with local schools, business, nonprofit organizations, and community leaders allows the colleges to become a proactive higher education institution.

They could develop new strategies and programs to be cultural responsive. Some of the programs, such as the "Taste of College", financial aid workshops, family higher education conference, cultural events for college students and their community, and creating a taskforce board at the college level to respond to students' cultural needs are the recommendations delineated in the following paragraphs These different areas allow for institutions of higher learning to strengthen the partnership with the Latino community and increase the college 
graduation rate of students.

\section{Taste of College}

Taste of College should target middle school eight-graders who are the first in their families to go to college. This idea was formulated by individuals at Lake County and Gurnee Illinois Chamber of commerce. The Taste of College program has provided a college path to eight graders by giving students hands-on experiences at a college campus. This program brings the local schools, businesses and colleges together. The students and parents found this type of program very helpful for their future college planning. The participants of this program had the opportunity to visit local colleges and universities and meet college students. This type of program is out of the box thinking. It provides an opportunity for local school districts and colleges to work together enriching students with positive experiences for them and their families.

\section{Free Application for Federal Student Aid (FAFSA) completion workshops}

Free Application for Federal Student Aid (FAFSA) completion workshops could be an outreach initiative which could strength the community college and the community relations. FAFSA workshops could be provided to high school seniors and their parents or any returning adult who needs assistance on completing and filing the FAFSA. The purpose for this type of outreach is to empower and support first-generation college students in particular Latina/o and minority and low-income students to continue their higher education. In higher education, there are many expectations that college faculty and staff expects from students, but rarely does anyone take the time to acknowledge the possible barriers that these students face. The whole financial aid process is very confusing and intimating, so it is very helpful to bring this type of service to the community as part of strengthening the relationships among the community, 
students and college.

\section{Family Conference}

Another outreach activity that can be done to promote cultural responsiveness within a college setting is to organize a family conference where high and middle school families are invited to a conference. At the family conference, parents are spoken about the importance, process of admittance into college and means to pay for college. Also, collaboration with Latino faculty and staff of the college provides opportunities for the staff and parents to learn from each other, in particular helping parents and families navigate the college system. Again, this is an opportunity for college and community members to work together and collaborated to increase the student entrance and college completion and eliminated barriers which are often first generation students and families faced due to a lock of families with the higher education system.

These types of outreach activities will send a clear message to families that they are not alone in their college journey and the college cares about their success. This idea came from a partnership that we had established with National Louis University, the College of Lake County, the University Center of Lake County and community leaders in Lake County.

\section{Cultural College Student Banquets}

Cultural college student banquets can be conducted where students can be recognized for their hard work at the end of the academic year. This event can be used to celebrate the accomplishments of students and invited stakeholders, such as: college administrators, faculty, student's families and community leaders. This will be a great opportunity for all the key holders of student success to interact and network with each other to create webs of support including possible internships, letters of support and references to their future employers. This enhances the students' professional contacts who they could add to their list of reference. This is also a 
great opportunity for the college to showcase their diversity initiative to their community at large. I got this idea from the participants of this research study. They mentioned during interviews how proud they felt when they attend to an event that their Latino advisor organized at the end of the year. They mentioned how meaningful it was to them and their families to see Latino professionals who attended this type of event that provides the participants with a sense of ownership, belonging or being part of something that celebrates their success and ethnicity and a sense of pride.

\section{Taskforce Board}

A taskforce board would be used to review and recommend culturally friendly policies to the institution. The main purpose of this board should be to guide the college to be more culturally responsive to the community, such that cultural polices reflect the students' demographics. The goal of this task committee should be to strengthen the partnership with the Latino community and increase the college graduation rate of Latino students. his taskforce should include members of the upper administration and faculty of the college, legislators, community members, alumni, parents, and current community college students.

These recommendations may not be the magic wand, but it could be a good start for a community college or any higher education institutions that is trying to be culturally responsive to their students and communities. These ideas came from the work that I have done in Lake County with the support of the University Center of Lake County's administration and community leaders and from the participants of this research study. The participants of this study shared their experiences and what made a difference to their college completion. The majority of these recommendations foster family-support, peer-support, cultural-mentoring, and resilienceresistance that this study found as contributing factors to the success of these nine participants. 


\section{Future Research}

This research investigated the college journey of Latino students who were able to successfully complete their associate degrees from community colleges. It would be important to learn of the impact on the families of successful and unsuccessful Latino community college students. The types of questions that should be explored are:

1. What type of policies and programs do Latino families feel are critical to the success of their student? How do parents feel about attending to cultural events at the college campus?

2. What are the parents' and students' perceptions about the higher education systems? When would be at appropriate time for parents and students to learned all about the college process? And how can college administrators and faculty could support them with this process?

3. In what ways does the undocumented status of students impact the ways in which the family and student resisted to the college planning process and college completion?

\section{Conclusion}

These findings unveil the voices of nine successful Latinos who started their postsecondary education at a community college and successfully completed their associate degrees. All nine participants came to the community college with community cultural wealth. This community cultural wealth provided them with significant strength. Institutions of higher learning need to value and recognize all of the assets that Latinos bring to their schools.

According to CRT and LatCrit, narrative experiences and knowledge, which student bring to the higher education, are valid and people in higher education need to listen to these voices in order to end deficit thinking, respecting all students regardless of their backgrounds (Yosso, 2005). 
These stories could also be used to empower other Latino students and their families and could be used as a tool to dismantle deficit thinking (Yosso, 2005; Rosales, 2006; Valencia, 2010; Rendon, 2016).

Analyzing these stories under the CRT and LatCrit lens illustrates how Latino students continue to experience and respond to resist racism and other forms of oppression at the community college level (Covarrubias \& Velez, 2014; Espino, 2008; Ramirez, 2011; Solórzano et al., 2005). Using CRT and LatCrit helps to reveal the layers of subordination that Latinos continue to experience based upon immigration status, cultural differences, language challenges, phenotype, accent, and surname (Espino, 2008; Yosso, 2005). Racism is a combination of ignorance, exploitation and power used to oppress African Americans, Latinos, Asians and other people of color on the basis of ethnicity, culture, color, and social-status (Yosso, 2005). Community cultural wealth is an amalgamation of assets that a student brings to the academic arena and also helps them to resist oppression (Rendon, 2016; Yosso, 2005).

With that said, all of the nine participants were very grateful that they took part in this study, were very proud of their journey, and loved sharing their story with me. Each felt that his or her story could make a difference for the next generation of community college students. Those of us in higher education need to listen and to respond to the needs of students, so as to provide a better future for all. Allow students to feel free to rest upon this land, as Esperanza did when her story was over. Let them be able to "press closer to the ground, until [their] bodies breath with the earth's (Munoz Ryan, 2000, p.15). This research provides insight into the ways in which institutions can be culturally responsive to Latino students in particular. The community college is the primary point of entry into post-secondary studies for many Latino students who are poised and ready to create communities of cultural wealth; the institutions should be ready to 
support Latino students' quest towards the post-secondary terrain. In this case, allowing students to feel welcomed and free to share their cultural wealth with everyone without the stigma of any prejudices. 


\section{REFERENCES}

Acuña, R. (1998). Sometimes there is no other side: Chicanos and the myths of equality. Notre Dame, IN: Notre Dame University Press.

Acuna, R. F. (2007). Occupied America: A history of Chicanos (6 $6^{\text {th }}$ ed.). New York, NY: Logman.

Adam, M. (2007). Use grants, not loans, for getting low-income Hispanic to college. Education Digest: Essential Reading Condensed for Quick Review, 72 (8), 51-55.

Aguirre Hernandez, E. (2010). Persistence and degree attainment: The role of individual decision making, varies forms of capital, and institutional factors among MexicanAmericans undergrads students (Doctoral dissertation). Available from ProQuest Dissertations and Theses database. (UMI 3433211).

Aguilar, J. A., MacGillivray, L., \& Walter, N. T. (2003). Latina educators and school discourse: Dealing with tension on the path to success. Journal of Latinos and Education, 2 (2), 89100.

Anaya, G., \& Cole, D., G. (2003). Maximizing student achievement efforts. In J. Castellanos \& L. Jones (Eds.), The majority in the minority: Expanding the representation of Latino faculty, administrators and students in higher education (pp. 95-107). Sterling, VA: Stylus.

Artiaga, M. (2013). A portraiture of six Hispanic women's academic pursuit in a community college setting: a qualitative study (Doctoral dissertation). Available from ProQuest Dissertation and Theses database. (UMI 3574483). 
Associated Press, (2013, May 1). How Facebook has grown: number of active users at Facebook over the years. Lifestyle Journal. Retrieved from: http://news.yahoo.com/number-activeusers-facebook-over-230449748.html

Baum, S., \& Kurose, C. (2013). Community colleges in context: Exploring financing of two-andfour-year institutions. In S. Baum, C. Kurose, S. Goldrick-Rab, P. Kinsley, T. Melguizo \& H. Kosiewicz (Eds.), Bringing the Higher Education Divide (pp.73-108). New York, NY: The Century Foundation Press.

Becerra, D. (2008). Difference in the perception of barriers in education among Latinos in the U.S. (Doctoral dissertation). Available from ProQuest Dissertations and Theses database. (UMI 3319070).

Becker, G. (1962). Investing in human capital: A theoretical analysis. The Journal of Political Economy, 70 (5), 9-49. Retrieved from: http://www.jstor.org/stable/1829103

Bell, D. A. (2009). Brown v. board of education and the interest convergence dilemma. In E. Taylor, D. Gillborn, \& G. Ladson-Billings (Eds.), Foundations of critical race theory in education (pp. 73-84). New York, NY: Taylor \& Francis.

Bell, D. A. (2009). Who's afraid of critical race theory? In E. Taylor, D. Gillborn, \& G. LadsonBillings (Eds.), Foundations of critical race theory in education (pp. 37-50). New York, NY: Taylor \& Francis.

Bell, D. A. (2013). After we' re gone: Prudent speculations on America in a post-racial epoch. In R. Delgado \& J. Stefancic (Eds.), Critical Race Theory: The cutting edge ( $3^{\text {rd }}$ ed., pp. 914). Philadelphia, PA: Temple University Press.

Berger, P. L., \& Luckmann, T. (1967). The social construction of reality: A treatise in the sociology of knowledge. Garden City, NY: Doubleday \& Company. 
Bleskachek, L. (2007). Latino student perceptions of support systems and challenges in a four year-university (Doctoral dissertation). Retrieved from: ProQuest. (3278103)

Bloom, D., \& Haskins, R. (2010). Helping high school dropouts improve their prospects. The Future of Children Princeton-Brookings, 20, 1-7.

Brown, S., \& Roorda, M. (2016). The condition of college \& career readiness 2015: Hispanic Students. Exelencia in Education, \& ACT: 1-21. Retrieved from: http://www.edexcelencia.org/gateway/download/22148/1467213821

Brown, S. E., Santiago, D., \& Lopez, E. (2003, March-April). Latinos in higher education: Today and tomorrow. The Magazine of Higher Learning, 23 (n.d), 40-46.

Brownstein, R. (2013, March). How colleges are making income inequality worse. National Journal. Retrieved from: http://www.nationaljournal.com/columns/politicalconnections/how-colleges-are-making-income-inequality-worse-20130307?print=true

Bryk, A., \& Toch, T. (2012, May 1). Essay on reforming remedial education at community colleges. Inside Higher Ed. Retrieved from: http://www.insidehighered.com/views/2012/05/01/essay-reforming-remedial-educationcommunity-colleges\#sthash.3C8ZjR30.dpbs

Burton, M. M. (2012).Dreams deferred: Testimonies of undocumented Latin@ student experience (Doctoral Dissertation). Retrieved from: ProQuest Dissertation and Theses database. (UMI 3509558).

Camacho Liu, M. (2011, July). Investing in higher education for Latino students: Trends in Latino college access and success. National Conference of State Legislatures. Retrieved from: http://www.ncsl.org/documents/educ/TrendsInLatinoSuccess.pdf 
Camacho Liu, M. (2012, April). Ensuring Latino success in college and the workforce. National Conference of State Legislators. Retrieved from: http://www.ncsl.org/research/education/ensuring-latino-success-in-college-andworkforce.aspx

Carnevale, A., P., Rose, S., J., \& Cheah, B. (2011). The college payoff: Education, occupation, lifetime earnings. The Georgetown University Center on Education and Workforce. 1-33.

Carlson, S. (2016). When college was a public good: As the population grown more diverse, support for grand efforts like the GI bill to open doors to higher education has dwindled. Coincidence?.Chronicle of Higher Education, 63 (15), 14-18.

Carrasco, E. R. (1996). Collective recognition as a communitarian device: Or, of course we want to be role models. La Raza Law Journal, 9.

Castellanos, J., Jones, L. (2003). Latino undergraduate experience in American higher education. In J. Castellanos \& L. Jones (Eds.), The majority in the minority: Expanding the representation of Latino faculty, administrators and students in higher education (pp. 113). Sterling, VA: Stylus.

Caudle, S.L. (2004). Qualitative data analysis. In J. S. Wholey (Ed.), Handbook of practical program evaluation ( $2^{\text {nd }}$ ed., pp 417-437). San Francisco, CA: Jossey-Bass.

Cavazos, A. G. \& Cavazos, J. (2010). Understanding the expectations of Latino students: A qualitative study for change. American Secondary Education, 38 (2), 95-109.

Cerezo, A., McWhirter, B. T., Peña, D., Valdez, M., \& Bustos, C. (2013). Giving voice: Utilizing critical race theory to facilitate consciousness of racial identify for Latina/o college students. Journal for Social Action in Counseling and Psychology, 5, 1-25. 
Chadwick, K. G. (2004). Improving schools through community engagement. Thousand Oaks, CA: Corwin Press.

Chapa, J. \& De La Rosa, B. (2003). Latino population growth, socioeconomic, and demographic characteristics, and implications for educational attainment. Education and Urban Society, 35, 1-20.

Chapa, J., \& De La Rosa, B. (2006). The Problematic pipeline: Demographic trends and Latino participation in graduate science, technology, engineering and mathematics programs. Journal of Hispanic Higher Education, 5, 203-221.

Chapa, J., Schink, W. (2006). California community colleges: Help or hindrance to Latinos in the higher education pipeline? In C. L. Horn, S. M. Flores \& G. Orfield (Eds.), Latino educational opportunity (pp. 41-50). San Francisco, CA: Jossey-Bass.

Chapa, J. \& Valencia, R.R. (1993). Latino population growth, demographic characteristic, and educational stagnation: An examination of recent trends. Hispanic Journal of Behavioral, 15(2), 165-187.

Chapman, T. K. (2013). Origin of and Connections to social justice in critical race theory in education. In M. Lynn \& A. D. Dixson (Eds.), Handbook of Critical Race Theory in Education (pp. 101-112). NY: Routlege Taylor \& Francis.

Chell, E. (2004). Critical Incident Techniques. In C. Cassell \& G. Symon. (Eds.), Essential guide to qualitative methods in organizational research (pp.45-60). London: Sage.

Cisneros, S. (1994). La casa en Mango street. New York, NY: Vintage Books.

Cohen, A. M. (1998). The shaping of American higher education: Emergence and growth of the contemporary system. San Fransco, CA: Jossey-Bass.

Coffey, A., \& Atkinson, P. (1996). Making sense of qualitative data. London: Sage. 
Cole, D., \& Espinoza, A. (2008). Examining the academic success of Latino students in science technology engineering and mathematics (STEM) majors. Journal of College Student Development, 49 (4), 285-300. Doi: 10.1353/csd.0.0018

Conley, D. T. (2007). Toward a more comprehensive conception of college readiness. Education Policy Improvement Center, 1-25.

Contreras, F. (2011). Achieving equity for Latino students: Expanding the pathway to higher education through public policy. New York, NY: Teachers College.

Covarrubias, A. (2011). Quantitative intersectionality: A Critical race analysis of the Chicana/o Education pipeline. Journal of Latinos and Education, 10 (2), 86-105. Doi: $10.1080 / 15348431.2011 .556519$

Covarrubias, A., \& Velez, V. (2014). Critical race quantitative intersectionality: An anti-racist research paradigm that refuses to "let the numbers speaks for themselves". Handbook of critical race theory in education. 270-285.

Crenshaw, K. W. (1988). Race, reform, and retrenchment. Transformation and Legitimation in Anti-Discrimination Law, 101(n. d.), pp. 1331-1351.

Davenport, M. Y. (2010). Examining Involvement as a critical factor: Perceptions from first generation \& non-first generation college students (Doctoral dissertation). Available from ProQuest Dissertations and Theses database. (UMI 3424371).

Datnow, A. \& Cooper, R. (2009). Peer networks of African American students in Independent schools: Affirmative academic success and racial identity. In E. Taylor, D. Gillborn, \& G. Ladson-Billings (Eds.), Foundations of critical race theory in education (pp.190-209). New York, NY: Taylor \& Francis. 
Delgado, R. (2009). Affirmative action as a majoritarian device: Or, do you really want to be a role model? In E. Taylor, D. Gillborn, \& G. Ladson-Billings (Eds.), Foundations of critical race theory in education (pp.109-116). New York, NY: Taylor \& Francis.

Delgado, R. (2013). Story for oppositionist and others: A plea for narrative. In R. Delgado \& S. Stefancic, Critical Race Theory: The cutting Edge ( $3^{\text {rd }}$ ed., pp.71-80). Philadelphia, PA: Temple University.

Delgado, R. (2013). Words that wound: A tort action for racial insults, epithets and name-calling. In R. Delgado \& S. Stefancic, Critical Race Theory: The cutting Edge ( $3^{\text {rd }}$ ed., pp.179186). Philadelphia, PA: Temple University.

Delgado, R. \& Stefancic, J. (2013). Discerning critical moments. In M. Lynn \& A. D. Dixson (Eds.), Handbook of Critical Race Theory in Education (pp.23-33). NY: Routlege Taylor \& Francis.

De la Riva, S. (2012). Deconstruction persistence in academic language among secondgeneration Latinos: How do second-generation Latino language minority community college students alter their academic trajectories? (Doctoral Dissertation). Available from ProQuest Dissertations and Theses database. (UMI 3542412).

De los Santos, A., \& De los Santos, G. (2005). Latinos and community colleges: A Pathway to graduate studies?. In J. Castellanos, A. M. Gloria, \& M. Kamimura (Eds.), The Latino Pathway to the Ph.D. Abriendo caminos (pp. 37-51). Sterling, VA: Stylus.

Dudziak, M. L. (2009). Desegregation as a cold war imperative. In E. Taylor, D. Gillborn, \& G. Ladson-Billings (Eds.) Foundations of critical race theory in education (pp.85-95). New York, NY: Taylor \& Francis. 
Espino, M. M. (2008). Master narratives and counter-narratives: An analysis of MexicanAmerican life stories of oppression and resistance along the journeys to the doctorate (Doctoral dissertation). Available from ProQuest Dissertations and Theses database. (UMI 3303575).

Espinoza, L. (1998). A vision towards liberation. 19 Chicano-Latino Law Review, 19 (N.d), pp.193-196. Retrieved from: http://www.heinonline.org.libproxy.lib.ilstu.edu/HOL/Page?page=193\&handle=hein.jour nals $\% 2$ Fchiclat19\&collection=journals $\# 203$

Espinoza, L. (1990). Masks and other disguises: Exposing legal academia. Harvard Law Review, 103 (N.d), 1878-886. Retrieved from: http://jstor.org/stable/1341322

Espinoza, L. \& Harris, A. (2013) Embracing the tar-baby: LatCrit theory and the sticky mess of race. In R. Delgado \& S. Stefancic, Critical Race Theory: The cutting Edge (3 ${ }^{\text {rd }}$ ed., pp.440-447). Philadelphia, PA: Temple University.

Fenske, R. H., Geronios, C. A., Keller, J. E, \& Moore, D. E. (1997) Early intervention programs: Opening the door to higher education. Washington, DC.: ASHE, The George Washington University, 25 (6).

Foley, E. D. (1997). Deficit thinking models based on culture: The anthropological protest. In R. R. Valencia (Ed.), The evolution of Deficit Thinking: Educational Thought and Practice. pp. 113-131. Washington, D.C.: The Falmer Press.

Freire, P. (1970). Pedagogy of the oppressed. New York, NY: Penguin Group.

Fry, R. (2002). Latinos in higher education: Many enroll, too few graduates. Pew Research Center Retrieved from: http://pewhispanic.org/files/reports/11.pdf 
Fry, R. (2010). Hispanic, High School Dropouts and GED. Pew Research Center, Retrieved from: http://www.pewhispanic.org/files/reports/122.pdf

Fry, R. (2011). 24\% growth from 2009-2010: Hispanic college enrollment spikes. Narrowing gaps with other groups. Pew Hispanic Center. Retrieved from: http://www.pewhispanic.org/files/2011/08/146.pdf

Fry, R., \& Lopez, M. H. (2012). Now largest minority group on four-year college campus: Hispanic student enrollment reach new highs in 2011. Pew Research Center, Retrieved from: http://www.pewhispanic.org/files/2012/08/Hispanic-Student-Enrollments-ReachNew-Highs-in-2011_FINAL.pdf

Fry, R., \& Taylor, P. (2013). Hispanic high school drop-out rate at record low: Hispanic high school graduates pass whites in rate of college enrollment. Pew Research Center, Retrieved from: http://www.pewhispanic.org/files/2013/05/PHC_college_enrollment_2013-05.pdf

Gándara, P. (1995). Over the ivy walls: The education mobility of low-income Chicanos. Albany, NY: State University of New York.

Gandara, P., \& Contreras, F. (2009). The Latino education crisis: The consequences of failed social policies. Harvard University Press.

Garcia, E. E., Wiese, A. M, Cuellar, D. (2011). Language, public policy, and schooling: A focus on Chicano English learners. In R. Valenica (Ed.), Chicano School Failure and Success. (pp. 143-159). Routledge, NY:Taylor and Francis Group.

Garcia, R. J. (1995). Critical race theory and proposition 197: The racial politics of immigration law. Chicano-Latino Law Review, 17, 118-154. 
Garcia Torres, C. (2009). Nuestras voces resisten: Experiences of Chicana/Latinas in pacific northwest (Doctoral dissertation). Available from ProQuest Dissertations and Theses database. (UMI 3382095)

Garrod, A., Kilkenny, R. and Gomez, C. (2007). Mi Voz, Mi Vida: Latino College students tell their life stories Ithaca, NY: Cornell University Press.

Garza, E., Reyes, P., \& Trueba, E. T. (2004). Resiliency and success; Migrant children in the U.S. Boulder, CO: Paradigm Publishers.

Geron, K. (2005). Latino Political Power. L. Rienner.

Gillborn, D. (2009). Education policy as an act of white supremacy: Whiteness, critical race theory, and education reform. In E. Taylor, D. Gillborn, \& G. Ladson-Billings (Eds.), Foundations of critical race theory in education (pp.51-69). New York, NY: Taylor \& Francis.

Gillborn, D. (2013). The policy of inequity: Using CRT to unmask white supremacy in education policy. In M. Lynn \& A. D. Dixson (Eds.), Handbook of Critical Race Theory in Education (pp. 129-139). New York: NY: Routledge Taylor \& Francis.

Gonzales, J. (2011). Harvest of empire: A history of Latinos in American. NY: Penguin Books.

Guest, G., Bunce, A., \& Johnson, L. (2006). How many interviews are enough? An experiment with data saturation and variability. Field Methods, 18 (1), 59-82. doi:

$10.1177 / 1525822 X 05279903$

Haney Lopez, I. F. (2013). The social construction of race. In R. Delgado \& S. Stefancic, Critical Race Theory: The cutting Edge ( ${ }^{\text {rd }}$ ed., pp.238-248). Philadelphia, PA: Temple University. 
Henderson, A. T., \& Berla, N. (1994). A new generation of evidence: The family is critical to student achievement. Retrieved from: http://www.eric.ed.gov/PDFS/ED375968.pdf

Hernandez, R., Siles, \& M., Rochin, R., I. (2001). Latino youth: Converting challenges to opportunities. Retrieved from: http://files.eric.ed.gov/fulltext/ED456014.pdf

Herrera, R. (2009). The college/university experience of Latino AVID students (Doctoral dissertation). Retrieved from: ProQuest. (UMI 3394888).

Herrera, R. (2003). Notes from a Latino graduate student at a predominantly white university. In J. Castellanos \& L. Jones (Eds.), The majority in the minority: Expanding the representation of faculty, administrators and students in higher education (pp. 111-125). Sterling, VA: Stylus.

Jain, D. (2009). Critical race theory and community colleges: Through the eyes of women student leaders of color. Community College Journal of Research and Practice. 34, (1), 78-91. Retrieved from: http://dx.doi.org/10.1080/10668920903385855.

Johnson, R.B. (1997). Examining the validity structure of qualitative research. Education, 118 (2), 282-292. Retrieved from: http://www.dralessandro.com/subpages/PDFfiles/Validity\%20Structure.pdf

Johnson, B. \& Christensen, L. (2012). Educational research: Quantitative, qualitative, and mixed approaches. Los Angeles, CA: Sage.

Johnson, K. R. (2000). LatCrit iv symposium: Rotating centers, expanding frontiers: LatCrit theory and marginal intersections: Foreword: Celebrating LatCrit theory: we do we do when the music stops? U. C. Davis Law Review, 33. 
Krogstad, J. M. (2015). 5 Facts about Latinos and education. Pew Research Center, Retrieved from: http://www.pewresearch.org/fact-tank/2015/05/26/5-facts-about-latinos-andeducation/

Krogstad, J. M., \& Fry, R. (2015). Hispanics to benefit from Obama's community college plan. Pew Research Center, Retrieved from: http://www.pewresearch.org/facttank/2015/01/20/hispanics-to-benefit-from-obamas-community-college-plan/

Krogstad, J. M., \& Lopez, G. (2016). Roughly half of Hispanics have experienced discrimination. Pew Research Center, Retrieved from: http://www.pewresearch.org/facttank/2016/06/29/roughly-half-of-hispanics-have-experienced-discrimination/

Ladson-Billings, G. (2009). Just what is critical race theory and what's it doing in a nice field like education? In E. Taylor, D. Gillborn, \& G. Ladson-Billings (Eds.) Foundations of critical race theory in education (pp.17-36). New York, NY: Taylor \& Francis.

Ladson-Billings, G. (2013). Critical race theory -What it is not! In M. Lynn \& A. D. Dixson (Eds.), Handbook of Critical Race Theory in Education (pp.34-47). NY: Routledge Taylor \& Francis.

Lederman, D. (2013, July, 31). Higher Ed: Engine of Inequity: Black and Latino young people are greatly underrepresented at selective college and overrepresented at open-access institutions - and the trends are worsening. Inside Higher Ed. Retrieved from: http://www.insidehighered.com/news/2013/07/31/report-documents-how-highereducation-exacerbates-racial-inequities\#sthash.e3rEVr2E.dpbs

Lester, S. (1999). An introduction to phenomenological research. Stan Lester Developments. Retrieved from: http://www.psyking.net/HTMLobj3825/Introduction_to_Phenomenological_Research-Lester.pdf 
Lopez, M. H., Gonzalez, A., \& Cuddington, D. (2013, June 19). Diverse Origins: The nation's 14 largest Hispanic origin groups. Pew Hispanic Center. Retrieved from: http://www.pewhispanic.org/files/2013/06/summary_report_final.pdf

Lodmer, E. J. (2008). In their own words: Factors leading to transfer as identified by ten resilient Latino community college students (Doctoral Dissertation). Retrieved from: ProQuest Dissertations and Theses database. (UMI 3322023).

Lynch, M., \& Engel, J. (2010, August 9). Big gaps, small gaps: Some colleges and universities do better than others in graduating Hispanic students. The Education Trust. Retrieved from: http://www.edtrust.org/sites/edtrust.org/files/publications/files/CRO\%20BriefHispanic.pdf.

Lynn, M, \& Parker, L. (2006). Critical race studies in education: Examining a decade of research on U.S. schools. The Urban Review, 38 (4), 257-299. doi: 10.1007/s11256-006-0035-5.

Lumina Foundation (2016, April). A strong nation: In Illinois, postsecondary learning building the talent that helps us rise, College Changes Everything, Tinley Park, IL.

MacDonald, V-M., \& Garcia, T. (2003). Historical perspectives on Latino access to higher education. In J. Castellanos \& L. Jones (Eds.), The majority in the minority: Expanding the representation of faculty, administrators and students in higher education (pp. 1543). Sterling, VA: Stylus.

Manning, K., Kinzie, J., \& Schuh, J. (2006). One size does not fit all. Roudledge, NY.

Matsuda, M. J. (1992). When the first quail calls: Multiple consciousness as jurisprudential method. Woman's Rights Law Report, 11(7). 
Mejia, M.C., Rodriguez, O., Johnson, H. (2016). Preparing students for success in California community college. Retrieved from: http://www.ppic.org/content/pubs/report/R_1116MMR.pdf

Menchaca, M. (1997). Early racist discourse: Roots of deficit thinking. In R. R. Valencia (Ed.), The evolution of Deficit Thinking: Educational Thought and Practice (pp. 13-40). Washington, D.C.: The Falmer Press.

Merisotis, J. P. (2014). A stronger nation through higher education: Visualizing data to help-us achieve a big goal for college attainment. Retrieved from: http://www.luminafoundation.org/newsroom/news_releases/2013-1204.html\#sthash.MZXuAbZF.dpuf.

Merriam, S. B. (1998). Qualitative research and case study application in education. San Francisco, CA: Jossey-Bass.

Merriam, S. B. (2009). Qualitative research: A guide to design and implementation: Revised and expanded from qualitative and research and case study applications in education. San Francisco, CA: Jossey-Bass.

Moltz, D. (2008, November 14) Why some of the best and brightest skip college. Inside Higher Ed. Retrieved from: http://insidehighered.comnews/2008/11/14/ihep

Munoz Ryan, P. (2000). Esperanza rising. New York, NY: Scholastics Inc.

Nelson, L. A. (2011, May 27). Raising graduation rates, and questions. Inside Higher Ed. Retrieved from: http://www.insidehighered.com/news/2011/05/27/san_diego_state_raises_graduation_rat es_in_part_by_becoming_more_selective\#sthash.LiGGtEjf.dpbs 
Nunez, A, (2014). Employing multiple intersectionality in educational research: Latino identities, contexts, and college access. Educational Research, 43, 2, 85-92. doi: $10.3102 / 0013189 X 14522320$

O’Brien, S. (2011, May 12). Student's success defies all odds. CNN Retrieved from: http://edition.cnn.com/2011/LIVING/05/12/soledad.education.latina/index.html

Oliva, M. (2004). Reluctant partnership, problem definition, and legislative internet: k-16 policy for Latino college success. Journal of Hispanic Higher Education, 3 (2), 209-230. doi: $10.1177 / 1538192704263574$

Oliva, N., Perez, J. C., \& Parker, L. (2013). Education policy contradictions: A LatCrit perspective on undocumented Latino students. In M. Lynn \& A. D. Dixson (Eds.), Handbook of Critical Race Theory in Education (pp.140-152). NY: Routledge Taylor \& Francis.

Orozco, V. (2003). Latinas and the undergraduate experience: No estamos solas. In J. Castellanos \& L. Jones (Eds.), The majority in the minority: Expanding the representation of faculty, administrators and students in higher education (pp. 127-137). Sterling, VA: Stylus.

Pacheco, M. (2012). Learning in/through everyday resistance: A cultural-historical perspective on community resources and curriculum. Educational Researcher, 41 (4), 121- 132. doi: $10.3102 / 0013189 X 12442982$

Parker, L., \& Lynn, M. (2009). What's race got to do with it? critical race theory's conflicts with and connections to qualitative research methodology and epistemology. In E. Taylor, D. Gillborn, \& G. Ladson-Billings (Eds.) Foundations of critical race theory in education (pp.148-160). New York, NY: Taylor \& Francis. 
Patten, E. (2016, April 20). The Nation's Latino population is defined by its youth: Nearly half of U.S.-born Latinos are younger than 18. Pew Research Center. Retrieved from: http://www.pewhispanic.org/2016/04/20/the-nations-latino-population-is-defined-by-itsyouth/

Patton, L. D., McEwen, M., Rendon, L., \& Howard-Hamilton, M. (2007). Critical race perspective on theory in student affairs. New Directions for Student Services, 120, 39-53.

Pearl, A. (1997). Cultural and accumulated environment deficit thinking. In R. R. Valencia (Ed.), The evolution of Deficit Thinking: Educational Thought and Practice (pp. 132-159). Washington, D.C.: The Falmer Press.

Pearl, A. (1997). Democratic education as an alternative to deficit thinking. In R. R. Valencia (Ed.), The evolution of Deficit Thinking: Educational Thought and Practice (pp. 211241). Washington, D.C.: The Falmer Press.

Perea, J. F. (2013). Race and the U.S.-Mexican border: tracing the trajectories of conquest. In R. Delgado \& S. Stefancic, Critical Race Theory: The cutting Edge (3 ${ }^{\text {rd }}$ ed., pp.333-341). Philadelphia, PA: Temple University.

Perez, Z. J. (2014, December). Removing barriers to higher education for undocumented students. Center for American Progress. Retrieved from: https://cdn.americanprogress.org/wp-content/uploads/2014/12/UndocHigherEdreport2.pdf

Petulla, S. (2011, Mach 10). Roadmap for Latino college success. Inside Higher Ed. Retrieved from: http://www.insidehighered.com/news/2011/03/10/report_looks_to_increase_latino_colleg e_attainment\#sthash.xummd2ih.dpbs 
Pew Hispanic Center (2013, July 1). Between two worlds: How young Latinos come of age in America. Pew Hispanic Center. Retrieved from: http://www.pewhispanic.org/files/reports/117.pdf

Poetker, A. L. (2015). Nuestro cuentos, nuestras voces: A narrative study exploring selfauthorship in undocumented Latinalo college students (Doctoral Dissertation). Available from ProQuest Dissertations and Theses database. (UMI 3703142).

Ramirez, R.A. (2011). Chicanas/os and Latinas/os crossing institutional fronteras: Critical race counter stories along the college transfer pipeline at Sacramento valley community college (Doctoral Dissertation). Available from ProQuest Dissertations and Theses database. (UMI 3474461).

Rendon, L. I. (1992). From the barrio to the academy: Revelations of a Mexican American “scholarship girl”. New Directions for Community Colleges, 80, 55-64.

Rendon, L. I., (1993). Validating culturally diverse students: Toward a new model of learning and student development. Innovative higher education, (19) (1), 33-51. Retrieved from: http://www.eric.ed.gov/PDFS/ED371672.pdf

Rendon, L. I. \& Hope, R. O. (1996). Educating a new majority: Transforming America's educational system for diversity. San Francisco: Jossey-Bass.

Rendon, L. I. (2016, April). How can colleges and universities foster success for Latin@ and underserved students?. Presentation conducted at the Illinois Latino Council on Higher Conference, Northern Illinois University, DeKalb, IL.

Richardson, R. C. Jr., (1983). Literacy in the open access college. San Francisco, CA: JosseyBass. 
Rooney, G. J. (2008). Low-income, first-generation, African-American and Latino students' perceptions of influencing factors on their successful path to enrollment in a four-year college (Doctoral dissertation). Available from ProQuest Dissertations and Theses database. (UMI 3307619).

Rosales, R. (2006). Manteniendo nuestra cultura (Sustaning our culture): Cultural and social adjustments of Latinos in Doctoral programs. In J. Castellanos, A. M. Gloria \& M. Kamimura (Eds.), The Latino Pathway to the Ph.D. Abriendo Camino(pp.201-209). Sterling, VA: Stylus.

Ryan, C. L. \& Bauman, K. (2016). Educational attainment in the United States: 2015 population characteristics current population report. United States Census Bureau; U.S. Department of Commerce Economic and Statics Administration. Retrieved from: www.census.gov

San Miguel, G. Jr. (2005). Contested learning: Latino education in the United States from 1950s to the present. In V. Kloosterman \& V. Gonzalez (Eds.). Latino students in American Schools: History Contemporary Views (pp.1-19). Westport, CT: Greenwood Publish Croup, Inc.

San Miguel, G. Jr., \& Valencia, R. R. (1998). From the treaty of Guadalupe Hidalgo to Hopwood: The Educational plight and struggle of Mexican Americans in the southwest. Harvard Educational Review, 68 (3), 353-413.

Santiago, D. (2011, March). Roadmap for ensuring American's future: By increasing Latino college completion. Exelencia in Education. Retrieved from: http://files.eric.ed.gov/fulltext/ED517165.pdf 
Santiago, D. A., \& Stettner, A. (2013, June). Supporting Latino community college students. Excelencia in Education. Retrieved from: http://www.edexcelencia.org/research/supporting-latino-community-college-studentsinvestment-our-economic-future

Santiago, D. A, Taylor, M., \& Calderon Galdeano, E. (2016, May). From selectivity to success: Latinos at selective institutions. Washington, D.C.: Excelencia in Education. Retrieved from: http://www.edexcelencia.org/gateway/download/23213/1469554188

Santiago, D. A., \& Calderon-Galdeano, E. (2015, March). Helping or hindering? State policies and Latino college completion. Washington, D.C.: Excelencia in Education. Retrieved from: http://www.edexcelencia.org/gateway/download/22267/1467221050

Shelton, L. J. (2014). The experience of undocumented Latin@ students who demonstrated resilience in navigating higher education (Doctoral Dissertation). Available from Dissertations and Theses database. (UMI 3634629).

Shorette, C. R., NASPA, \&, Harris, F. (2014). Lands of first opportunity: Community colleges and the success of young men of color. Student Affairs Administration in Higher Education. Retrieved from: http://www.naspa.org/rpi/posts/lands-of-first-opportunitycommunity-colleges-and-the-success-of-young-men

Solórzano, D. G. (1998). Critical race theory, race and gender microaggressions, and the experience of Chicana and Chicano scholars. Qualitative Studies in Education, 11 (1), $121-136$.

Solórzano, D. G. (2013). Critical race theory's intellectual roots: My email epistolary with Dirrick Bell. In M. Lynn \& A. D. Dixson (Eds.), Handbook of Critical Race Theory in Education (pp.48-68). NY: Routlege Taylor \& Francis. 
Solorzano, D. G., \& Delgado Bernal, (2001). Examining transformational resistance through a critical race and LatCrit theory framework: Chicana and Chicano students in an urban context. Urban Education, 36 (3), 308-342. doi:10.1177/0042085901363002

Solórzano, D. G., Villalpando, O. \& Oseguera, L. (2005). Educational inequities and Latino undergraduate students in the united states: A critical race analysis of their educational progress. Journal of Hispanic Higher Education, 4 (3), 272-294.

Doi:10.1177/1538192705276550

Solórzano, D. G., \& Yosso, T. J. (2001a). Critical race and LatCrit theory and method: counterstorytelling: Chicana and Chicano graduate school experiences. Qualitative Studies in Education, 14 (4), 471-495. doi:10.1080/0951890110063365

Solórzano, D. G., \& Yosso, T. J. (2001b). From racial stereotyping and deficit discourse. Multicultural education, 9 (1), 2-8.

Solórzano, D. G., \& Yosso, T. J. (2001c). LatCrit v symposium; Class in LatCrit: Theory and praxis i a world of economic inequality; Latcrit in new context; Maintaining social justices hopes within academic realities: a Freirean approach to critical race/LatCrit pedagogy. Denver University Law Review, 595, 1-18.

Solórzano, D. G., \& Yosso, T. J. (2009). Critical race methodology: Counter-Storytelling as an analytical framework for educational research. In E. Taylor, D. Gillborn, \& G. LadsonBillings (Eds.), Foundations of critical race theory in education (pp.131-147). New York, NY: Taylor \& Francis. 
State of Illinois Board of Higher Education, Public Agenda Many Futures Illinois. (2013). Report to the governor and general assembly on underrepresented groups in Illinois higher education: Annual Report 2012. Retrieved from: http://www.isac.org/dotAsset/9fd04e34332c-4260-9fe5-171f85975ed8.pdf

Steele, C. M. (2009). A threat in the air: How stereotypes shape intellectual identify and performance. In E. Taylor, D. Gillborn, \& G. Ladson-Billings (Eds.) Foundations of critical race theory in education (pp.163-189). New York, NY: Taylor \& Francis.

Stratford, M. (2013, November, 13). Michelle Obama speaks about higher education at Washington high school. Inside Higher Ed. Retrieved from: http://www.insidehighered.com/news/2013/11/13/michelle-obama-speech-signals-newadministration-focus-boosting-low-income-college\#sthash.sWIPRMU1.dpbs

Social Security Administration. Social security administration application for social security card. Retrieved from: https://www.ssa.gov/forms/ss-5.pdf

Taylor, E. (1998). A primer on critical race theory. The Journal of Black in Higher Education, (19), 122-124. Retrieved from: http://www.jstor./sici?sici=1077-

3711\%28199821\%290\%3A19\%3C122\%3AAPOCRT\%3E2.0.CO\%3B-2

Taylor, E. (2009). Critical race theory and interest convergence in the backlash against affirmative action: Washington state and initiative 200. In E. Taylor, D. Gillborn, \& G. Ladson-Billings (Eds.) Foundations of critical race theory in education (pp. 117-128). New York, NY: Taylor \& Francis. 
Taylor, J. L., \& Lichtenberger, E. J. (2013). Who has access to dual credit in Illinois? Examining high school characteristics and dual credit participants' rates. Illinois education Research Council. Retrieved from: http://www.collegechangeseverything.org/dotAsset/816226ca-51c9-40d8-97ed81d2d0f1f90e.pdf

Tierney, W. G. (2004). Academic triage: Challenges confronting college preparation programs. Qualitative Inquiry, 10 (6), 950-962.

The Campaign for College Opportunity. (2013). The state of Latinos in California higher education: The economic and social imperative for advancing Latino college achievement. Retrieved from: http://www.latinopost.com/home/news/services

Thelin, J. R. (2004). A history of American higher education. Baltimore, MD: The John Hopkins University Press.

Trucios-Haynes, E. (2001) Why race matters: LatCrit theory Latino racial identity. Berkeley, $L a$ Raza Journal. 12 (1), 1-42. Retrieved from: http://homepage.smc.edu/preciado_christina/Current/Sociology\%2031/Readings/Why\%2 0Race\%20Matters\%20LatCrit.pdf

Tushnet, M. V. (2009). The “we've done enough” theory of school desegregation. In E. Taylor, D. Gillborn, \& G. Ladson-Billings (Eds.), Foundations of critical race theory in education (pp. 99-108). New York, NY: Taylor \& Francis.

United States Census Bureau. (2011). More working women than men have college degree. Retrieved from: http://www.census.gov/newsroom/releases/archives/education/cb1172.html 
U.S. Census Bureau. (2014, September). College enrollment declines for second year in a row, census bureau reports. Retrieved from: https://www.census.gov/newsroom/pressreleases/2014/cb14-177.html

U.S. Department of Homeland Security (2016, October). U.S. citizen and immigration services. Retrieved from: https://www.uscis.gov/green-card/green-card-through-family

Valdez, T. M. (2015). A case study of community cultural wealth among mountain west Chicana/o, college students (Doctoral Dissertation). Available from ProQuest Dissertations and Theses database. (UMI 3728126).

Valdes, F. (1997). Foreword: Under construction-LatCrit consciousness, community, and theory. California Law Review, 85, (5), 1087-1142.

Valencia, R. R. (1997). Conceptualized the notion of deficit thinking. In R. R. Valencia (Ed.), The evolution of Deficit Thinking: Educational Thought and Practice (pp. 1-12). Washington, D.C.: The Falmer Press.

Valencia, R. R. (1997). Genetic pathology model of deficit thinking. In R. R. Valencia (Ed.), The evolution of Deficit Thinking: Educational Thought and Practice (pp. 41-112). Washington, D.C.: The Falmer Press.

Valencia, R. R. (2010). Dismantling contemporary deficit thinking: Educational thought and practice. New York, NY: Routledge.

Valencia, R. R., \& Solorzano, D. G. (1997). Contemporary deficit thinking. In R. R. Valencia (Ed.), The evolution of Deficit Thinking: Educational Thought and Practice (pp. 160210). Washington, D.C.: The Falmer Press.

Valenzuela, A. (1999). Subtractive schooling: U.S.-Mexican youth and the politics of caring. Albany, NY: State University of New York Press. 
Valverde, L. A., Baltazar, A., Acevedo, J. \& Perez, M. E. (2008). Why the United States can no longer wait to educate its Latino population. In L. Valderde (Ed.), Latino change agents in higher education: Shaping a system that works for all (3-21). San Francisco, CA: Jossey-Bass.

Villalpando, O. (2004). Practical considerations of critical race theory and Latino critical theory for Latino college students. New Directions for Studies, 105, 41-50.

Villaneda, R. (May, 2011). Hispanic scholarship fund beliefs in education. Hispanic Business, 28. Retrieved from: http://eds.a.ebscohost.com.libproxy.lib.ilstu.edu/eds/pdfviewer/pdfviewer?vid=5\&sid=43 282974-3edc-448d-9211-d855f0462914\%40sessionmgr4004\&hid=4102

Villanueva, V. A. (2015). A study of Latino student persistence in emerging adulthood: A ground theory study (Doctoral Dissertation). Available from: ProQuest Dissertations and Theses database. (UMI 3689250).

Villenas, S. \& Foley, D. E. (2011). Critical Ethnographies of Education in the Latino Diaspora. In R. Velencia (Ed.), Chicano School Failure and success: Past, Present, and Future $\left(3^{\text {rd }}\right.$ Ed., pp.177-196). New York, NY: Routledge.

Wholey, J. S., Hatry, H. P. \& Newcomer, K. E. (2010). Handbook of practical program evaluation. San Francisco, CA: Jossey-Bass.

Wilson, R. (2006). The dynamics of organizational culture and academic planning. Planning for Higher Education, 34 (3), 5-17.

Williams, P. J. (1991). The alchemy of race and rights: Diary of a law professor. Cambridge, MA: Harvard University Press. 
W. K. Kellogg Foundation. Enlace connection: what makes a difference in education of Latinos U.S. students: learning from the experience of 13 ENLACE partnerships.1-42.

Wolf, L. A. (2007) A mixed method study of rural Iowa Latino high school students to determine barriers to access (Doctoral dissertation). Retrieved from: ProQuest. (3274892).

Worley, V. (2010). The calibans of public schools: "At risk" students placed at risk. Journal of Philosophy and History of Education, 60, 236-240.

Yosso, T. (2002). Critical Race Media Literacy: Challenging deficit discourse about Chicanas/os. Journal of Popular Film \& Television. 52-62.

Yosso, T. (2005). Whose culture has capital? A critical race theory discussion of community cultural wealth. Race Ethnicity and Education, 8, (1), 69-91. Retrieved from: http://dx.doi.org/10.1080/1361332052000341006

Yosso, T. J. Smith, W., Ceja, M., \& Solorzano, D. G. (2009). Critical race theory, racial microaggressions, and campus racial climate for Latino undergraduates. Harvard Educational Review, 79 (4), 659-690.

Yosso, T. J, Villalpando, O., Delgado Bernal, D., \& Solorzono, D. G. (2001, April 1). Critical race theory in Chicanalo education. National Association for Chicana and Chicano Studies Annual Conference. Retrieved from: http://scholarworks.sjsu.edu/cgi/viewcontent.cgi?article=1036\&context=naccs 


\section{APPENDIX A: RECRUITMENT LETTER}

Dear Facebook Friends,

I need your assistance. I am looking for people to participate in a research study on the Latino experience in community colleges. The criteria that I have created to select the participants are the following:

- Self-identified as Hispanic, Latino, or Chicano

- First-generation college student from his or her family

- Started their post-secondary education at a community college

- Completed his/her associate degree at community college in the last 5 years

- Pursued and/or achieved a baccalaureate degree

I would like to invite them to participate in my research study about Stories of Perceptions of Latino students at community colleges. This study will be conducted by me, C. Myra GaytanMorales, a doctoral student at Illinois State University, Department of Educational

Administration and Foundations. The purpose of this study is to examine the stories of successful Latino community college students. The participation in is this study is entirely voluntary and not related to any ethnic program offered by Illinois State University or any community colleges.

The participant's records of this study will be kept confidential. Any information collected through the interviews will remain private and secured at the researcher's office and on a secured laptop. In addition, I will take following steps to disposal collected data:

I will take the following steps to dispose of collected data:

1. Facebook "Dissertation Group" page will closed after one month of making paper copies of the comments as transcripts.

2. Skype's video recordings will be seeing only by the Co-PI, and

3. Skype's video recordings will be deleted one month after the CO-PI coded and analyzed the Skype video recording.

4. All of the transcripts collected from the FB "Dissertation Group" and Skype video recordings will be destroyed three years after the final defense of this dissertation research.

There may be a risk to you of losing your confidentiality that someone will know you based on what is revealed in the discussion, and feeling anxious during the online discussion or during the interview and recording. However, to eliminate the above risks, you are being asked to take the 
followings steps:

1. Use a pseudonym in your Facebook communications and an Avatar rather than a photo.

2. Be aware that your post may reveal things that might reveal your identity, so be mindful of protecting your own confidentiality.

3. In case you are concerned that you have revealed too much in the posts, please contact the Co-PI, Columba M. Gaytan-Morales, immediately, using the contact information provided.

4. In addition, in order to minimize the feeling anxious during the online discussion, please note that you do not have to answer every question if you do not feel comfortable during the online discussion, and you have the right to end the online discussion and interview at any time.

The decision whether or not to participate in this study will not affect any future relations with the researcher or the sponsor institution, Illinois State University.

If you feel that you meet the requirements or have any friends who meet these requirements and would like to participate in this research study please feel free to contact me.

Thank you for your assistance,

Columba M Gaytan-Morales 


\section{APPENDIX B: LETTER OF CONSENT}

\section{Dear Participant:}

I am a doctoral student under the direction of Dr. Dianne Gardner Renn and Dr. Pamela Hoff, Illinois State University, Educational Administration and Foundations. I am conducting a research study to examine the stories of successful Latino community college students in order to learn from the student experiences and understand what contributed to their successes.

You are being asked to take part in this research study because you are a member of the group that the researcher is studying. This study seeks six to ten participants to participate in this online research study. If you agree to participate in this study, your participation will consist of answering basic demographic questions and then joining a Facebook discussion group, "Dissertation Group". The purpose of the "Dissertation Group" will be to examine the experiences of Latinos who completed an associate degree at a community college and then matriculated to a four-year college or university. This discussion will take place over a period of three weeks. Following that, you may also be asked to participate in a Skype interview at your convenience.

Some of the risks that you may take under this study are the following:

1. There may be a risk to you of losing your confidentiality;

2. Someone may know you based on what you revealed in the FB discussion; and,

3. Feeling anxious during the online discussion or during the interview and recording.

However, in order to eliminate the identified risks, you are being asked to take the following steps:

1. Use a pseudonym in your Facebook communications and an Avatar rather than a photo.

2. Be aware that your post may reveal things as well as your identity, so be mindful of protecting your own confidentiality.

3. In case you are concerned that you have revealed too much in the posts, please contact the Co-PI, Columba M. Gaytan-Morales, immediately, using the contact information provided.

4. In addition, in order to minimize the risk of feeling anxious during the online discussion, please note that you do not have to answer every question if you do not feel comfortable during the online discussion, and you have the right to end the online discussion and interview at any time. 
All of the data collected for this study will be disposal in the following steps:

1. The Facebook "Dissertation Group" page will be closed after one month of making paper copies of the comments as transcripts;

2. The video recording on Skype will be seen only by the Co-PI; and ,

3. Skype's video recordings will be deleted one month after the CO-PI has coded and analyzed the Skype video recording.

All of the transcripts collected from the FB "Dissertation Group" and Skype video recordings will be destroyed three years after the final defense of this dissertation research.

The results of the research study may be published or presented, but your name will not be used. I will take all precautions to maintain your confidentiality. There is no direct benefit to you, other than the interest you may have in being part of an online community of Latinos who will discuss their perceptions and experiences. Overall the study will offer a view of the experiences of Latinos in community colleges that can be used in policy decisions and for further research. In that way, you will be supporting the success of Latino students moving forward.

If you choose not to participate or to withdraw from the study at any time, there will be no penalty of any kind. You recognize that your identity may be revealed to others in the Facebook discussion, although you may use a pseudonym if you wish. Please note that privacy cannot be guaranteed given the setting of this study, via social media, however, I will take all precautions to maintain your confidentiality.

If you have any questions concerning the research study, please contact the Co-Principal investigator, Columba M Gaytan-Morales, or Dr. Dianne Gardner Renn, the Principal investigator.

If you have questions about your rights as a research participant, you may contact the Research Ethics \& Compliance Office at Illinois State University at (309) 438-2529 or via email at rec@ilstu.edu, or via email at rec@ilstu.edu.

Sincerely,

Columba M Gaytan-Morales 
Your signature below indicates that you have read the information provided above, and have had an opportunity to ask questions as needed and you agree to participate in this research study. I give my consent to participate in the above study. I understand that my interview will be kept confidential, and I also understand that privacy cannot be guaranteed given the setting of this study. Please scan this letter and email it back to me. Please retain a copy of this letter for your own records.

Participant's Signature

Date 
1. What is your name?

2. Email?

3. Phone number?

4. What is your gender?

5. What year were you born?

6. Where were you born?

7. Which race/ethnic best describes you? (please choose only one)
a. American Indian or Alaska Native
b. Asia/ Pacific Islander
c. Black or African American
d. Hispanic/Latino
e. Latino decent
f. Chicano
g. White / Caucasian
h. Multiple ethnicity / Other (please specify)

8. If your ethnic heritage is Hispanic/Latino, please indicate the appropriate group(s) that best describes you?
a) Cuba
b) Mexican
c) Chicano
d) Puerto Rican
e) South/Central American
f) Other

9. What year did you start college?

10. What is the highest level of school you have completed?

11. How many college credit hours have you earned as of today?

12. Are you currently working?

13. Are you interested in participating in this research study? 


\section{APPENDIX D: LETTER OF CONSENT (SKYPE INTERVIEW)}

\section{Dear Participant:}

I am a doctoral student under the direction of Dr. Dianne Gardner Renn and Dr. Pamela Hoff, Illinois State University, Educational Administration and Foundations. I am conducting a research study to examine the stories of successful Latino community college students in order to learn from the student experiences and understand what contributed to their success. You have previously responded to a set of basic demographic questions and then joined a Facebook group discussing the experiences of Latinos who completed associates degrees at community colleges and then matriculated to four-year colleges or universities. Given your consent, I am now asking you to participate in a Skype interview at your convenience. The Skype interviews could take about 45-60 minutes and will be video recorded. Skype's internal video-recording will be used. Skype's video recordings will be seeing only by the Co-PI.

All of the data collected for this study will be disposal in the following steps:

1. Skype's video recordings will be deleted one month after the CO-PI has coded and analyzed the Skype video recording.

2. All of the transcripts collected from the FB "Dissertation Group" and Skype video recordings will be destroyed three years after the final defense of this dissertation research.

Your participation in this study is voluntary. If you choose not to participate or to withdraw from the study at any time, there will be no penalty of any kind.

The results of the research study may be published or presented, but your name will not be used. I will take all precautions to maintain your confidentiality. There is no direct benefit to you, other than the interest you may have in being part of an online community of Latinos who will discuss their perceptions and experiences. Overall the study will offer a view of the experiences of Latinos in community colleges that can be used in policy decisions and for further research. In that way, you will be supporting the successes of Latino students moving forward.

If you agree to participate in the study, please sign page two, scan it, and email it to me at mgaytan@ucenter.org. Please retain a copy of this letter for your own records. 
If you have any questions concerning the research study, please call me the Co-Principal investigator, or Dr. Dianne Gardner Renn, the Principal Investigator.

If you have any questions about your rights as a subject/participant in this research, or you feel you have been placed at risk, you can also contact the Research Ethics \& Compliance Office at Illinois State University at (309) 438-2529, or via email at rec@ilstu.edu.

Sincerely,

\section{Columba M Gaytan-Morales}

I give my consent to participate in the above study. I understand that my interview will be kept confidential, and I also understand that privacy cannot be guaranteed given the setting of this study. Please scan this letter and email or fax it. Please retain a copy of this letter for your own records. 


\section{APPENDIX E: INTERVIEW PROTOCOL (FACEBOOK-DISSERTATION GROUP}

\section{DISCUSSION)}

1. How would you describe yourself? What are some of the accomplishments that you have achieved during your life? And what are the major challenges you have overcome?

2. What was your education goal and why did you decide to attend a community college?

3. In attending the community college what were your expectations about how the community college faculty and staff treat Latino students?

4. Describe your experience or relationship with your instructors at the community college?

5. Did you ever feel that you were stereotyped based on your ethnicity? If yes, what were these stereotypes?

6. What were your experiences in getting assistance such as, college support services, mentoring, tutoring, advising, and financial aid as a Latino student at your community college?

7. What barriers did you encounter as a Latino student at a community college?

8. What strategies did you use to help you overcome any barriers?

9. How did your Latino cultural background, experience, family support, help you overcome barriers to complete your associate degree?

10. Who influenced you the most to successfully completing your associate degree?

11. What are some of the issues that Latino students face in your opinion?

12. Do you see yourself as a social change agent for other Latinos? If yes, how so?

13. What were your goals after you graduated with your associate degree?

14. What should I know about your perceptions, feelings, and experiences at the community college that you have not already shared? 


\section{APPENDIX F: INDIVIDUAL INTERVIEW QUESTIONS}

1. Tell me a story about your support system (at home, friends, work, school, either) that you used while you attended a community college.

2. Think of a story when someone motivated you to persist to finishing an associate degree. Did you realize you needed help? Who did you first go to? What did they say or do?

3. Think of a story when you sought out student support services? Did you go to parents? Why or why not? Which services did you initially seek out? Did you find what you were seeking?

4. Tell me a story when someone helped you to accomplish your goals. How did they help you? What was the goal? How did you find them? (Why) Did you continue to seek their advice?

5. Tell me a story when someone or of an event that you attended at college that made you feel proud of your culture/heritage?

6. Think about a story when someone made you feel uncomfortable because of ethnicity? How did you respond? What action did you take? What was the outcome?

7. Tell me a story when you felt that you were being stereotyped by someone from the college and how do you felt about it?

8. Think of a story when you relied on your family values that helped you to cope with negative college experience that you may have encountered at your community college?

9. Tell me the story of how these experiences led you to become a social change agent? How did this impact your decision-making process when considering a major? 